Aus der Abteilung Kardiologie und Pneumologie

(Prof. Dr. med. G. Hasenfuß)

im Zentrum Innere Medizin

der Medizinischen Fakultät der Universität Göttingen

\title{
Entwicklung und Erprobung eines in-vitro-Modellsystems zur Untersuchung von lastabhängigen Regulationsvorgängen der myokardialen Genexpression
}

\author{
INAUGURAL-DISSERTATION \\ zur Erlangung des Doktorgrades \\ der Medizinischen Fakultät \\ der Georg-August-Universität zu Göttingen
}

vorgelegt von

Johannes Werner Junge

aus

Göttingen

Göttingen 2007 
D e k a n:

I. Berichterstatter:

II. Berichterstatter/in:

III. Berichterstatter/in:

Tag der mündlichen Prüfung:
Prof. Dr. med. C. Frömmel

Prof. Dr. med. G. Hasenfuß 


\section{Inhaltsverzeichnis}

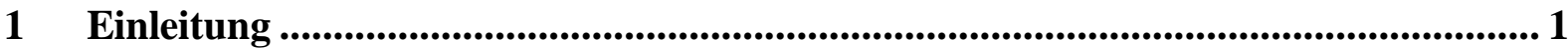

$1.1 \quad$ Der Mechanismus der elektromechanischen Kopplung ...................................... 1

1.2 Störungen des $\mathrm{Ca}^{2+}$-Stoffwechsels bei Herzinsuffizienz........................................ 4

1.2.1 Veränderungen der $\mathrm{Ca}^{2+}$-Konzentrationen............................................. 4

1.2.2 Störungen des sarkoplasmatischen Calciumrücktransportes ......................... 4

1.3 Mögliche Ursachen für die verminderte SERCA-Expression bei Herzinsuffizienz ... 4

1.3.1 Der Einfluss von Dehnung auf die Genexpression.................................... 6

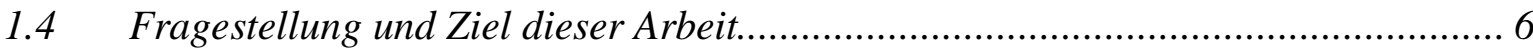

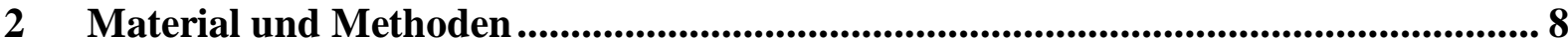

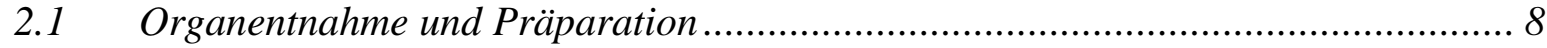

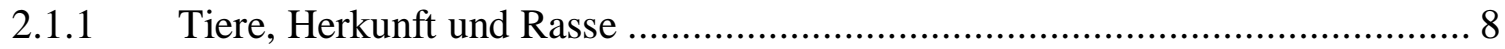

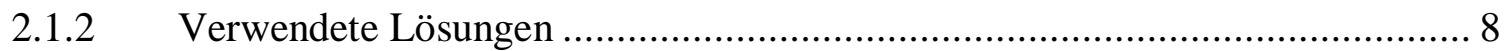

2.1.2.1 Experimentierlösung (Krebs-Henseleit-Lösung) ..................................... 8

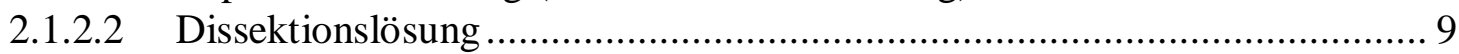

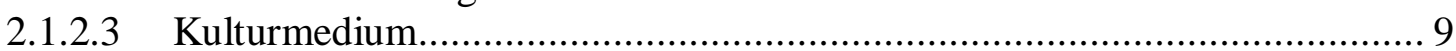

2.1.3 Organentnahme und Präparation der Trabekel.......................................... 10

2.1.3.1 Präparation des Herzens ................................................................ 10

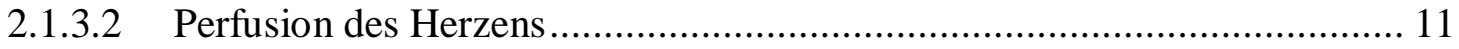

2.1.3.3 Präparation und Auswahl der Trabekel................................................. 11

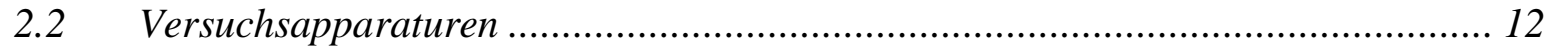

2.2.1 Geschlossene Anlage für isometrische Kontraktionen ............................... 12

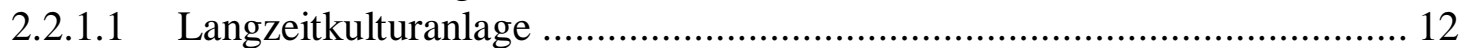

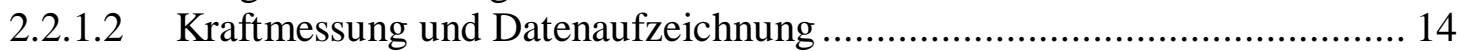

2.2.2 Offene Anlage für isotonische Kontraktionen ........................................... 15

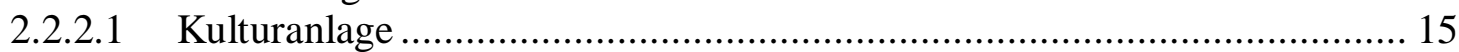

2.2.2.2 Steuerung der Verkürzung ........................................................... 17

2.2.2.3 Verkürzungsmessung und Datenaufzeichnung ..................................... 18

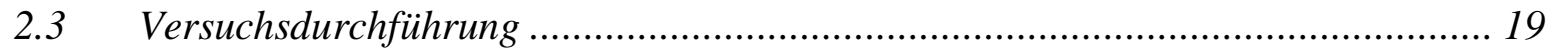

2.3.1 Versuchsprotokoll isotonische Versuche ................................................ 19

2.3.2 Versuchsprotokoll isometrische Versuche................................................ 21

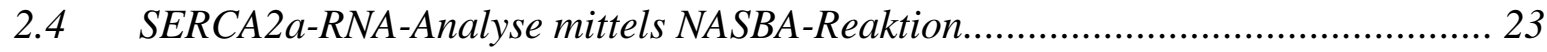

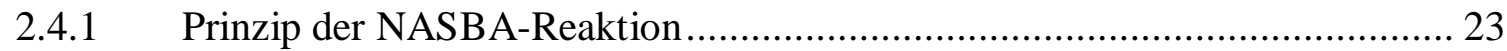

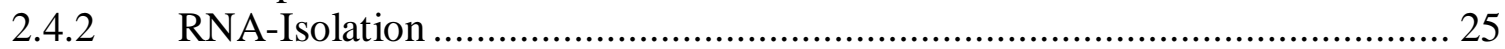

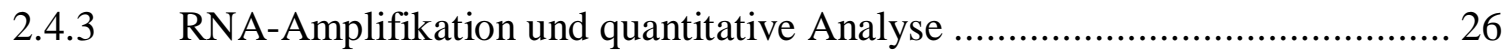

2.5 Darstellung der Ergebnisse und statistische Auswertung .................................. 27

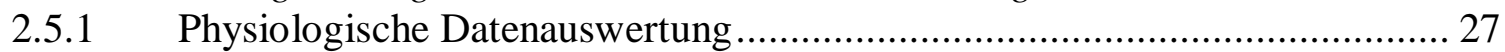

2.5.2 Biochemische Datenauswertung …...................................................... 27

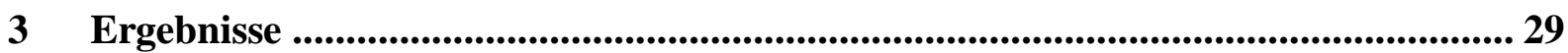

3.1 Entwicklung der isotonischen Kulturanlage, funktionelle Ergebnisse................... 29

3.1.1 Zahl der verwendeten Proben............................................................... 29 
3.1.2 Funktion der Steuerung (entwickelte und diastolische Kräfte)..................... 29

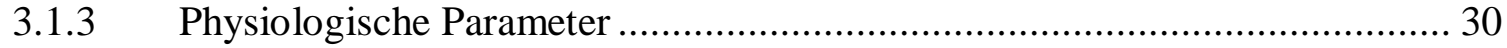

3.1.3.1 Verkürzungs- und Längenparameter ................................................ 30

3.1.3.2 Zeitparameter der Verkürzung ............................................................... 33

3.2 Funktionelle Messwerte der isometrisch kultivierten Herzmuskelstreifen.............. 34

3.2.1 Zahl der verwendeten Proben....................................................................... 34

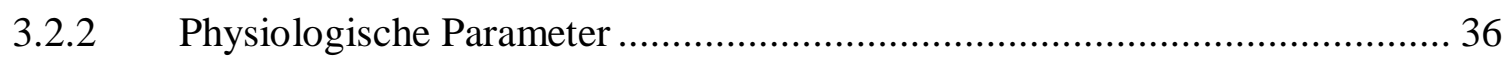

3.2.2.1 Diastolische Spannung und entwickelte Kraft ..................................... 36

3.2.2.2 Zeitparameter der Kraftentwicklung.................................................... 37

$3.3 \quad$ Vergleich von isotonischen und isometrischen Kulturbedingungen ...................... 38

3.3.1 Zusammenfassung und Vergleich der funktionellen Ergebnisse .................... 38

3.3.2 SERCA2a-mRNA-Level in isotonisch bzw. isometrisch kultivierten

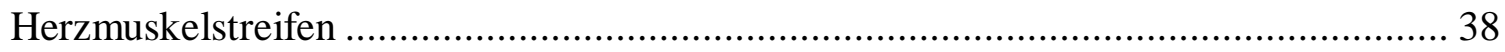

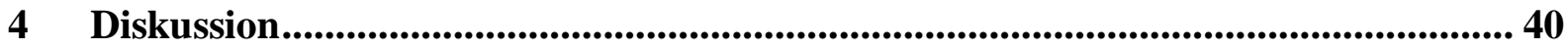

4.1 Auswahl geeigneter experimenteller Bedingungen zur Untersuchung ................. 40

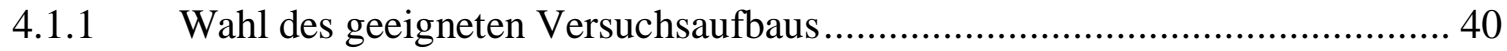

4.1.2 Wahl der Vordehnung............................................................................. 43

4.1.3 Wahl der geeigneten Methode zur biochemischen Probenuntersuchung ........ 44

4.1.4 Technische Probleme ......................................................................................... 44

4.2 Entwicklung einer Versuchsanlage zur Messung von Dehnung an isotonisch

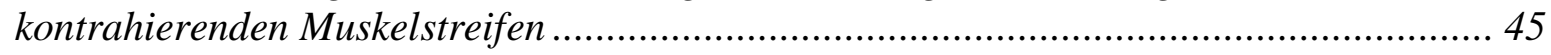

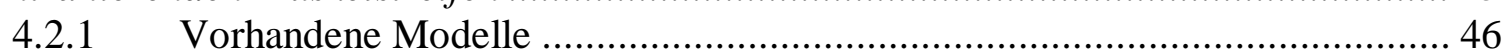

4.2.2 Eigenschaften und Funktion der entwickelten isotonischen Steuerung .......... 48

4.3 Bewertung und Vergleich der Ergebnisse ........................................................ 50

4.3.1 Vergleich von funktionellen isotonischen und isometrischen Ergebnissen..... 50

4.3.2 Interpretation der Messwerte................................................................ 53

4.3.2.1 Verkürzungsfraktion bzw. entwickelte Kraft und diastolische Spannung ... 53

4.3.2.2 Zeitparameter der Kontraktion ...................................................................... 54

4.3.3 SERCA2a-mRNA-Expression unter isotonischen und isometrischen

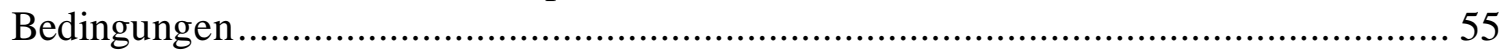

4.4 Möglichkeiten und Grenzen der isotonischen Steuerung .................................. 56

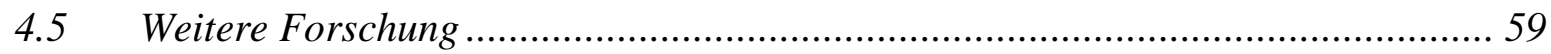

5 Zusammenfassung........................................................................................................ 61

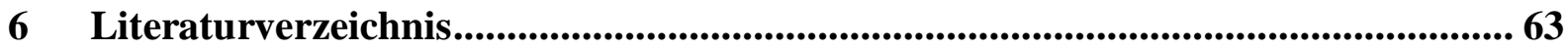




\section{Abbildungs- und Tabellenverzeichnis}

Abb. 1-1 .2

Abb. 2-1 13

Abb. 2-2 ….................................. 16

Abb. 2-3 ........................................ 19

Abb. 2-4 ....................................... 24

Abb. 3-1 ........................................ 30

Abb. 3-2 …................................... 31

Abb. 3-3 …..................................... 32

Abb. 3-4 ....................................... 32

Abb. 3-5 …................................... 33

Abb. 3-6 ....................................... 34

Abb. 3-7 ......................................... 36

Abb. 3-8 ....................................... 37

Abb. 3-9 .........................................39

Abb. 4-1 ......................................51
Tabelle 1 ....................................... 6

Tabelle 2 ................................. 8 


\section{Einleitung}

Die Herzinsuffizienz ist eine der Krankheiten, die im klinischen Alltag von großer Bedeutung sind, deren Pathogenese und Pathophysiologie aber zu großen Teilen noch unklar ist. Dieses Verständnis ist jedoch unerlässlich für die Entwicklung von Therapiemöglichkeiten, die die Herzinsuffizienz ursächlich behandeln oder gar heilen können. Neben den bekannten hämodynamischen Veränderungen und klinischen Symptomen der Herzinsuffizienz wurden in den letzten Jahren auch funktionelle und molekulare Änderungen auf Myokardebene entdeckt. Ein wesentliches funktionelles Charakteristikum der Herzinsuffizienz ist dabei die Veränderung der Kraft-Frequenz-Beziehung. Die Kraft-Frequenz-Beziehung wurde erstmals von Bowditch im Jahre 1871 beschrieben. Er beobachtete, dass die Kraftentwicklung der Herzmuskulatur mit zunehmender Stimulationsfrequenz ansteigt. Er beschrieb dies damals erstmalig beim Frosch, es zeigte sich aber im Verlauf, dass diese positive Kraft-FrequenzBeziehung bei fast allen Spezies, einschließlich des Menschen, unter physiologischen Bedingungen vorherrscht. Beim gesunden menschlichen Herzen liegt der Bereich, in dem die Kraft-Frequenz-Beziehung positiv ist, zwischen 30 und 150 Schlägen pro Minute (Pieske et al. 1995). Beim insuffizienten Herzen ist das Optimum dieser Kraftentwicklung zu niedrigeren Frequenzen (in der Regel zwischen 30 und 60/min) verschoben, während bei höheren, in vivo eher vorherrschenden Frequenzen eine negative Kraft-Frequenz-Beziehung zu beobachten ist, d.h., die entwickelte Kraft des Herzmuskels nimmt mit zunehmender Stimulationsfrequenz ab (Mulieri et al. 1992, Pieske et al. 1995).

In den letzten Jahren beschäftigte sich die kardiologische Grundlagenforschung sehr intensiv mit den molekularen Veränderungen im insuffizienten Herzen und konnte hier teilweise erhebliche Erfolge erzielen. Ein Großteil dieser Ergebnisse wird im Folgenden zusammengefasst. Weitgehend unbekannt ist hingegen, welche Mechanismen auf zellulärer Ebene eine Veränderung des Genexpressionsmusters, also die Entwicklung einer gesunden Herzmuskelzelle hin zu einer Zelle mit insuffizientem Phänotyp, induzieren. Gegenstand der hier vorgestellten Arbeit ist es, ein Modellsystem zu entwickeln, welches die Untersuchung des Zusammenhangs zwischen der Vor- und Nachlast und dem Genexpressionsverhalten von Herzmuskelgewebe untersucht.

\subsection{Der Mechanismus der elektromechanischen Kopplung}

Calcium spielt eine entscheidende Rolle bei der sog. elektromechanischen Kopplung. Hierunter versteht man den Mechanismus, mit dem die elektrischen Impulse, die aus dem 
Sinusknoten über das Reizleitungssystem des Herzens an die einzelnen Herzmuskelzellen weitergegeben werden, in eine Muskelkontraktion umgewandelt werden. Die Herzinsuffizienz geht mit einer Veränderung der elektromechanischen Kopplung einher, so dass hier zunächst deren grundlegende Mechanismen erläutert werden sollen (nach Eschenhagen und Weil 1998).

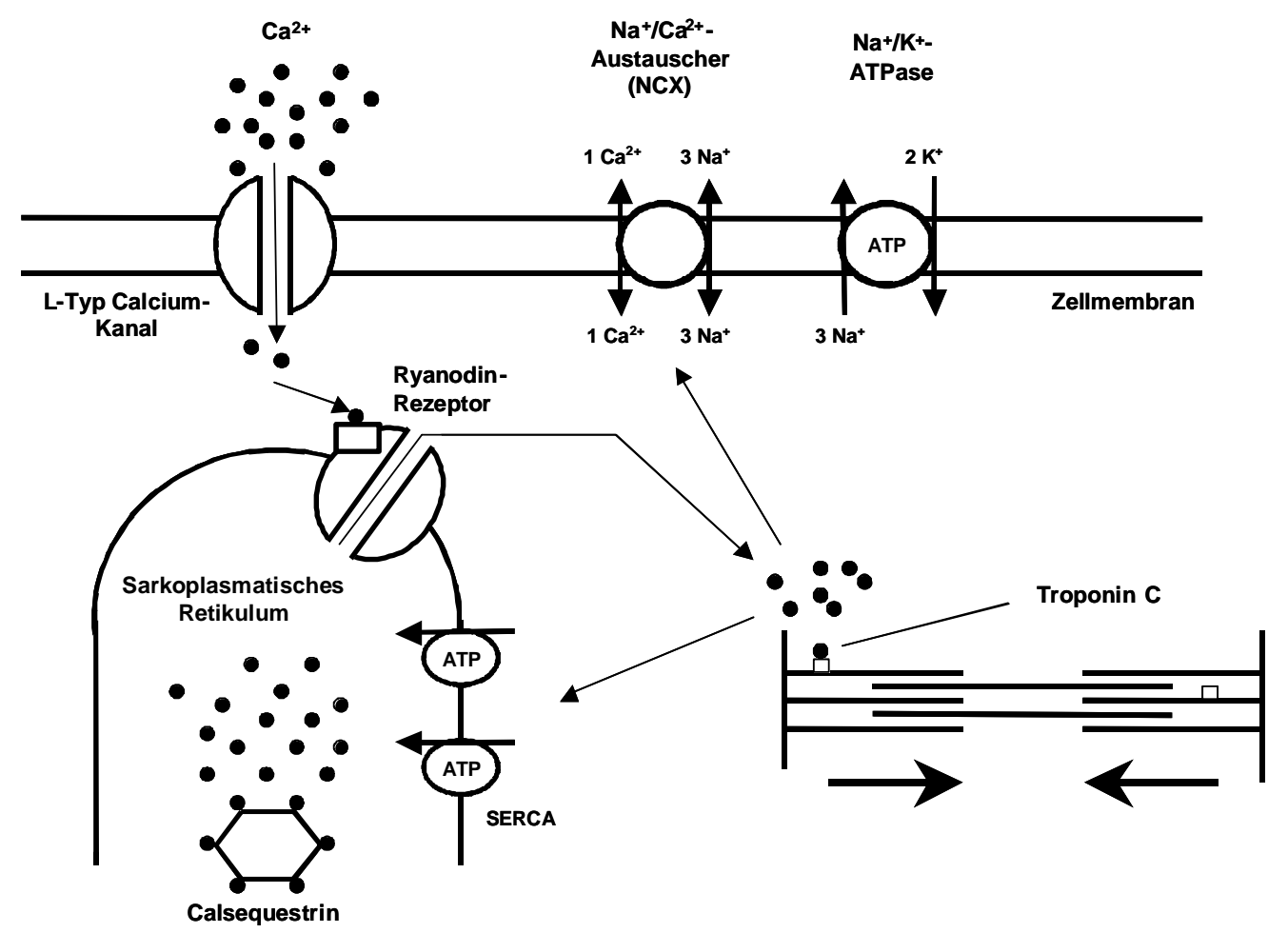

Abbildung 1-1: Prinzip der elektromechanischen Kopplung im Herzmuskel. Ausschnitt aus einem einzelnen Kardiomyozyten, Erläuterungen im Text. • : Ca2+-Ionen, SERCA: SarkoplasmastischesRetikulum-Calcium-ATPase, ATP: Adenosintriphosphat

Als Reaktion auf den elektrischen Impuls, der eine Herzmuskelzelle erreicht, öffnen sich schnelle $\mathrm{Na}^{+}$-Kanäle, über die $\mathrm{Na}^{+}$-Ionen entlang des Konzentrationsgradienten in die Zelle einströmen (Abb. 1-1). Sie verursachen eine Depolarisation, welche ab einem bestimmten Schwellenwert die Öffnung von langsamen $\mathrm{Ca}^{2+}$-Kanälen triggert, die sich wie die Natriumkanäle auf der Zellmembran befinden. Dieser Calciumeinstrom reicht allerdings noch nicht aus, eine hinreichende Kontraktion des kontraktilen Apparates auszulösen. In der Zelle befinden sich im sarkoplasmatischen Retikulum (SR), das mit seinen Ausläufern bis dicht unter die Zellmembran reicht, ausgedehnte $\mathrm{Ca}^{2+}$-Speicher. Die Calciumionen sind dort zum größten Teil an das Calciumbindungsprotein Calsequestrin (CS) gebunden. Durch das systolisch über die Zellmembran einfließende Calcium wird nun der - zumindest beim 
Menschen - quantitativ bedeutsamere Calciumeinstrom aus dem SR getriggert. Dieser Einstrom erfolgt über Calciumkanäle in der SR-Membran, sogenannte Ryanodin-Rezeptoren, die sich - aktiviert durch die Bindung von $\mathrm{Ca}^{2+}$-Ionen - öffnen. Beim Menschen und beim Kaninchen macht dieser Einstrom aus dem SR etwa 70\% des gesamten systolischen Calciumeinstromes aus (Bers 1993). Die $\mathrm{Ca}^{2+}$-Ionen binden nun an Troponin $\mathrm{C}$ und lösen somit eine Kontraktion der Myofilamente aus.

In der Diastole diffundieren die Calciumionen von ihren Bindungsstellen am Troponin $\mathrm{C} a \mathrm{~b}$. Es müssen nun effektive Calciumeliminationsmechanismen greifen, um die $\mathrm{Ca}^{2+}$-Ionen innerhalb von wenigen Millisekunden wieder aus dem Zytosol zu entfernen. Dies geschieht über zwei Wege: Zum einen werden unter ATP-Verbrauch $\mathrm{Ca}^{2+}$-Ionen durch die SR-CalciumATPase (SERCA) in das sarkoplasmatische Retikulum zurückgepumpt. Die im Herzmuskel vorherrschende Isoform ist die SERCA2a (Hasenfuß 1998a). Über die SERCA werden ca. $70 \%$ des systolisch in das Zytoplasma eingeströmten Calciums eliminiert, dies entspricht dem Anteil des aus dem SR eingeströmten Calciums. Das zu Beginn der Systole von extrazellulär eingeströmte Calcium muss allerdings auch wieder aus dem Zytoplasma nach außen eliminiert werden, damit es nicht zu einer $\mathrm{Ca}^{2+}$-Überladung der Zelle kommt. Dies geschieht über den Natrium-Calcium-Austauscher (NCX). Er befördert ein $\mathrm{Ca}^{2+}$-Ion gegen das Konzentrationsgefälle nach extrazellulär und transportiert dafür $3 \mathrm{Na}^{+}$-Ionen nach intrazellulär. Unter physiologischen Bedingungen transportiert der NCX ca. 30\% des systolisch eingeströmten Calciums aus der Zelle. Die Elimination durch die zellmembranständige $\mathrm{Ca}^{2+}$ ATPase spielt im Herzmuskel keine bedeutende Rolle (Bers 1993). Treibende Kraft für den Transport von $\mathrm{Ca}^{2+}$-Ionen gegen einen Konzentrationsgradienten nach extrazellulär durch den NCX ist das elektrische Potenzial über der Zellmembran, hauptsächlich bedingt durch die extrazellulär höhere Konzentration an $\mathrm{Na}^{+}$-Ionen. Falls sich die intrazelluläre $\mathrm{Na}^{+}$-Konzentration erhöht (z.B. durch Hemmung der $\mathrm{Na}^{+} / \mathrm{K}^{+}$-ATPase, die $3 \mathrm{Na}^{+}$-Ionen im Austausch für 2 $\mathrm{K}^{+}$-Ionen nach extrazellulär befördert), transportiert der NCX ab einem bestimmten Punkt in einem „Rückwärtsmodus“ $\mathrm{Ca}^{2+}$-Ionen in die Zelle hinein bzw. weniger aus der Zelle hinaus (Ladilov et al. 1999, Eschenhagen und Weil 1998). Somit kommt es zu einer erhöhten $\mathrm{Ca}^{2+}{ }_{-}$ Konzentration in der Herzmuskelzelle und einer Erhöhung der Kontraktionskraft. Auf diesem Mechanismus beruht beispielsweise die positiv inotrope Wirkung von Herzglykosiden, welche die $\mathrm{Na}^{+} / \mathrm{Ka}^{+}$-ATPase hemmen. 


\subsection{Störungen des $\mathrm{Ca}^{2+}$-Stoffwechsels bei Herzinsuffizienz}

\subsubsection{Veränderungen der $\mathrm{Ca}^{2+}-$ Konzentrationen}

Durch die Messung von $\mathrm{Ca}^{2+}$-Transienten in Myozyten mit Hilfe von Calciumindikatoren wie Aequorin (Pieske et al. 1995) oder fura-2 (Beuckelmann et al. 1992) konnten neue Erkenntnisse über die Veränderung des $\mathrm{Ca}^{2+}$-Stoffwechsels bei Herzinsuffizienz gewonnen werden. So wurde gezeigt, dass die Menge des zirkulierenden Calciums in insuffizienten menschlichen Herzmuskelstreifen reduziert ist (Hasenfuß et al. 1992). Weiterhin wurde an isolierten humanen Myozyten gezeigt, dass es bei Herzinsuffizienz zu einem reduzierten maximalen systolischen Calcium-Transienten, so wie zu einem erhöhten diastolischen Calciumgehalt kommt (Beuckelmann et al. 1992).

\subsubsection{Störungen des sarkoplasmatischen Calciumrücktransportes}

Diese Befunde legen nahe, dass Störungen der diastolischen $\mathrm{Ca}^{2+}$-Elimination und insbesondere der diastolischen Wiederaufnahme von Calcium in das SR eine entscheidende Rolle in der Pathogenese der Herzinsuffizienz darstellen. Durch die verminderte Wiederaufnahme von Calcium in das SR verbleiben einerseits mehr $\mathrm{Ca}^{2+}$-Ionen im Zytosol, andererseits steht weniger Calcium im SR für die systolische Freisetzung zur Verfügung.

Es gilt mittlerweile durch viele Untersuchungen als gesichert, dass die Expression von SERCA2a-mRNA (messenger-RNA) im insuffizienten menschlichen Herzen reduziert ist (Überblick siehe Hasenfuß 1998c). Was die Proteinkonzentrationen von SERCA2a im humanen insuffizienten Myokardium betrifft, so ergaben sich uneinheitliche Resultate. Einige Arbeitsgruppen fanden eine Abnahme des SERCA2a-Gehaltes, andere hingegen keinen signifikanten Unterschied im Vergleich zum gesunden Myokard (Überblick siehe Hasenfuß 1998c). Mehrere Arbeitsgruppen fanden weiterhin eine Reduzierung der SERCA2a-Aktivität bzw. der Calciumwiederaufnahme in das SR (Schwinger et al. 1995, Hasenfuß et al. 1994).

\subsection{Mögliche Ursachen für die verminderte SERCA-Expression bei Herzinsuffizienz}

Eine zentrale Fragestellung ist nun, welche Mechanismen für die Veränderungen der SERCA2a-Aktivität bzw. -Menge verantwortlich sind. Wie aus Tab. 1-1 ersichtlich, wirken viele verschiedene pathophysiologische Mechanismen bei der Herzinsuffizienz zusammen (Eschenhagen und Weil 1998). Man kann grob unterscheiden in mechanische und neurohumorale Einflussfaktoren. 


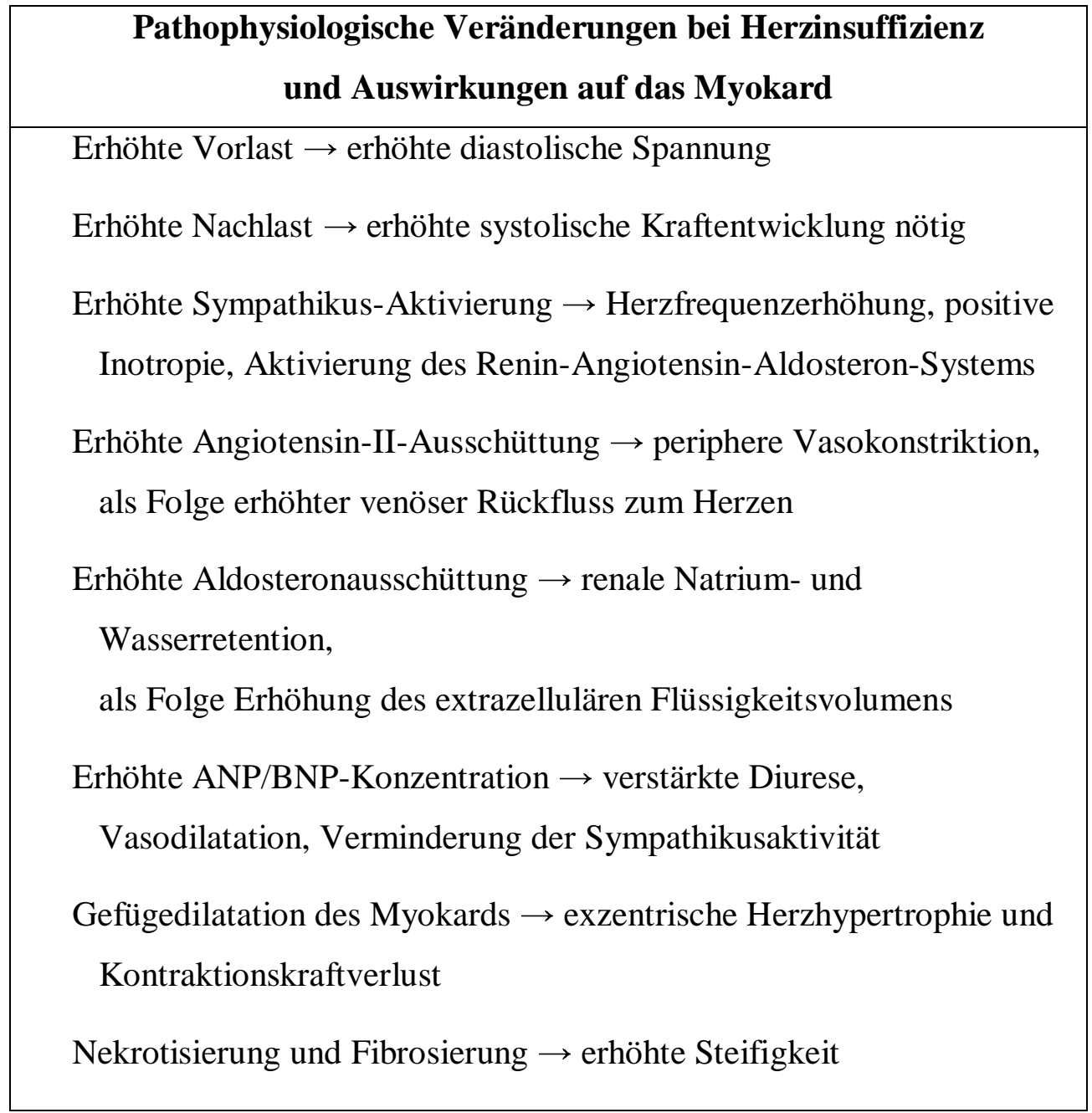

\section{Tabelle 1 (nach Eschenhagen und Weil 1998)}

Mechanische Einflussfaktoren sind Folgen von Veränderungen der hämodynamischen Situation bei Herzinsuffizienz im Sinne einer erhöhten Vorlast bzw. Nachlast. Die Vorlasterhöhung entsteht durch das insuffiziente Herzschlagvolumen. Dies führt dazu, dass sich Blut vor der Herzkammer staut (z. B. in der pulmonalen Strombahn bei Linksherzinsuffizienz, klinisch manifestiert als Lungenödem, oder im venösen Niederdrucksystem, klinisch manifestiert z.B. als periphere Ödeme). Somit herrscht ein erhöhter Druck im Vorhof und somit auch ein erhöhter enddiastolischer Druck im Ventrikel. Dieser chronisch erhöhte Druck wird auch für viele strukturelle Veränderungen am Herzmuskel im Rahmen der Herzinsuffizienzentstehung (Gefügedilatation, Fibrosierung) verantwortlich gemacht.

Es stellt sich die Frage, ob das Zusammentreffen aller genannten (und vielleicht noch einiger weiterer, z. T. bisher unbekannter) Mechanismen und pathophysiologischen Veränderungen 
die SERCA-Aktivität beeinflusst, oder ob es einzelne isolierte Einflussfaktoren sind, die für die Änderung der SERCA-Aktivität verantwortlich sind. Ein Regulationsmechanismus für die Änderung der SERCA-Aktivität ist die Änderung der Genexpression. Eine erhöhte Genexpression bedeutet eine erhöhte Menge an SERCA-Proteinen, so daß mehr enzymatische Aktivität zur Verfügung steht. Ein möglicher Auslöser für die Expressionsänderung ist die gesteigerte Wandspannung bzw. Dehnung der Myozyten, bedingt durch die erhöhte Vorlast im insuffizienten Herzen.

\subsubsection{Der Einfluss von Dehnung auf die Genexpression}

Gemäß dem Laplace'schen Gesetz gibt es in der Wand des Herzens eine Wandspannung. Diese ist zum einen von dem in den Herzhöhlen herrschenden Druck abhängig, zum anderen von dem Durchmesser des Ventrikels und der Wanddicke. Mehrere Modelle haben versucht, die Stärke der Wandspannung sowie ihre Verteilung über die Ventrikelwand annähernd quantitativ zu bestimmen (Yin 1981). Wong und Rautaharju etwa haben 1968 ein Modell entwickelt, bei dem sie das Herz vereinfacht als dickwandigen ellipsoiden Hohlkörper betrachten. Berechnungen mit diesem Modell zeigten, dass bei zunehmendem Druck in der Höhle die Wandspannung zunimmt, und dass die Wandspannung an der Innenseite des Herzens (also im Endokard) höher ist als in weiter außen gelegenen Wandanteilen (also im Epikard).

Prestle et al. haben nun 1999 gezeigt, dass die SERCA2a-mRNA- und Proteinexpression von subepikardial nach subendokardial - also mit zunehmender Wandspannung - abnimmt, während die Expression von NCX1 (der kardialen Isoform des NCX) unverändert bleibt. Da eine zunehmende Wandspannung gleichbedeutend mit zunehmender Dehnung der Muskelfasern ist, ergibt sich die These, dass Dehnung für die Genexpression von SERCA2a, nicht aber für die von NCX von Bedeutung ist.

\subsection{Fragestellung und Ziel dieser Arbeit}

Zur Untersuchung des Einflusses von Dehnung auf die Genexpression, z. B. von SERCA2a, steht ein etabliertes Langzeitkultursystem zur Verfügung, mit dessen Hilfe die Kultur von kontrahierenden Kaninchenherzmuskelsteifen über 48 Stunden möglich ist (Janssen et al. 1998, Janssen et al. 1999b). In diesem Versuchsaufbau lassen sich genaue Vorlasten definieren, so dass sich hier z. B. der Einfluss von Dehnung auf die Genexpression von SERCA2a untersuchen lässt. 
In dieser Kulturanlage lassen sich Muskelpräparate nur unter isometrischen Bedingungen kultivieren, d. h. das Muskelpräparat erzeugt bei der Kontraktion eine Kraft, ohne sich zu verkürzen. Physiologischerweise führt das Herz jedoch keine rein isometrischen Kontraktionen aus. Lediglich zu Beginn der Systole, bis zum Erreichen des diastolischen Aortendruckes, kontrahiert es isometrisch. Nach der Öffnung der Aortenklappe schlägt das Herz annähernd isotonisch, d.h., bei gleich bleibender Druckerzeugung verkürzen sich die Muskelfasern und das Herz wirft aus. Es handelt sich somit um eine kombinierte Kontraktion aus einem isometrischen und einem isotonischen Anteil (sog. auxotone Kontraktion).

Ziel dieser Arbeit ist es, ausgehend von dem vorhandenen Kultursystem einen Versuchsaufbau zu entwickeln, der es ermöglicht, ein isoliertes Muskelpräparat isotonisch, d. h. bei konstanter Vorlast ohne Nachlast, kontrahieren zu lassen. Dadurch wird neben einer rein isometrischen Kontraktion auch eine isotonische oder auxotone Kontraktion möglich. Wichtigstes Element hierfür ist ein Steuerungssystem, das die Verkürzung des Muskels so steuert, dass die Nachlast konstant bleibt. Für den vorhandenen Versuchsaufbau steht kein geeignetes Steuerungssystem zur Verfügung, das kompatibel zum verwendeten System ist.

Wichtigster Bestandteil dieser Arbeit ist es nun, ein solches System zu entwickeln. Dessen Entwicklung stellt erhebliche Anforderungen an die Geschwindigkeit von Hard- und Software. Das System muss so konstruiert sein, dass ein Muskelpräparat dort geeignete und konstante Kulturbedingungen vorfindet. Hierzu bietet sich der vorhandene Aufbau der im ersten Teil verwendeten Langzeitkulturanlage an. Weiterhin muss die Steuerung des Systems extrem schnell arbeiten. Die Kompatibilität mit bisherigen Versuchsaufbauten im Labor ist ein weiterer wesentlicher Punkt, der bei der Entwicklung beachtet werden muss.

Zur Validierung der entwickelten Anlage sollen funktionelle Messdaten gewonnen werden und mit denen aus der bekannten Kulturanlage für isometrisch kontrahierende Präparate verglichen werden. Weiterhin soll auch die Vergleichbarkeit biochemischer Messwerte gezeigt werden. Hierzu soll die mRNA-Konzentration von SERCA2a in den kultivierten Präparaten untersucht werden. SERCA2a wurde gewählt, da sie - wie oben erwähnt - das Untersuchungsziel zukünftiger Genexpressionsuntersuchungen ist. 


\section{Material und Methoden}

\subsection{Organentnahme und Präparation}

\subsubsection{Tiere, Herkunft und Rasse}

Für die Durchführung der Experimente wurden weibliche, adulte „Chinchilla-Bastard“Kaninchen der Fa. Charles River Laboratories Deutschland verwendet. Die Tiere wogen zwischen 1,5 und $2 \mathrm{~kg}$, das Alter lag zwischen 3 und 6 Monaten.

\subsubsection{Verwendete Lösungen}

\subsubsection{Experimentierlösung (Krebs-Henseleit-Lösung)}

Als Basislösung für die Dissektion und die erste Phase der Inkubation der Trabekel vom Stimulationsbeginn bis zum Übergang auf das Kulturmedium wurde eine modifizierte KrebsHenseleit-Lösung (KH-Lösung) verwendet, im Folgenden sind die Konzentrationen der einzelnen Substanzen angegeben (nach Zeitz 2001):

Konzentration

(in $\mathrm{mmol} / \mathrm{l}$ )

\begin{tabular}{|ll|l|}
\hline Natriumchlorid & $\mathrm{NaCl}$ & 116,0 \\
\hline Kaliumchlorid & $\mathrm{KCl}$ & 5,0 \\
\hline Natriumdihydrogenphosphat & $\mathrm{NaH}_{2} \mathrm{PO}_{4}$ & 2,0 \\
\hline Magnesiumchlorid & $\mathrm{MgCl}_{2}$ & 1,2 \\
\hline Natriumsulfat & $\mathrm{Na}_{2} \mathrm{SO}_{4}$ & 1,2 \\
\hline Natriumhydrogencarbonat & $\mathrm{NaHCO}_{3}$ & 20,0 \\
\hline Glucose & $\mathrm{C}_{6} \mathrm{H}_{12} \mathrm{O}_{6}$ & 10,0 \\
\hline Calciumchlorid & $\mathrm{CaCl}_{2}$ & 0,25 \\
\hline
\end{tabular}

Tabelle 2

Im Vorfeld der Versuche wurde als Vorrat eine 10fach konzentrierte Stammlösung aus den obigen Zutaten mit Ausnahme von Natriumhydrogencarbonat, Glucose und Calciumchlorid hergestellt. Diese Bestandteile wurden erst kurz vor Beginn des Versuches der einfach konzentrierten Lösung zugefügt. 
Für die Experimente wurde eine $\mathrm{Ca}^{2+}$-Konzentration von 1,75 mM gewählt. Ausgehend von der 0,25-mM-Basislösung wurde diese während des Experiments durch Zugabe von Calciumchlorid erreicht, wobei zur Schonung des Muskels die Konzentration allmählich gesteigert wurde (Näheres s. Kap. 2.3.1).

Zur Aufrechterhaltung eines physiologischen $\mathrm{pH}$-Wertes von 7,4 enthielt die Experimentierlösung einen Kohlensäurepuffer. Zum Erreichen des Puffergleichgewichtes und zur ausreichenden Versorgung mit Sauerstoff wurde die Lösung vor und während aller Versuche mit Carbogengas $\left(95 \% \mathrm{O}_{2}, 5 \% \mathrm{CO}_{2}\right)$ äquilibriert. Bei physiologischer Temperatur von $37^{\circ} \mathrm{C}$, so haben regelmäßige Stichproben gezeigt, ist somit der $\mathrm{pH}-$ Wert ideal eingestellt.

\subsubsection{Dissektionslösung}

Um das Myokard während der Präparationsphase bis zur Wiederperfusion mit oxigenierter Experimentierlösung vor Schädigungen durch Hypoxie oder Verletzung der Zellmembranen zu schützen, wurde der obigen Experimentierlösung 20 mM 2,3-Butandion-Monoxim (BDM) zugefügt. Diese Substanz verhindert zum einen die Kontraktion des Muskels durch Unterbindung der Querbrückenbindung der Myofilamente und führt dadurch zu einem reduzierten Sauerstoffverbrauch. Zum anderen vermindert sie die Ausbildung einer Kontraktur nach Wiedererhöhung der extrazellulären $\mathrm{Ca}^{2+}$-Konzentration zu Beginn des Experimentes und schützt das Myokard vor Schäden durch eine eventuelle Ischämiezeit während der Perfusion oder Präparation (Sellin und McArdle 1994). Weiterhin wurde gezeigt, dass BDM Schäden durch Schnittverletzungen während der Präparation verhindern kann (Mulieri L et al. 1989).

\subsubsection{Kulturmedium}

Für die Inkubation der Trabekel über einen längeren Zeitraum ist die Krebs-Henseleit-Lösung ungeeignet, da hier wichtige physiologische Supplemente fehlen. Ohne entsprechende Substrate (Nukleinsäuren, Aminosäuren) sind keine anabolen Zellvorgänge möglich, die Untersuchung von Produkten dieser Vorgänge ist jedoch integraler Bestandteil dieser Arbeit.

Es wurde ein flüssiges Zellkulturmedium M199 der Fa. Sigma-Aldrich, München verwendet. Es enthält neben Nährstoffen wie Glukose auch Aminosäuren, Spurenelemente und Vitamine. Die Calciumkonzentration beträgt hier, wie auch am Ende in der Krebs-Henseleit-Lösung (s.u.), 1,75 mM. Weiterhin enthält das Medium zur Aufrechterhaltung des physiologischen pH-Wertes einen HEPES-Puffer, sowie Natriumhydrogencarbonat, das zusammen mit dem Carbogen aus der Begasung einen Kohlensäurepuffer bildet. Im Medium enthaltenes Phenolrot als Indikator lässt während des Experimentes eine grobe $\mathrm{pH}$-Abschätzung zu und 
ermöglicht es, starke Abweichungen im pH durch etwaige Störfaktoren im System rasch zu erkennen.

Damit im Medium alle physiologischen Aminosäuren vorhanden sind, wurden dem Medium zusätzlich $2 \mathrm{mM}$ L-Carnitin, $5 \mathrm{mM}$ Kreatin, $5 \mathrm{mM}$ Taurin, sowie $2 \mathrm{mM}$ D,L-Glutaminsäure zugesetzt, außerdem 0,2\% Rinder-Serumalbumin, 100 i.E./ml Penicillin, 0,1 mg/ml Streptomycin, sowie 20 i.E./ml Humaninsulin (Insulin rapid ${ }^{\circledR}$ der Fa. Hoechst, Frankfurt).

\subsubsection{Organentnahme und Präparation der Trabekel}

\subsubsection{Präparation des Herzens}

Vor der Präparation wurden die Tiere eingeschläfert. Dazu erhielten sie über eine Vene auf der Ohrrückseite eine Injektion von 100 mg Thiopental in $10 \mathrm{ml}$ isotonischer Kochsalzlösung, sowie 5000 i.E. Heparin zur Antikoagulation. Sobald der Cornealreflex erloschen war, wurde mit der Präparation begonnen. Diese musste recht schnell erfolgen, da das Herz, das auch unter der Anästhesie weiter schlägt, durch das Fehlen der Atmung unzureichend oxygeniert ist. Die Zeitspanne vom Beginn der Präparation bis zur Wiederperfusion des Herzens mit oxygenierter Lösung (s. u.) sollte im Idealfall 30 Sekunden bis maximal 1 Minute betragen.

Nachdem im Bereich des Thorax und des oberen Abdomens das Fell grob entfernt wurde, erfolgte ein medianer longitudinaler Bauchschnitt bis zum Xiphoid. Nachdem das Xiphoid mit einer Klemme nach oben fixiert wurde, erfolgten transversale Schnitte entlang dem Zwerchfell. Der Thorax wurde eröffnet, indem beidseitig die Rippen in der Axillarlinie durchtrennt und anschließend das Zwerchfell von der vorderen Thoraxwand abpräpariert wurde. Darauf ließ sich die vordere Thoraxhälfte nach kranial aufklappen. Das Herz wurde vom vorderen Mediastinum stumpf abpräpariert und anschließend der Perikardbeutel an der Herzspitze inzidiert und nach kranial eröffnet. Die ventral vor den anderen Gefäßen liegende Aorta ascendens wurde stumpf von den anderen Gefäßen getrennt und dargestellt.

Anschließend wurde die Aorta ascendens ca. $5 \mathrm{~mm}$ hinter der Aortenwurzel durchtrennt, die Durchtrennung der übrigen Gefäße erfolgte en bloc mit 1-2 Schnitten. Das entnommene Herz wurde anschließend zur groben Spülung nacheinander in zwei Gefäße mit BDM-haltiger Dissektionslösung überführt und anschließend zur Perfusion in die ebenfalls mit Dissektionslösung gefüllte Präparierschale transferiert. 


\subsubsection{Perfusion des Herzens}

Die Perfusion des Herzens nach der Präparation erfolgte mit in einem Vorratsgefäß voroxygenierter BDM-haltiger Experimentierlösung $\left(0,25 \mathrm{mM} \mathrm{Ca}^{2+}\right)$ bei Zimmertemperatur. Dazu wurde das Herz in der Präparierschale über eine in die Aorta gesteckte Kanüle, deren Außendurchmesser in etwa der Größe der Aorta entspricht, retrograd ca. 3-5 Minuten perfundiert, bis alles Blut aus den Koronarien und den Ventrikeln gespült war.

\subsubsection{Präparation und Auswahl der Trabekel}

Die nachfolgenden Präparationsschritte wurden mithilfe eines Stereomikroskops der Fa. Carl Zeiss bei 2- bis 8-facher Vergrößerung durchgeführt. Aufgrund der geringen Größe der anatomischen Strukturen des Kaninchenherzens wurden Feinpinzetten und Mikrochirurgiescheren aus der Augenheilkunde der Fa. Aesculap, Tuttlingen verwendet.

Nach der Perfusion wurde der rechte Ventrikel mit einem Schnitt vom Truncus pulmonalis am Septum entlang bis zur Herzspitze eröffnet, anschließend wurde die basale Seite des Ventrikels durch Umschneidung der Aorta in der Ventilebene vom Septum aus in Richtung der Trikuspidalklappe mobilisiert. Nach Durchtrennung der Chordae tendineae ließen sich nun Vorder- und Seitenwand des rechten Ventrikels nach lateral aufklappen.

Für die Experimente wurden wandständige Trabekel oder kleine Papillarmuskeln aus dem rechten Ventrikel mit einer Länge zwischen 2 und 8 mm, im Mittel 3,63 $\pm 0,31 \mathrm{~mm}(\mathrm{n}=16)$ bei den isometrischen und 2,59 $\pm 0,27 \mathrm{~mm}(\mathrm{n}=20)$ bei den isotonischen Versuchen verwendet.

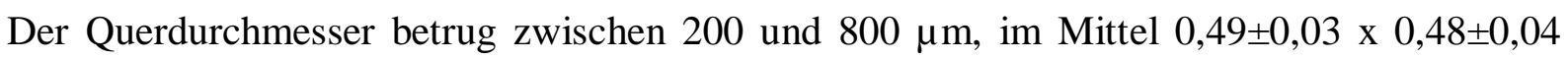
$\mathrm{mm}(\mathrm{n}=16)$ bei den isometrischen Versuchen und $0,39 \pm 0,04 \times 0,38 \pm 0,04 \mathrm{~mm}(\mathrm{n}=20)$ bei den isotonischen Versuchen. Die Vermessung erfolgte in der Präparierschale im ungedehnten Zustand mittels einer normierten Skala in der Optik des Binokulars. Es hat sich gezeigt, dass bei Muskelstreifen, die deutlich dicker als die oben verwendeten waren, während des 6 Stunden andauernden Versuchsablaufes häufiger Muskelschäden durch Hypoxie auftreten (Janssen et al. 1998). Aus diesem Grund wurden auch routinemäßig keine Trabekel oder Papillarmuskel aus dem linken Ventrikel gewonnen, da diese in der Regel deutlich dicker als die rechtsventrikulären sind.

Bei den nun folgenden Präparationsschritten musste genauestens darauf geachtet werden, die gewählten Trabekel weder zu berühren noch sie zu dehnen, da schon geringste Verletzungen der Trabekel die Präparate unbrauchbar machen können. Dies äußert sich dann darin, dass der Muskelstreifen nach Stimulationsbeginn nicht bzw. nur unzureichend schlägt, oder dass er während des Ablaufs des Experiments in Kontraktur geht und somit verworfen werden muss. 
Die Präparation der Trabekel erfolgte so, dass an beiden Enden noch ein Block aus Ventrikelwand übrig blieb, um Schädigungen des kontrahierenden Teils der Trabekel durch das Einspannen in die Anlage zu verhindern (ter Keurs et al. 1980). Die Anzahl der gewonnenen Trabekel war stark von den morphologischen Gegebenheiten des Herzens (Beschaffenheit der Trabekelstruktur, ausreichendes Vorhandensein von dünnen Papillarmuskeln) abhängig, sie schwankte zwischen null und etwa fünf brauchbaren Präparaten.

\subsection{Versuchsapparaturen}

\subsubsection{Geschlossene Anlage für isometrische Kontraktionen}

Es soll hier im Folgenden zunächst die Langzeitkulturanlage für die Kultur von Herzmuskelstreifen unter isometrischen Bedingungen beschrieben werden, da sie als Basis für die Entwicklung des isometrischen Versuchsaufbaus diente und von ihr viele grundlegende Teile (z.B. Stimulator, Kraftmesser, LabView ${ }^{\circledR}$-Applikation) übernommen werden. Außerdem soll sie weiterhin als Plattform dienen, in die zukünfig die entwickelte isotonische Steuerung integriert werden soll.

\subsubsection{Langzeitkulturanlage}

Für die Durchführung der Experimente verwendeten wir eine etwas modifizierte geschlossene ex-vivo-Muskel-Kulturanlage, die in unserer Arbeitsgruppe entwickelt (Janssen et al. 1998, Janssen et al. 1999b) und erfolgreich verwendet wurde (Lehnart et al. 2000, Janssen et al. 2002), sie ist schematisch in Abb. 2-1 dargestellt.

Kernstück bilden 4 geschlossene Kulturkammern. In diesen befinden sich zum Einspannen der Trabekel jeweils auf der einen Seite ein Haken aus rostfreiem Stahl, auf der anderen Seite eine nach oben gebogene Drahtschlinge aus Titan-Iridium-Draht, sie dient quasi als „Körbchen“ für den Gewebsblock am einen Ende der Trabekel. Der Haken ist mit einer verschlossenen Kanüle verbunden, die aus der Kammer herausführt. Am Ende dieser Verlängerung befindet sich eine Mikrometerschraube, die es erlaubt, die Position des Hakens exakt und reproduzierbar zu verändern. Das Drahtkörbchen ist über eine geknickte Kanüle mit einem Kraftaufnehmer verbunden (Modell KG4, Fa. Scientific-Instruments, Heidelberg). Dieser eignet sich besonders für diese Art von Experimenten, denn er ermöglicht es, Kräfte im Bereich von wenigen $\mathrm{mN}$ zu messen. Trotz dieser hohen Messempfindlichkeit ist er gegenüber mechanischen Manipulationen (z.B. beim Einspannen des Muskels) äußerst robust. 


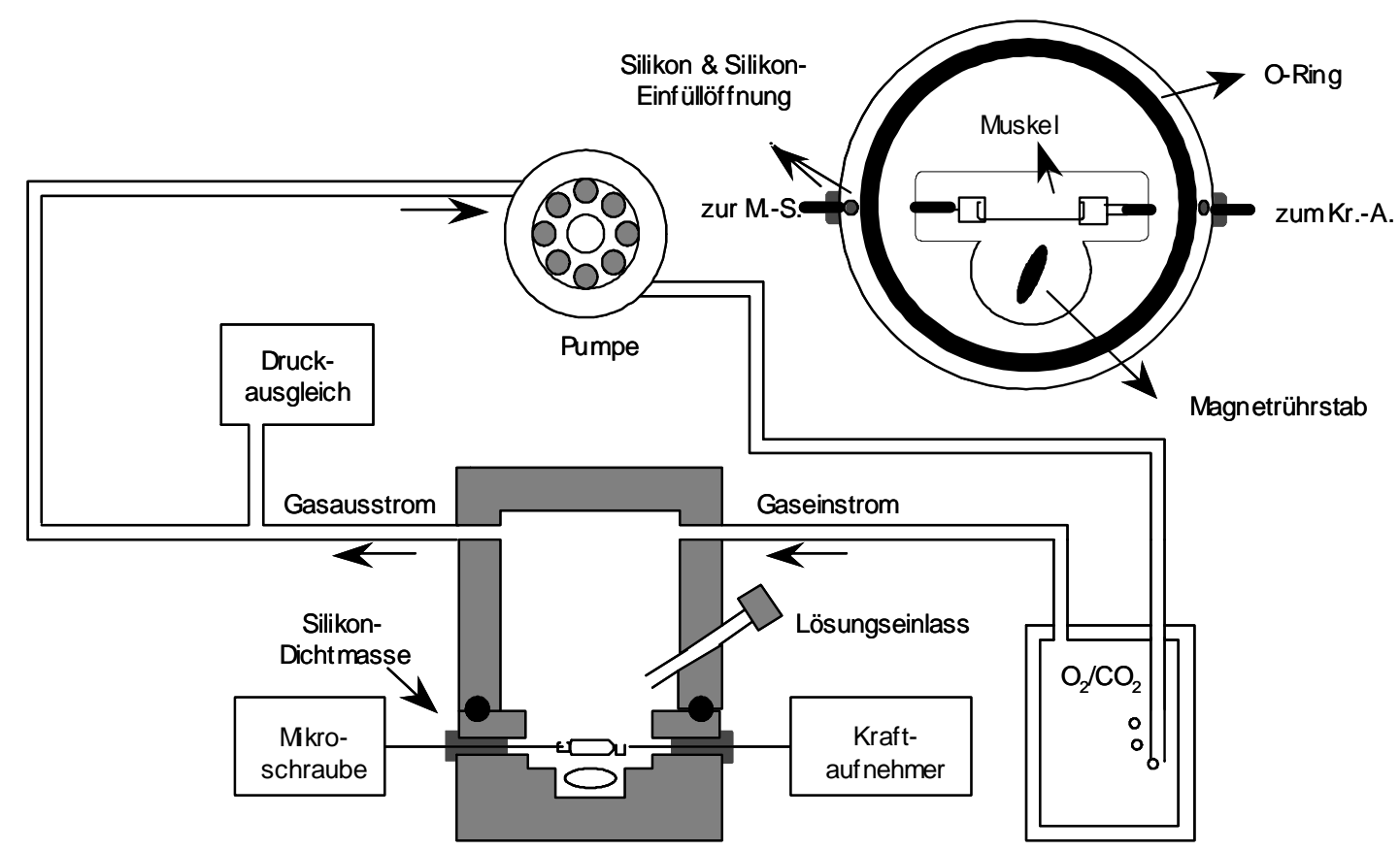

Abbildung 2-1: Schematischer Aufbau der Langzeitkulturanlage (modifiziert nach Janssen et al. 1998). Zur Vereinfachung ist hier nur eine Muskelkulturkammer eingezeichnet. Die für die Versuche benutzte Anlage bestand aus 4 in Reihe betriebenen Kulturkammern, d.h., der Gasausstrom der einen Kammer war mit dem Gaseinstrom der nächsten Kammer verbunden, die Kraftmessung und Temperierung erfolgte für jede Kammer getrennt.

Rechts oben eingefügt: vergrößerte Draufsicht einer Muskelkulturkammer ohne Deckel. Kr.-A.: Kraftaufnehmer, M.-S.: Mikroschraube

Die Öffnungen in der Kammer für die Kanülen mit Haken und Körbchen wurden vor Beginn des Versuches mit niedrigvisköser Silikonmasse (Fa. Bayer, Leverkusen) abgedichtet.

Im Inneren der Kammern befindet sich ein Tefloneinsatz mit einem ausgefrästen Organbad, das mit ca. $3 \mathrm{ml}$ Kulturmedium gefüllt wird, so dass der eingespannte Muskel vollständig mit Flüssigkeit bedeckt ist. Im Sockel der Anlage befindet sich ein motorgetriebener Magnetrührer, durch den das Medium kontinuierlich mithilfe eines ca. 0,5 cm langen Magnetrührstabes gerührt werden kann, ohne die Kammer öffnen zu müssen.

Nach oben hin wird die Kammer durch einen Metalldeckel mit einem gläsernen Sichtfenster verschlossen, der auf die Kammer geschraubt wird. In ihm befindet sich eine verschließbare Einfüllöffnung, durch die während des Versuches das Medium eingefüllt oder ausgetauscht werden kann. Der Sockel mit dem Organbad sowie der Deckel können mithilfe von drei Piezo-Heizelementen auf $37^{\circ} \mathrm{C}$ geheizt werden, um das Kulturmedium auf physiologischer Temperatur zu halten.

Bei dieser Anlage wird anders als bei ähnlichen typischerweise verwendeten offenen Versuchsanlagen (Zeitz 2001, Janssen et al. 1999a) auf eine Zirkulation des Mediums 
verzichtet, da sich dies in einem geschlossenen System nicht zufriedenstellend verwirklichen lässt. Stattdessen zirkuliert befeuchtetes Carbogengas aus einem Vorratsbehältnis durch in Reihe verbundene Kammern (s. Abb. 2-1). Es strömt, angetrieben von einer Walzenpumpe, durch Tygon ${ }^{\circledR}$-Schläuche (Fa. Masterflex, Gelsenkirchen) über zwei Öffnungen im Deckel in die bzw. aus der Kammer. Am Ende der Reihe befindet sich ein im Nebenschluss angeschlossenes Behältnis mit Wasser, das zur Luftbefeuchtung sowie zum Druckausgleich dient.

Die Stimulation erfolgt End-zu-End mit bipolarer Stimulation, d.h., die eine Elektrode ist am Haken, die andere am Körbchen befestigt, die Stimulation erfolgt somit durch den Muskel hindurch. Zur Erzeugung der Impulse wird ein Stimulator der Fa. Scientific-Instruments, Heidelberg verwendet. Er erzeugt mit einer vorgegebenen Frequenz ein extern ableitbares Triggersignal, das zugleich als Trigger für die Datenaufzeichnung dient. Mit kurzer vorgegebener Verzögerung erzeugt er dann an bis zu 4 Ausgängen jeweils einen elektrischen Impuls, wobei die Parameter (Spannung, Impulslänge) wiederum frei wählbar sind. In unserem Fall betrug die Impulslänge $3 \mathrm{~ms}$ und die Stimulationsspannung zwischen 1 und 4,5 V (s. Kap. 2.3.2).

\subsubsection{Kraftmessung und Datenaufzeichnung}

Der Kraftaufnehmer liefert über das dazugehörige Steuergerät am Ausgang ein Gleichspannungssignal, welches sich proportional zur gemessenen Kraft verhält. Bei der hier gewählten Einstellung entspricht 0,1 Volt Spannungsänderung einer Kraft von $1 \mathrm{mN}$. Dieser Wert muss durch regelmäßige Kalibrierungen nach jedem Neuaufbau der Anlage mit definierten Gewichten, die an den Kraftaufnehmer gehängt werden, überprüft werden.

Das Spannungssignal wird mit einer in einen handelsüblichen PC (Fa. Apple, Feldkirchen) eingebauten Analog-Digital-Wandlerkarte (Modell PCI-1200 der Fa. National Instruments, München) aufgezeichnet. Sie ist in der Lage, bei einem Messbereich von $\pm 5 \mathrm{~V} 10^{5}$ Samples, d.h. Spannungsänderungen pro Sekunde, aufzuzeichnen.

Die Datenerfassung erfolgte mit einer in unserer Arbeitsgruppe entwickelten Applikation, die unter der Softwareumgebung LabView ${ }^{\circledR}$ der Fa. National Instruments läuft. Bei LabView ${ }^{\circledR}$ handelt es sich um eine graphische Programmieroberfläche, die besonders für die Entwicklung und die Ausführung von Programmen zur Steuerung und Datenerfassung geeignet ist. In Verbindung mit der A/D-Wandlerkarte ermöglicht es die verwendete LabView ${ }^{\circledR}$ Anwendung, Kraftsignale aufzuzeichnen, zu speichern sowie über mehrere Kontraktionen gemittelte Kraftsignale auszugeben. Die gemessene Kraft wird automatisch durch die 
Querschnittsfläche - errechnet aus Höhe und Breite des Muskels - geteilt, so dass man den korrigierten Kraftwert als $\mathrm{mN} / \mathrm{mm}^{2}$ Querschnittsfläche erhält.

Weiterhin ist es möglich, nach der Versuchsdurchführung physiologische Parameter wie Zeitpunkt der maximalen Kontraktion, Zeit bis zur 50\%igen Relaxation und andere automatisch $\mathrm{zu}$ berechnen und in exportierbarer Form auszugeben. Der genauere Aufbau dieses Programms ist von Zeitz 2001 detailliert beschrieben worden.

Für die geschlossene isometrische Anlage wurde ein modifiziertes Programm benutzt, das in der Lage war, vier Kanäle gleichzeitig aufzuzeichnen. Erfasst wurden von jeder Kontraktion der maximale und der minimale Kraftwert (letzterer entspricht der diastolischen Spannung, im Folgenden $\mathrm{F}_{\text {dia }}$ ). Die Differenz aus der maximalen Kraft und der diastolischen Kraft entspricht der systolischen oder entwickelten Kraft, im Folgenden $F_{\text {dev }}$. Alle 30 Minuten bzw. nach manueller Auslösung wurde eine komplette Kontraktion aufgezeichnet, d.h. 900 Messwerte über $900 \mathrm{~ms}$ nach dem vom Stimulator erzeugten Triggerimpuls. Um Störimpulse, z.B. Druckschwankungen durch die Gaszirkulation oder durch den Magnetrührer im Medium zu verringern, zeichnete das Programm eine gemittelte Kontraktion aus den letzten 5 Kontraktionen auf.

\subsubsection{Offene Anlage für isotonische Kontraktionen}

\subsubsection{Kulturanlage}

Die Grundlage der Anlage bildet die oben bereits erwähnte und bei Zeitz 2001 beschriebene offene Anlage zur Kraftmessung an Herzmuskeltrabekeln. Kraftmessung und Datenaufzeichnung funktionieren genau wie in der geschlossenen Anlage. Anders als bei dieser Anlage, kommt hier zirkulierendes Medium zum Einsatz (Abb. 2-2). Es befindet sich in einem beheizten, ca. $100 \mathrm{ml}$ fassenden Vorratsgefäß, in dem es mit Carbogengas über eine Mikrofilterkerze (Fa. Schott) begast wird. Das Medium fließt dann angetrieben von einer Walzenpumpe durch einen Gegenstrom-Wärmetauscher, in dem es nochmals auf $37^{\circ} \mathrm{C}$ erwärmt wird, in ein ca. 1,5 ml fassendes, oben offenes Organbad. Anschließend wird es über eine gebogene Kanüle von der Oberfläche des Organbades abgesaugt und durch einen weiteren Schlauch wieder zurück in das Vorratsgefäß gepumpt. Die Fördergeschwindigkeit beträgt in Zuflussrichtung etwa $10 \mathrm{ml} / \mathrm{min}$. Die Pumpe fördert im Rückflusstrakt etwa 20 $\mathrm{ml} / \mathrm{min}$. Diese doppelte Förderleistung dient dazu, sicherzustellen, dass selbst bei Schwankungen im Zu- oder Ablauf das Organbad nie überläuft. Um Verdunstungen, die 


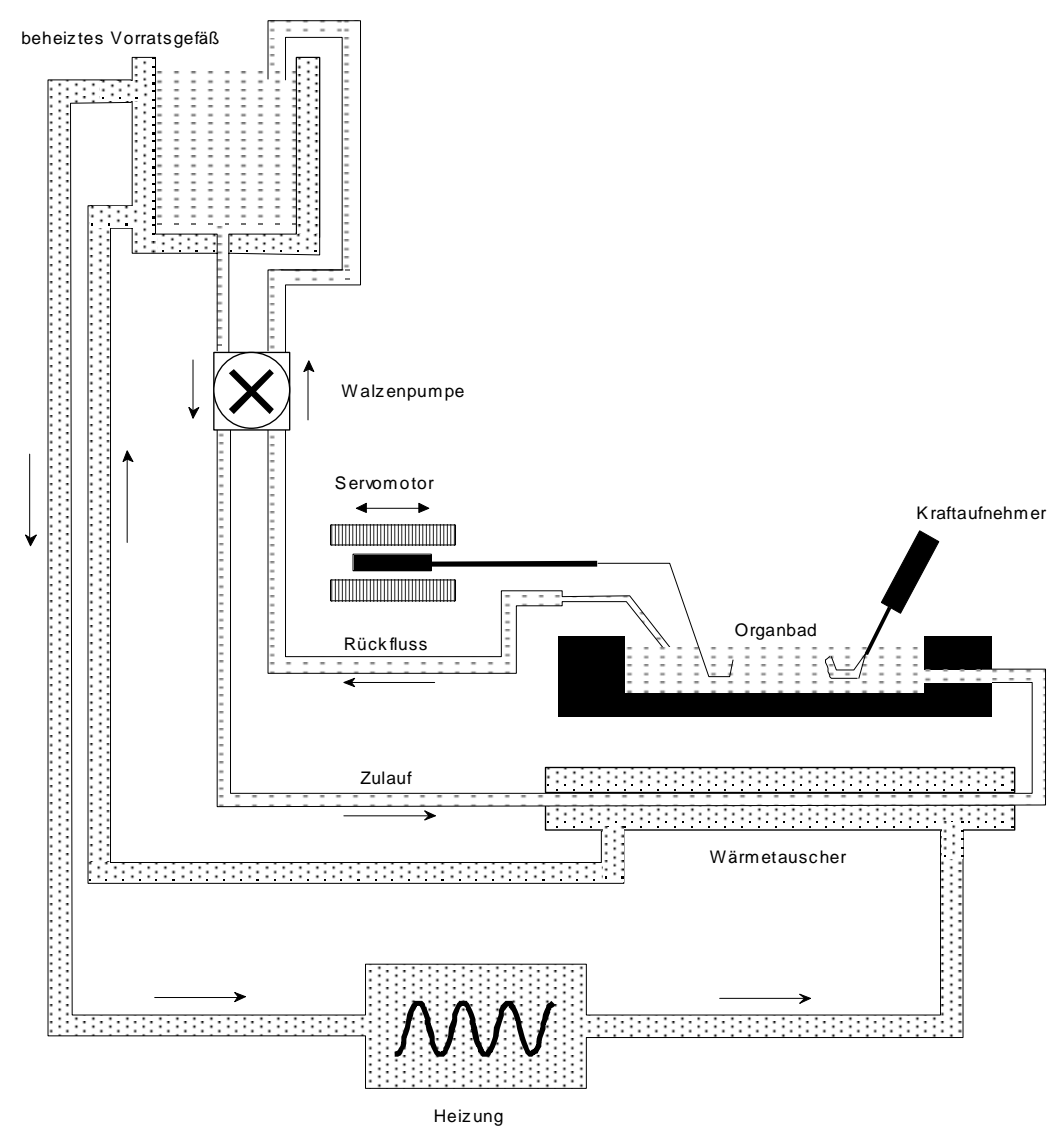

Abbildung 2-2: Aufbau der offenen isotonischen Kulturanlage. Man beachte den größervolumigen Rücklauf des Kulturmediums. Dies bewirkt eine größere Rück- als Hinfördermenge. Damit ist gewährleistet, dass geringe Schwankungen in der Rückförderleistung (z. B. durch Verstopfung) nicht sofort zu einem Überlaufen des Organbades führen.

durch die lebhaft sprudelnde Begasung gefördert werden, zu vermeiden, wurde das Vorratsgefäß möglichst luftdicht mit Parafilm verschlossen.

Die Stimulation erfolgt hier nicht End-zu-End durch den Muskel, sondern als bipolare Feldstimulation über zwei parallel zur Trabekel im Organbad liegende Platinelektroden. Die Stimulationsspannung liegt hier in der Regel etwas höher als bei der End-zu-End-Stimulation, etwa zwischen 3,5 und 4,5 V.

Die Fixierung der Präparate im Organbad ist nahezu identisch mit dem für die geschlossene Anlage beschriebenen Verfahren. Im Unterschied zur isometrischen Anlage ist die Kanüle mit dem Haken nicht mit einer Mikrometerschraube, sondern mit einem Linearmotor der Fa. Scientific-Instruments verbunden (s. Abb. 2-2). Dieser Motor kann einerseits den Haken im Ruhezustand fest in einer Position fixieren, in Verbindung mit dem dazugehörigen angeschlossenen Steuergerät kann der Haken jedoch auch äußerst schnell über eine Länge von etwa $2 \mathrm{~cm}$ horizontal bewegt werden. Die maximale Längenänderungsfrequenz des Motors beträgt etwa $1,5 \mathrm{kHz}$. 


\subsubsection{Steuerung der Verkürzung}

Die genaue Motorposition kann dem Steuergerät über ein analoges Spannungssignal vorgegeben werden. Es verhält sich über einen Bereich von \pm 8 V Gleichspannung proportional zur Position des Motors, wobei eine Verringerung der Spannung eine Bewegung des Motors in Richtung des Kraftaufnehmers - also eine Muskelverkürzung - bedeutet. Die Steuerung erfolgte aus Performancegründen auf einem eigenen Rechner mithilfe eines selbst geschriebenen LabView ${ }^{\circledR}$-Programmes. Die hier eingesetzte Wandlerkarte (Modell PCI-MIO 16E, Fa. National Instruments, München) ist in der Lage, $5 \times 10^{5}$ Samples pro Sekunde (Eingang und Ausgang zusammengenommen) zu verarbeiten.

Das Steuerungsprogramm, das in einer Endlosschleife (3000 Durchläufe/s) immer wieder durchlaufen wird, benutzt als zentralen Steueralgorithmus einen sog. PID-Regler. Es erhält vom Benutzer einen Kraftsollwert $\mathrm{F}_{\mathrm{s}}$ vorgegeben, welcher der $\mathrm{zu}$ haltenden diastolischen Spannung entspricht. Weiterhin erhält das Programm kontinuierlich von der Wandlerkarte den aktuellen Kraftwert in Form eines Spannungssignals $U_{i}$.

Das Programm errechnet nun drei Komponenten: einen proportionalen Anteil (P), einen integralen Anteil (I), sowie einen differentialen Anteil (D). Der P-Anteil errechnet sich einfach aus der Differenz von $\mathrm{U}_{\mathrm{i}}$ und $\mathrm{F}_{\mathrm{s}}$. Der I-Anteil ist das Integral unter der KraftdifferenzZeit-Kurve von $U_{i}-F_{s}$ über den Zeitraum $\Delta t$ (entspricht einer vorgegebenen Anzahl von Programmdurchläufen). Im Idealfall sollte das Integral gegen null gehen, d. h., die gemessene Kraft entspricht immer dem Referenzwert (damit ist $F_{\text {dev }}=0$ ). Der D-Anteil ist die Steigung der Kraft-Zeit-Kurve von $U_{\mathrm{i}}$ über den Zeitraum $\Delta \mathrm{t}$. Im Idealfall sollte auch dieser Wert gleich null sein, da die Kraft immer konstant sein soll. Aus diesen drei Faktoren errechnet sich nach der Formel $K=a P+b I+c D$ der Korrekturwert K (Böttle et al. 1985). Ein K > 0 bedeutet, dass die Spannung des Muskels in diesem Moment zu hoch ist, der Motor also den Muskel verkürzen muss. Entsprechend bedeutet ein $\mathrm{K}<0$ eine unzureichende Spannung, der Motor muss den Muskel dehnen. Die Parameter a, b und c sind vorgegebene Faktoren, die die Wichtung der drei Steueralgorithmen regeln. Empirisch wurden Wichtungsfaktoren von a = 1, $\mathrm{b}=0,001$ und $\mathrm{c}=0,5$ ermittelt. Problematisch ist insbesondere eine hohe Gewichtung des IAnteils, da das Integral über einen längeren Zeitraum analysiert wird und plötzliche starke Ausschläge des Kraftsignals bei zu hohem c über viele Kontraktionen eine Verschiebung des Ausgangssignals in eine Richtung verursachen.

Als weiteren Parameter benötigt das Programm die Vorgabe der sog. Korrekturschrittgröße s. Wenn nun $\mathrm{K}>0$ ist, so zieht das Programm vom momentanen Wert der Ausgangsspannung 
$\left(\mathrm{U}_{\mathrm{a}}\right)$, der als Variable in jeder Programmschleife mitläuft, den Wert $\mathrm{s}$ ab, falls $\mathrm{K}<0$, addiert es s hinzu und gibt anschließend den neuen Spannungswert als $U_{a}$ an das Motorsteuergerät aus.

Die richtige Wahl von s ist sehr wichtig für eine optimale Steuerung. Wird s zu groß gewählt, ist der Motor zwar schneller, er bewegt sich aber in größeren und damit auch ruckhafteren Schritten, was eine unruhigere Kraftkurve und ein z. T. deutlich stärkeres Rauschen des Kraftsignals erzeugt. Wird s zu klein gewählt, so ist das Kraftsignal zwar in der Regel ruhiger und rauschfreier, der Motor bewegt sich dann allerdings zu langsam, was zu einer sichtbaren Kraftentwicklung $F_{\text {dev }}$ führt. Es ist jedes Mal schwierig, $s$ für den entsprechenden Versuch optimal zu wählen.

\subsubsection{Verkürzungsmessung und Datenaufzeichnung}

Die computergesteuerte Datenaufzeichnung erfolgte wiederum mithilfe der oben beschriebenen Wandlerkarte, sowie einer LabView ${ }^{\circledR}$-Applikation. Hier können parallel zwei Kanäle gemessen werden und jeweils in Echtzeit der Zeitverlauf der diastolischen und der entwickelten $\mathrm{Kraft}\left(\mathrm{F}_{\mathrm{dia}}\right.$ und $\left.\mathrm{F}_{\mathrm{dev}}\right)$, vollständige aktuelle bzw. über die letzten Kontraktionen gemittelte Kontraktions-Zeit-Kurven, sowie grundlegende errechnete Kontraktionsparameter (z.B. der Zeitpunkt der maximalen Kraftentwicklung) gleichzeitig dargestellt und erfasst werden. Dieses eigentlich nur für die Kraftaufzeichnung entwickelte Programm lässt sich ohne größere Modifikationen auch zur Simultanmessung von Kraft und Verkürzung verwenden.

Die Verkürzung wird über die aktuelle Motorposition bestimmt. Diese wird vom Steuergerät über eine analoge Spannung ausgegeben. Dabei entspricht eine Änderung der Spannung um 1 $\mathrm{V}$ einer Längenänderung von $500 \mu \mathrm{m}$, Spannungszunahme bedeutet eine Verkürzung des Muskels.

Während auf dem Kraftkanal die aktuelle Kraft nach automatischer Umrechnung als Kraft $/ \mathrm{mm}^{2}$ Querschnittsfläche der Trabekel erfasst wird, wird auf dem Verkürzungskanal die reine Eingangsspannung registriert. Diese kann anschließend in die Position des Motors umgerechnet werden. Die Differenz zwischen maximaler und minimaler Position entspricht der absoluten Verkürzung des Muskels. Da ein langer Muskel absolut viel stärker verkürzt als ein kurzer Muskel, erfolgt die Angabe der Verkürzung im Folgenden als sog. Verkürzungsfraktion (VF), d.h. absolute Verkürzung dividiert durch diastolische Ausgangslänge der Trabekel, angegeben in Prozent. 
Neben der VF wurden in unserem Fall noch die diastolische Länge $\left(\mathrm{L}_{\mathrm{dia}}\right)$, die Zeit bis zur maximalen Verkürzung (TTP = time to peak) sowie die Zeit bis zu 50\% Relaxation $(\mathrm{RT50}=$ relaxation time to $50 \%$ ) erfasst.

Die genaue Verschaltung von Mess-, Steuerungsrechner und Motoreinheit ist noch einmal zusammenfassend in Abb. 2-3 dargestellt.

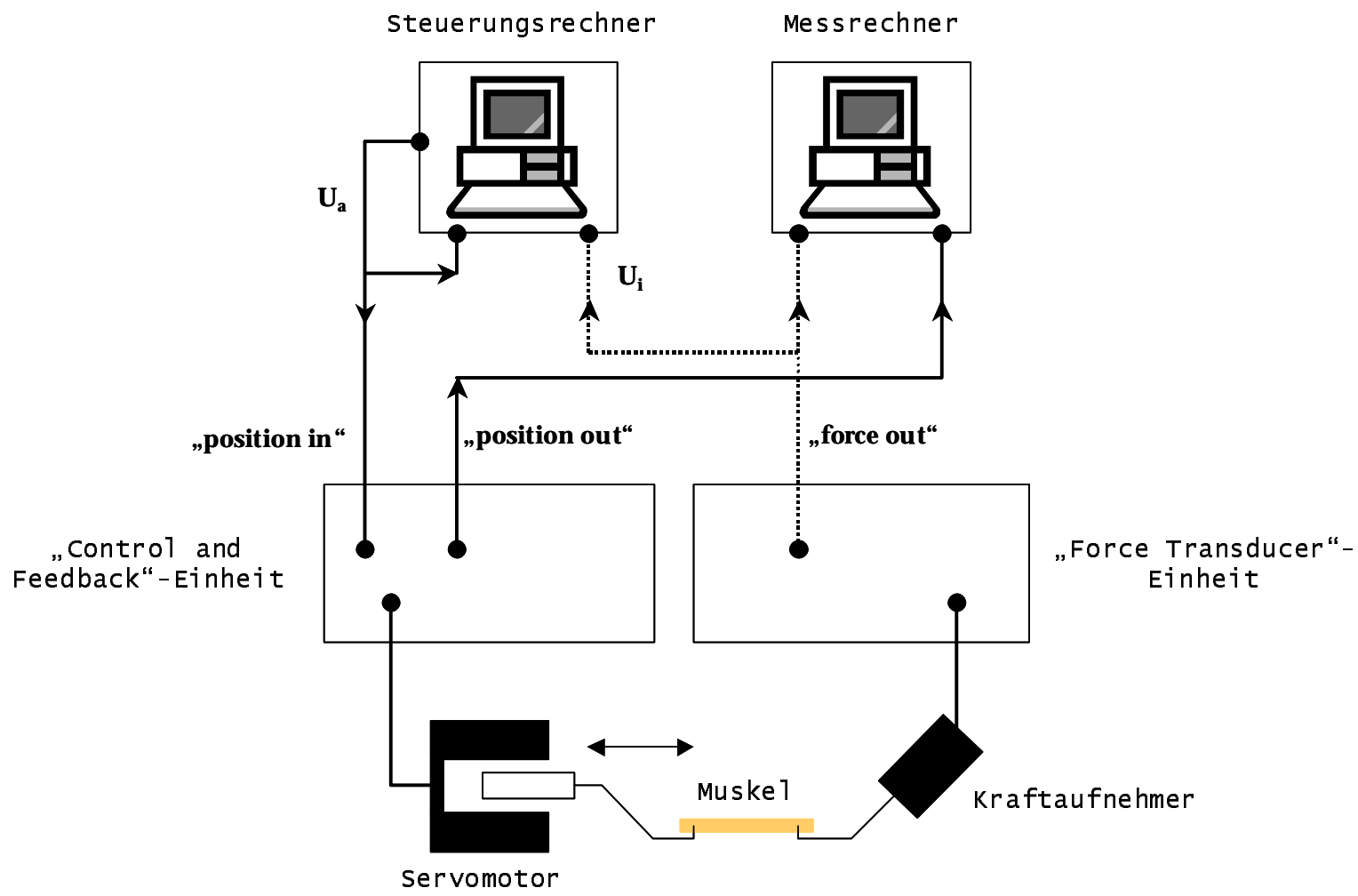

Abbildung 2-3: Schema der Verschaltung von Steuerungs- und Messrechner mit den vorhandenen Steuerund Messeinheiten. Die direkte Weitergabe von $U_{a}$ vom Ausgang des Steuerungsrechners zum Eingang ist innerhalb des Steuerungsalgorithmus realisiert und hier nur zur Verdeutlichung des Prinzips als physikalische Verbindung skizziert.

\subsection{Versuchsdurchführung}

\subsubsection{Versuchsprotokoll isotonische Versuche}

Vor dem Einspannen des Muskels wurde die Anlage mit $110 \mathrm{ml}$ Experimentierlösung gefüllt, die begast und vorgewärmt durch die Anlage zirkulierte. Die $\mathrm{Ca}^{2+}$-Konzentration betrug hier 0,5 mM. Die wie in Abschnitt 2.1.3.3 beschrieben gewonnenen Trabekel bzw. Papillarmuskeln wurden in die Versuchskammer überführt. Dies geschah berührungslos mittels einer großlumigen Pipette, in die der Muskelstreifen zusammen mit etwas Dissektionslösung eingesogen wurde. Anschließend wurde der Muskel unter dem Stereomikroskop mittels zweier 
Feinpinzetten in die Anlage eingespannt. Dazu wurde der Gewebsblock bzw. der Sehnenfadenrest am einen Ende des Muskels von hinten durch das etwas aufgedehnte Drahtkörbchen gezogen und auf den Haken aufgespießt, wobei der Durchtrittspunkt des Hakens möglichst weit von der eigentlichen Trabekel entfernt sein soll. Anschließend wurde das Drahtkörbchen wieder vorsichtig zusammengebogen. Bei diesen Schritten gilt analog, die bereits bei der Präparation erwähnten Vorsichtsmaßnahmen zu beachten, insbesondere darf der Muskel nicht zu stark gedehnt werden und das Körbchen muss weit genug sein, um die Trabekel nicht zu quetschen. Der Abstand zwischen Haken und Körbchen wurde so eingestellt, dass der Muskel frei und ungedehnt hängt, d.h. der Muskelblock dem Körbchen nicht direkt anliegt. Da beim Transfer der Trabekel immer auch etwas BDM-haltige Dissektionslösung mit in das Organbad gelangt, wurden nach Wiederbeginn der Zirkulation die ersten $10 \mathrm{ml}$ aus dem Rücklauf verworfen.

Nachdem der Muskel in der Anlage vermessen und die Dimensionen in das Messprogramm eingegeben wurden, welches dann automatisch die Kraft pro Querschnittsfläche errechnet, wurde über einen Zeitraum von etwa 10 Minuten die Calciumkonzentration durch Hinzufügen von $\mathrm{CaCl}_{2}$ in $0,25 \mathrm{mM}$-Schritten auf $1,75 \mathrm{mM} \mathrm{Ca}^{2+}$ erhöht. Hierbei war darauf zu achten, dass der Muskel nicht in Kontraktur geriet, was bei vorhandenen Membranschädigungen während der $\mathrm{Ca}^{2+}$-Erhöhung vorkommen kann. In diesem Fall muss der Muskel sofort stimuliert und im weiteren Verlauf kritisch beobachtet werden. Bei einigen Präparaten kam es dann allmählich zu einer Normalisierung der Kontraktionsparameter, andere Präparate mussten schließlich verworfen werden.

Bei unkomplizierter Calciumkonzentrationserhöhung wurde bei einer Calciumkonzentration von 1,0 $\mathrm{mM}$ die Stimulation aktiviert und die Stimulationsspannung auf einen Wert von etwa 30\% über der Reizschwelle geregelt. Anschließend wurde das Präparat leicht vorgedehnt, sodass die Muskelblöcke an Haken und Körbchen anlagen und eine minimale systolische Kraftentwicklung nachweisbar war. Falls bei einzelnen Präparaten keine oder nur geringe Kontraktionen messbar waren, wurden sie noch etwas weiter auf etwa $0,5 \mathrm{mN} / \mathrm{mm}^{2} F_{\text {dia }}$ gedehnt. Sollte es dann während der nächsten 10 Minuten auch unter Erhöhung der Stimulationsspannung zu keiner stabilen Kontraktion der Trabekel gekommen sein, so musste der Muskelstreifen verworfen werden.

Sobald bei schlagenden Präparaten eine minimale Kraftentwicklung sichtbar war, wurde das Steuerprogramm für die Motorsteuerung gestartet und der Muskel kontrahierte von hier an isoton. Nun wurde die Trabekel über etwa 15-20 Minuten schrittweise durch Erhöhung des Kraftsollwertes $F_{\mathrm{s}}$ auf einen diastolischen Wert von etwa $4,7 \mathrm{mN} / \mathrm{mm}^{2}$ vorgedehnt. Hierbei 
wurde auch die Korrekturschrittgröße s nachreguliert (s. Kap. 2.2.2.2). Besonders bei langen Muskeln musste sie z. T. deutlich erhöht werden, damit der Motor die starke absolute Verkürzung schnell genug ausgleichen konnte.

Sobald sich der Muskel auf der endgültigen Dehnungsstufe stabilisiert hatte, wurde die Experimentierlösung aus dem Vorratsgefäß abgesaugt und sofort durch M199 ersetzt. Anschließend erfolgte eine kurze fünfminütige Stabilisierungsphase.

Sobald der Muskel nun stabil kontrahierte, d. h. eine gleichbleibende diastolische Länge $\mathrm{L}_{\text {dia }}$ und Verkürzungsfraktion VF hatte, wurde die Datenaufzeichnung gestartet. Gleichzeitig wurde die Länge des Muskels im gedehnten Zustand mithilfe des Stereomikroskops bestimmt. Dies war notwendig, da sich die Positionsausgabe des Motors, die aufgezeichnet wurde, nicht auf Null eichen lässt. Somit konnten während des Versuches nur Positionsänderungen bestimmt werden, die auf die optisch gemessene Ausgangslänge bezogen werden mussten.

Nach 6 Stunden wurde der Versuch beendet. Präparate, die nach Ablauf der Versuchsdauer deutlich schlugen und eine normale Verkürzung zeigten (keine Nachkontraktionen, keine Oszillationen in der Diastole, keine Arrhythmien, keine Extrakontraktionen), wurden in die Auswertung übernommen. Zuerst wurde die Stimulation und anschließend die Steuerung abgeschaltet.

Nun wurden die Präparate aus der Anlage entnommen und eingefroren. Dazu wurde das in der Kammer vorhandene Medium durch BDM-haltige Lösung ersetzt. Da für die molekularbiologische Untersuchung nur die Teile der Trabekel interessant sind, die frei in der Kammer geschlagen haben bzw. gedehnt waren, mussten die beidseitigen Muskelblöcke abgetrennt werden. Dies geschah in-situ unter mikroskopischer Kontrolle im Organbad. Anschließend wurden die Trabekel sofort in ein kleines Kunststoffgefäß überführt und in flüssigem Stickstoff tiefgefroren. Bei Proben, die für die RNA-Analyse vorgesehen waren, enthielt das Gefäß zusätzlich RNAse-inhibierenden Puffer (RNAlater®, Fa. Qiagen, Hilden). Bis zur molekularbiologischen Aufarbeitung wurden die Proben bei $-80^{\circ} \mathrm{C}$ aufbewahrt.

\subsubsection{Versuchsprotokoll isometrische Versuche}

Vor Beginn des Versuches wurden die geöffneten Kammern mit vorgewärmter und vorbegaster BDM-haltiger Dissektionslösung gefüllt. Der Aufbau und die Bestückung der Anlage erfolgte unter nichtsterilen Bedingungen, da sich im Verlauf der Experimente gezeigt hatte, dass es während der sechsstündigen Versuchszeit in der Regel nicht zu relevanten bakteriellen oder mykotischen Kontaminationen kommt. Aus Sicherheitsgründen wurde die Anlage jedoch nach 6 Versuchen zerlegt und autoklaviert. Die wie in Abschnitt 2.1.3.3 beschrieben gewon- 
nenen Trabekel bzw. Papillarmuskeln wurden wie in Kap 2.3.1 beschrieben in die Versuchskammer überführt. Der Abstand zwischen Haken und Körbchen wurde wiederum so eingestellt, dass der Muskel frei und ungedehnt hängt und der Muskelblock dem Körbchen nicht direkt anliegt. Dieser Zustand wird im Folgenden als „ungedehnt“ bezeichnet.

Anschließend wurden die Kammern verschlossen, die Rührer aktiviert, das Gasreservoir mit Carbogen gefüllt und die Gaszirkulation eingeschaltet. Nun wurde die Dissektionslösung gegen BDM-freie Krebs-Henseleit-Lösung ausgetauscht und die $\mathrm{Ca}^{2+}$-Konzentration von 0,25 $\mathrm{mM}$ in der Dissektionslösung auf 1,75 mM erhöht. Dies geschah über einen Zeitraum von etwa 20 Minuten in mehreren Schritten. Dabei wurde mit einer Kanüle durch die Einfüllöffnung jeweils so viel Lösung abgesogen, dass der Muskel gerade noch vollständig mit Flüssigkeit bedeckt war und anschließend durch die gleiche Menge wieder ersetzt. Konkret benutzten wir Krebs-Henseleit-Lösung mit $\mathrm{Ca}^{2+}$-Konzentrationen von 0,5 mM, $1 \mathrm{mM}$ und $1,75 \mathrm{mM} \mathrm{Ca}^{2+}$ (in Form von Calciumchlorid), wobei jeder Schritt zweimal durchgeführt wurde, insgesamt also 6 Lösungswechsel.

Die Stimulation wurde direkt nach dem ersten Wechsel auf 0,5 mM Lösung gestartet, d.h., sobald die kardiopleg wirkende BDM-Lösung ausgetauscht wurde. Üblicherweise betrug die Stimulationsspannung 2 - 4 V. Sobald eine Kontraktion in der Kraftaufzeichnung erkennbar war, wurde die Spannung (nach Janssen et al. 1998) so eingestellt, dass sie etwa 30\% über der Stimulationsschwelle lag. Die Stimulation erfolgte mit einer Frequenz von $1 \mathrm{~Hz}$.

Fünf Minuten nach Abschluss der $\mathrm{Ca}^{2+}$-Konzentrationserhöhung und einer anschließenden Nachfüllung des Carbogenreservoirs erfolgte, ebenfalls in zwei Schritten, ein Wechsel auf ebenfalls vorbegastes und vorgewärmtes Medium M199 (s. Kap 2.1.2.3). Anschließend erhielten die Muskeln - alle im ungedehnten Zustand - eine Stunde Zeit, um sich zu stabilisieren und zu äquilibrieren.

Nach der Stabilisierungsphase wurden Präparate ausgewählt, die gedehnt werden sollten. Dies geschah nach dem Zufallsprinzip, mit der Einschränkung, dass versucht wurde, eine gleiche Anzahl gedehnter und ungedehnter Präparate zu erhalten. Auch wurde möglichst darauf geachtet, dass morphologisch ähnliche Präparate (im Bezug auf Länge und Durchmesser) paarweise beiden Gruppen zugeordnet wurden.

Die für die Dehnung vorgesehenen Präparate wurden über einen Zeitraum von ca. 30-45 Minuten auf etwa 95\% der maximalen Sarkomerlänge $\left(\mathrm{L}_{\max }\right)$ gedehnt (s. Kap. 4.1.2). Dies erfolgte in einzelnen kleinen Schritten, danach erhielt der Muskel jeweils Zeit, sich zu stabilisieren. Erst danach war es möglich, den durch die Dehnung erzeugten sofortigen (Frank-Starling-Mechanismus) und den verzögerten Kraftanstieg (sog. Anrep-Effekt, Nichols 
et al. 1988) zu beurteilen, um das Erreichen von $\mathrm{L}_{\max }$ - gekennzeichnet durch ausbleibenden systolischen Kraftanstieg in Verbindung mit deutlich erhöhtem diastolischen Spannungsanstieg - zu erkennen. Nach Abschluss der Dehnung wurde die Datenerfassung aktiviert.

Sechs Stunden nach Beginn der Datenaufzeichnung wurde der Versuch beendet. Davor wurde eine visuelle Beurteilung der evtl. noch vorhandenen Kontraktionen sowie der Morphologie der Präparate (bes. im Hinblick auf mögliche Hyperkontrakturen) vorgenommen. Präparate, die hier Zeichen einer Schädigung oder Hyperkontraktur aufwiesen, wurden verworfen. Ebenso wurden gedehnte Proben, deren entwickelte Kraft $\mathrm{F}_{\text {dev }}$ um mehr als 50\% gegenüber dem Versuchsbeginn abgefallen war, verworfen.

Zuerst wurden die Kammern eröffnet. Dann wurde das in der Kammer vorhandene Medium durch BDM-haltige Lösung ersetzt. Dies führte rasch zum Erliegen der Kontraktionen. Anschließend wurden die Präparate wie im vorherigen Kapitel beschrieben geborgen und in flüssigem Stickstoff tiefgefroren.

\subsection{SERCA2a-RNA-Analyse mittels NASBA-Reaktion}

\subsubsection{Prinzip der NASBA-Reaktion}

Die Analyse der Muskelstreifen erfolgte mithilfe der NASBA-Methode (Abkürzung für engl. nucleic acid sequence-based amplification). Dabei handelt es sich um ein Verfahren zur isothermalen RNA-Amplifikation um das bis $\mathrm{zu} 10^{10}$-fache der Ausgangsmenge. Diese Amplifikation ist RNA-spezifisch und funktioniert auch in Gegenwart von DNA. Dies ermöglicht eine direkte Analyse von aus Zellen gewonnener RNA, ohne dass Reste von genomischer DNA vorher aufwendig eliminiert werden müssen. Mit diesem Verfahren ist es möglich, die geringe mRNA-Menge einer Muskeltrabekel von typischerweise etwa $550 \mathrm{ng}$ zu amplifizieren und semiquantitativ zu untersuchen. Das Verfahren ist von Compton 1991 und Heim et al. 1998 genauer beschrieben worden. Das Prinzip soll im Folgenden kurz dargestellt werden.

Die Reaktion besteht aus einer initialen nichtzyklischen und einer anschließenden zyklischen Phase. Beide Phasen laufen zeitgleich in einem Reaktionsgefäß ab. Die Amplifikation erfolgt bei einer konstanten Temperatur von $41^{\circ} \mathrm{C}$, anders als z. B. bei einer PCR, wo nacheinander mit unterschiedlichen Temperaturen inkubiert werden muss. Das Schema der Reaktion ist in Abb. 2-4 dargestellt. 


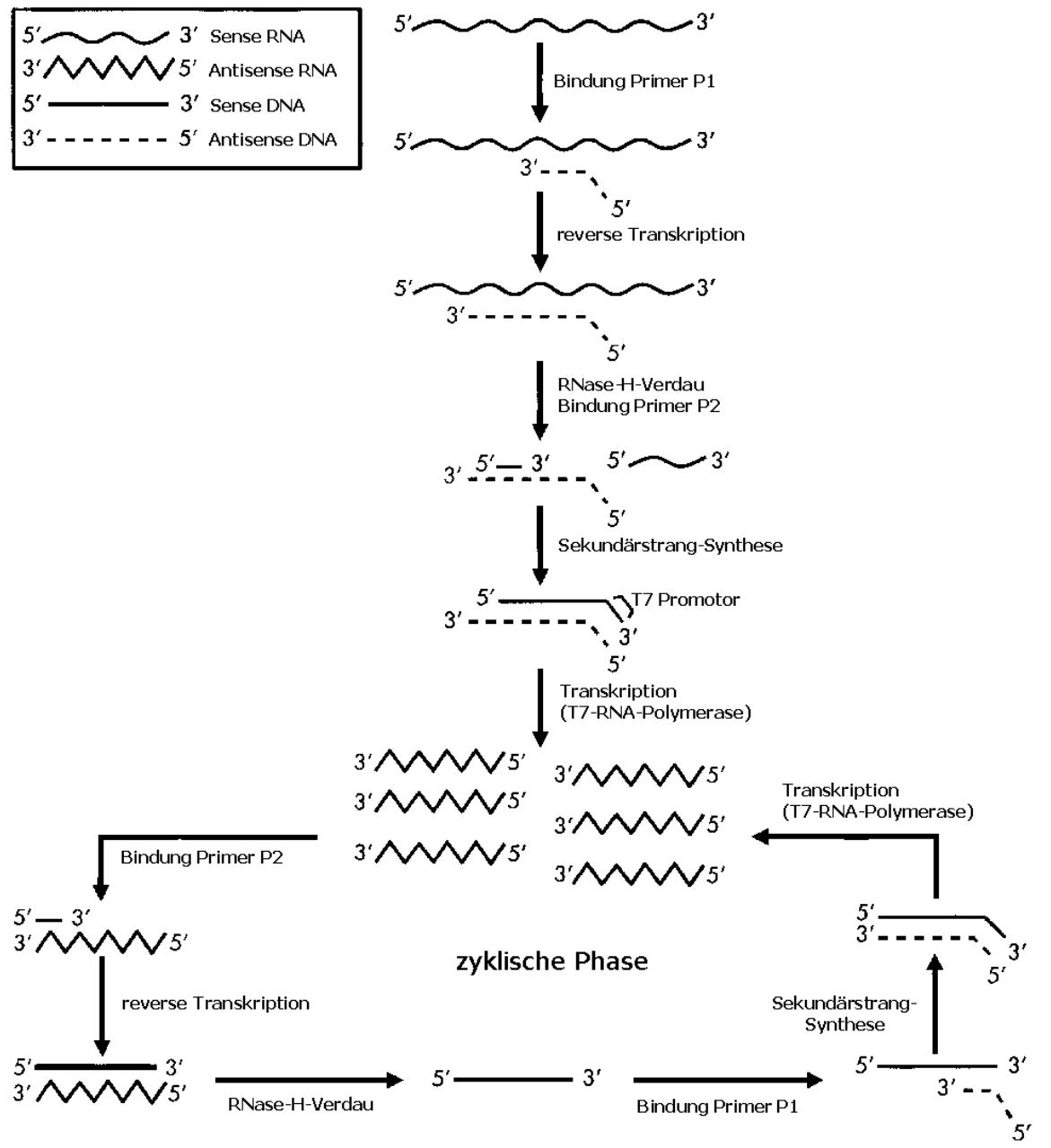

Abbildung 2-4: Prinzip der NASBA-Reaktion, modifiziert nach: RNAmplifier Handbook 2001, S. 7

Für die Reaktion werden zwei Primer von etwa 20 Basenpaaren Länge benötigt, die spezifisch einen Abschnitt der Sequenz der zu untersuchenden mRNA flankieren. Der Primer (P1), der das 3'-Ende der gesuchten Sequenz (hier 250 Basenpaare lang) flankiert, enthält zusätzlich am 5'-Ende als Überhang die T7-Promotorsequenz aus 31 Nukleotiden (AAT TCT AAT ACG ACT CAC TAT AGG GAG AAG G), er ist also insgesamt 51 Basenpaare lang. Weiterhin werden für die Reaktion neben einer ausreichenden Menge Nukleosidtriphosphaten als Substrate drei Enzyme benötigt: T7-RNA-Polymerase (aus dem Bakteriophagen T7), E.coliRNase-H, sowie AMV-reverse-Transkriptase.

Vor der ersten, nichtzyklischen Phase erfolgt vor Zugabe der Enzyme eine Inkubation bei $65^{\circ}$ C, um vorhandene RNA-Sekundärstrukturen aufzubrechen und somit eine optimale Bindung der Primer zu ermöglichen. Diese Temperatur ist gewählt, damit es noch nicht zu einer Denaturierung von Doppelstrang-DNA (dsDNA) kommt, an die die Primer binden könnten. 
Die nächsten Schritte erfolgen alle in einem Reaktionsgefäß bei $41^{\circ} \mathrm{C}$. Zuerst bindet der Primer P1 am 3'-Ende der Vorlage-RNA. Nach der Primerbindung wird dieser am 3'-Ende durch die AMV-reverse-Transkriptase verlängert. Es entsteht ein Strang copy-DNA (cDNA) in Form eines RNA:DNA-Hybrids. Die RNase-H kann nun die RNA aus dem Hybrid lösen und verdauen. Entscheidend ist, dass RNase-H nur RNA aus DNA:RNA-Hybriden verdaut und keine Einzelstrang-RNA (ssRNA), sonst wäre es unmöglich, ssRNA als Reaktionsendprodukt zu erhalten. An die entstandene einzelsträngige cDNA bindet nun am 3'-Ende der Primer P2. Die reverse Transkriptase synthetisiert anschließend einen komplementären DNAStrang. Als Resultat dieser ersten Reaktionen ist eine dsDNA mit der gesuchten Sequenz entstanden, die zusätzlich die T7-Promotorsequenz enthält. Das dritte Enzym der Mischung, die T7-RNA-Polymerase, kann nun beginnend von der für sie spezifischen Promotorsequenz aus eine zu der dsDNA komplementäre ssRNA transkribieren, pro Molekül etwa 100 Kopien. In der zweiten, sog. zyklischen Phase, bindet der Primer P2 zunächst an jedes der entstandenen ssRNA-Moleküle und wird von der reversen Transkriptase verlängert. Es entsteht wieder ein DNA:RNA-Hybrid, aus dem die RNase-H die RNA herauslösen und verdauen kann. An die entstandene ssDNA kann wieder der Primer P1 binden und die reverse Transkriptase eine dsDNA mit aktiver T7-Promotorsequenz erzeugen. Hiervon kann dann anschließend die T7-RNA-Polymerase neue ssRNA-Moleküle bilden, die wieder als Ausgangsprodukt für die zyklische Phase dienen können.

Auf diese Weise ist es möglich, innerhalb von 90 Minuten eine hohe Anzahl Kopien des gewünschten RNA-Abschnittes, allerdings als antisense-RNA, zu erhalten.

\subsubsection{RNA-Isolation}

Die Isolation erfolgte mithilfe eines RNeasy ${ }^{\circledR}$-Mini-Kits der Fa. Qiagen, Hilden. Das Verfahren wurde entsprechend dem Protokoll durchgeführt, das dem Produkt beigefügt ist. Zuerst wurden die Proben in gefrorenem Zustand homogenisiert. Anschließend erfolgte ein Proteinverdau mit Proteinase K. Das gewonnene Lysat wurde durch eine Säule mit einer Silikamatrix zentrifugiert. In dieser Säule wurde die RNA gebunden. Eventuell ebenfalls gebundene DNA wurde durch zwischenzeitliche Zugabe von DNase auf die Säule verdaut. Nach mehreren Wasch- und Zentrifugierschritten ließ sich schließlich die gewonnene RNA mit destilliertem Wasser aus der Säule herauslösen.

Die genaue Bestimmung der gewonnenen RNA-Menge erfolgte durch Extinktionsmessung im Photometer. Die Ausbeute an RNA pro Muskel schwankte von Präparation zu Präparation, sie lag im Mittel etwa bei $10 \mathrm{ng} / \mu 1$ Lysat. Diese gewonnene Menge RNA reicht aus, um sowohl 
die Gene für SERCA, als auch in einer weiteren Reaktion die für Calsequestrin zu untersuchen.

\subsubsection{RNA-Amplifikation und quantitative Analyse}

Die gewonnene RNA wurde mithilfe der oben beschriebenen NASBA-Methode amplifiziert. Dies geschah mit dem RNampliFire ${ }^{\circledR}-K i t$ der Fa. Qiagen gemäß dem im Handbuch angegebenen Protokoll, welches dem von Heim et al. 1998 vorgestellten Protokoll entspricht. Die für jede Reaktion eingesetzte Menge an RNA betrug $1 \mathrm{ng}$.

Die Primer wurden so gewählt, dass Amplifikate von 250 Basenpaaren entstehen, die spezifische Ausschnitte der mRNA-Sequenzen von SERCA2a bzw. Calsequestrin sind.

Die direkte quantitative Analyse der RNA-Menge ist mit diesem Verfahren nicht möglich, da es unmöglich ist, den genauen Amplifikationsfaktor zu bestimmen. Hier hilft eine semiquantitative vergleichende Bestimmung mithilfe eines Standards. Hierfür wurden RNASequenzen synthetisiert, die genau wie die zu untersuchenden RNA-Moleküle am 3'- bzw. 5'Ende die für die Primer P1 und P2 spezifischen Bindungssequenzen besitzen, jedoch 100 Basenpaare kürzer sind.

Wenn nun die zu untersuchende RNA zusammen mit einer genau definierten Menge dieses Standards in einen NASBA-Ansatz kommt, so konkurrieren beide Moleküle kompetitiv um die zur Verfügung stehenden Primer. Je nach Konzentration der eingesetzten RNA-Moleküle wird entweder die RNA der Probe oder der Standard vermehrt amplifiziert. Durch die unterschiedliche Länge der Fragmente lassen sich diese anschließend mittels Gelelektrophorese voneinander unterscheiden.

Jede NASBA-Reaktion wurde in acht parallelen Ansätzen mit unterschiedlichen Standardmengen durchgeführt. Bei der Untersuchung von SERCA waren das $1 \times 10^{9}, 5 \times 10^{8}, 1 \times 10^{8}$, $5 \times 10^{7}, 1 \times 10^{7}, 5 \times 10^{6}$ und $1 \times 10^{6}$, bei der Untersuchung von Calsequestrin $1 \times 10^{7}, 8 \times 10^{6}, 5 \times 10^{6}$, $3 \times 10^{6}, 1 \times 10^{6}, 8 \times 10^{5}, 5 \times 10^{5}$ und $3 \times 10^{5}$ Moleküle Standard pro Ansatz.

Nach der NASBA-Reaktion wurden die einzelnen Proben mithilfe eines mit Ethidiumbromid gefärbten 2,5\%igen Agarosegels elektrophoretisch getrennt. Durch den Längenunterschied des Standards ist dieser gut als eigene Bande unter der des zu untersuchenden Gens zu identifizieren.

Die Intensität der einzelnen Banden wurde anschließend mittels Photoimager bestimmt. Anschließend wurde der Quotient aus den Intensitäten der Bande der Probe und des Standards gebildet. Durch Auftragung der Logarithmen aller Quotienten gegen die Logarithmen der Menge an eingesetztem Standard ließ sich eine Funktionsgerade extrapolieren. Wenn nun der 
Logarithmus des Quotienten gleich null gesetzt wurde (der Quotient also gleich 1 ist), konnte anhand der ermittelten Funktionsgleichung die Anzahl der in der Probe enthaltenen Moleküle der Ziel-RNA ermittelt werden.

\subsection{Darstellung der Ergebnisse und statistische Auswertung}

\subsubsection{Physiologische Datenauswertung}

Bei den isometrischen Versuchen wurde pro Kanal alle 30 Minuten ein komplettes, aus den letzten 5 Kontraktionen gemitteltes Kraft-Zeit-Diagramm einer Kontraktion über $900 \mathrm{~ms}$ aufgezeichnet. Bei den isotonischen Versuchen erfolgte die Mittelung aus den letzten 20 Kontraktionen. Zusätzlich zum Kraft-Zeit-Diagramm wurde auch ein Längen-Zeit-Diagramm aufgezeichnet. Innerhalb der ersten Stunde wurde hier zusätzlich alle 15 Minuten eine gemittelte Kontraktion aufgezeichnet.

Ausgewertet und grafisch dargestellt wurden bei allen gedehnten isometrischen Versuchen die diastolische Spannung $\left(\mathrm{F}_{\mathrm{dia}}\right)$ in $\mathrm{mN} / \mathrm{mm}^{2}$ Muskelquerschnittsfläche zu Beginn des Versuches, sowie über die gesamte Versuchslaufzeit die entwickelte $\mathrm{Kraft}\left(\mathrm{F}_{\mathrm{dev}}\right)$, ebenfalls in $\mathrm{mN} / \mathrm{mm}^{2}$, sowie die Zeit bis zum Erreichen von $\mathrm{F}_{\mathrm{dev}}$ (TTP) und die Zeit von $\mathrm{F}_{\mathrm{dev}}$ bis zur 50\%igen Relaxation (RT50), jeweils in Millisekunden. Bei den isometrischen Versuchen wurde über die gesamte Laufzeit $\mathrm{F}_{\mathrm{dia}}, \mathrm{F}_{\mathrm{dev}}$, die diastolische Länge $\left(\mathrm{L}_{\mathrm{dia}}\right)$ in $\mu \mathrm{m}$, sowie die Verkürzungsfraktion (VF) in Prozent angegeben, ferner TTP und RT50, diesmal jedoch bezogen auf die Verkürzung.

Die Darstellung erfolgte als Mittelwert aus allen in die Untersuchung einbezogenen Präparaten, die Schwankungsbreite wurde als Standardmessfehler angegeben. Zur Signifikanzprüfung wurde ein gepaarter t-Test benutzt. Falls die Stichproben nicht normal verteilt waren, kam der Wilcoxon-Vorzeichen-Test zur Anwendung.

\subsubsection{Biochemische Datenauswertung}

Es hat sich gezeigt, dass es zwischen einzelnen Präparaten in Bezug auf die Größenordnung der gemessenen RNA-Molekül-Anzahl in der NASBA-Reaktion erhebliche Schwankungsbreiten gibt. Aus diesem Grund wurden bei den isometrischen Versuchen, bei denen gedehnte und ungedehnte Proben miteinander vergleichbar sein sollten, nur Präparate in die Auswertung mit einbezogen, bei denen sich aus einem Kaninchen jeweils ein ungedehntes sowie ein gedehntes Präparat untersuchen ließen. Wenn für eine Gruppe innerhalb eines Versuches mehr als eine Probe gewonnen werden konnte, so wurde der aus allen Werten berechnete 
Mittelwert verwendet. Die Angabe der RNA-Menge erfolgt als Quotient aus SERCA- zu

Calsequestrin-Kopienanzahl. Calsequestrin gilt im Herzmuskel als „housekeeping gene“, was bedeutet, dass es in sehr konstanten Mengen im Gewebe vorkommt und damit eine sinnvolle Bezugsgröße darstellt. Zur Signifikanzbestimmung wurde der gepaarte t-Test benutzt. 


\section{Ergebnisse}

\subsection{Entwicklung der isotonischen Kulturanlage, funktionelle Ergebnisse}

\subsubsection{Zahl der verwendeten Proben}

Insgesamt wurden 20 Trabekel an der isotonischen Anlage kultiviert. Ein Präparat wurde verworfen, da der Muskel nach $6 \mathrm{~h}$ nur noch sehr schwache Kontraktionen mit deutlicher Relaxationsstörung durchführte. Zwei Proben und die dazugehörigen physiologischen Messdaten mussten aus technischen Gründen verworfen werden. Somit kamen insgesamt 17 Proben in die physiologische Auswertung. Für die mRNA-Analyse wurden 9 Proben verwendet.

\subsubsection{Funktion der Steuerung (entwickelte und diastolische Kräfte)}

Im Idealfall sollte ein isotonisch schlagender Muskel eine konstante diastolische Spannung $\left(F_{\text {dia }}\right)$ aufweisen. Weiterhin sollte keine entwickelte Kraft $\left(F_{\text {dev }}\right)$ nachweisbar sein. Letzteres ließ sich bei unseren Versuchen annähernd vollständig verwirklichen.

Abb. 3-1 zeigt ein typisches, aus 10 gemessenen Kontraktionen gemitteltes Kraftsignal über den Zeitraum von $900 \mathrm{~ms}$ nach einer Stimulation. Die Mittelung war erforderlich, da das Rohsignal einen hohen Rauschgrad aufweist, der es z. T. schwierig macht, die noch vorhandene Kontraktion sicher zu erkennen. Besonders ausgeprägt ist dieses Rauschen in der diastolischen Phase nach Beendigung der Kontraktion (in Abb. 3-1 ab etwa 300 ms).

Man erkennt in der Abbildung zu Beginn einen minimalen Gipfel von $\mathrm{F}_{\mathrm{dev}}$, gefolgt von einem kurzen spitzen Abfall der diastolischen Spannung. Dieses Phänomen tritt auf, da die Steuerung offensichtlich eine etwas zu langsame Reaktionszeit hat. Somit kann sie den Beginn der Kontraktion nicht schnell genug ausgleichen, es kommt zu einer geringen entwickelten Kraft. Sie lag in den durchgeführten Experimenten zwischen $0,3 \pm 0,05 \mathrm{mN} / \mathrm{mm}^{2}(\mathrm{t}=345 \mathrm{~min})$ und $0,5 \pm 0,06 \mathrm{mN} / \mathrm{mm}^{2}(\mathrm{t}=30 \mathrm{~min})$, im Mittel bei $0,4 \pm 0,02 \mathrm{mN} / \mathrm{mm}^{2}$. Fremdversuche in einer identisch aufgebauten Anlage zeigen, dass isometrisch schlagende Muskelpräparate unter identischen Versuchsbedingungen eine durchschnittliche Kraft von 25,1 $\pm 2,6 \mathrm{mN} / \mathrm{mm}^{2}$ entwickeln (Daten nicht gezeigt). Dies bedeutet, dass es durch die isotonische Steuerung möglich ist, $\mathrm{F}_{\mathrm{dev}}$ auf weniger als $2 \%$ der isometrisch entwickelten Kraft zu reduzieren. 


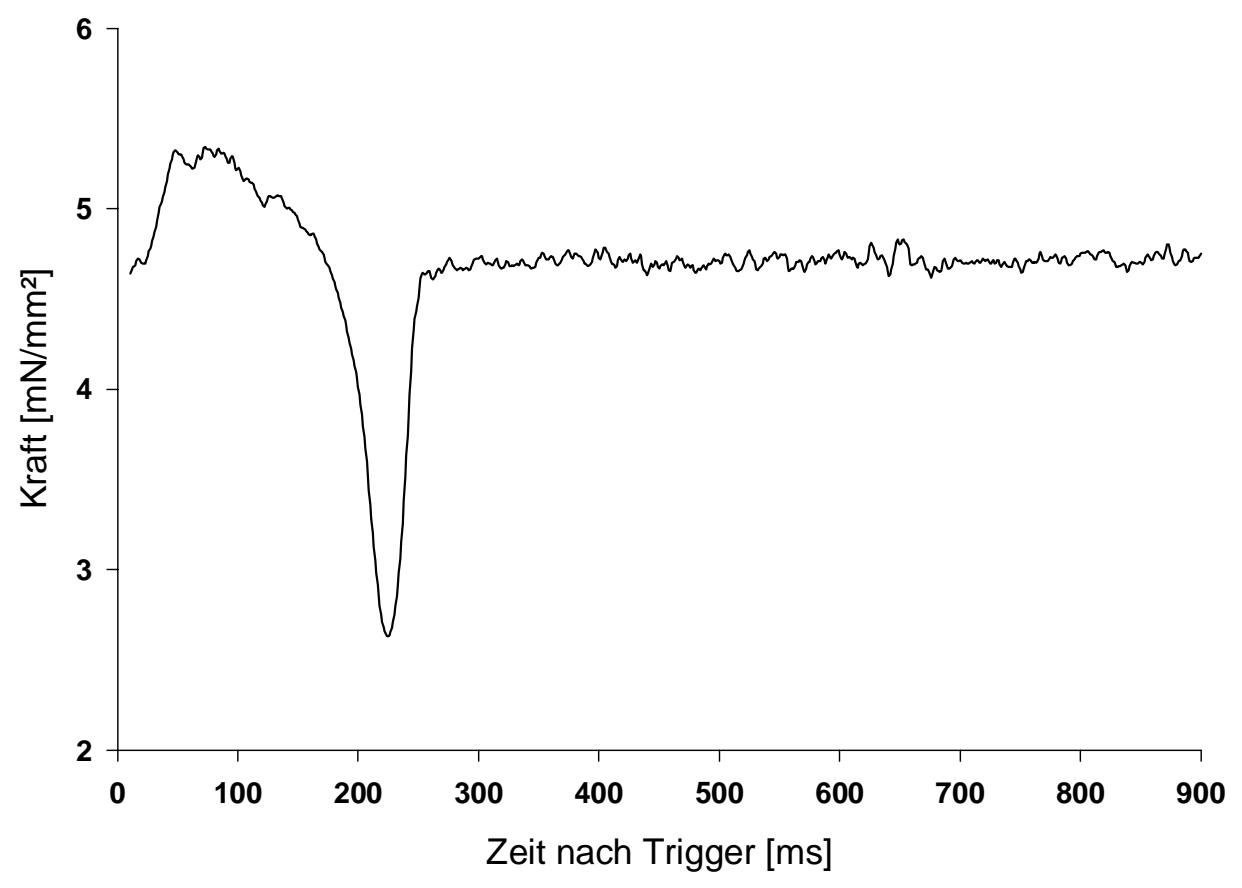

Abbildung 3-1: Aufzeichnung des Kraftverlaufes einer Kontraktion in der isotonischen Anlage, gemittelt über 10 Kontraktionen. Die Stimulation erfolgte $20 \mathrm{~ms}$ nach dem Triggerimpuls. Das Signal wurde über 900 ms aufgezeichnet, in den letzten $100 \mathrm{~ms}$ bis zum nächsten Trigger erfolgte die Verarbeitung der Daten (Mittelung, grafische Darstellung, Errechnung der Kontraktionsparameter).

Ebenso reagiert die Steuerung etwas zu spät auf das Ende der Kontraktion, es kommt somit zu einem Abfall von $\mathrm{F}_{\mathrm{dia}}$, den die Steuerung aber schnell ausgleicht. Im Folgenden bezieht sich $F_{\text {dia }}$ daher nicht auf diesen kurzen Abfall, sondern auf den Kraftwert in der funktionellen Diastole des Präparates (in diesem Beispiel beginnend etwa bei 300 ms). Aus Abb. 3-2 wird ersichtlich, dass es gelungen ist, $F_{\text {dia }}$ annähernd konstant zu halten. Der Wert schwankt zwischen 4,71 $\pm 0,06 \mathrm{mN} / \mathrm{mm}^{2}(\mathrm{t}=75 \mathrm{~min})$ und 4,69 $\pm 0,07 \mathrm{mN} / \mathrm{mm}^{2}(\mathrm{t}=30 \mathrm{~min})$, die Schwankung um den Sollwert von 4,7 mN/ $\mathrm{mm}^{2}$ liegt im Rahmen der maximal möglichen Messgenauigkeit der Anlage. Dies zeigt, dass die hier entwickelte Steuerung in der Lage ist, $F_{\text {dia }}$ auf einem vorgewählten Wert konstant zu halten.

\subsubsection{Physiologische Parameter}

\subsubsection{Verkürzungs- und Längenparameter}

Der wichtigste Parameter zur Beurteilung der Kontraktionsfähigkeit ist für isotonische Versuche die Verkürzungsfraktion (VF). Hierunter versteht man die prozentuale Verkürzung 


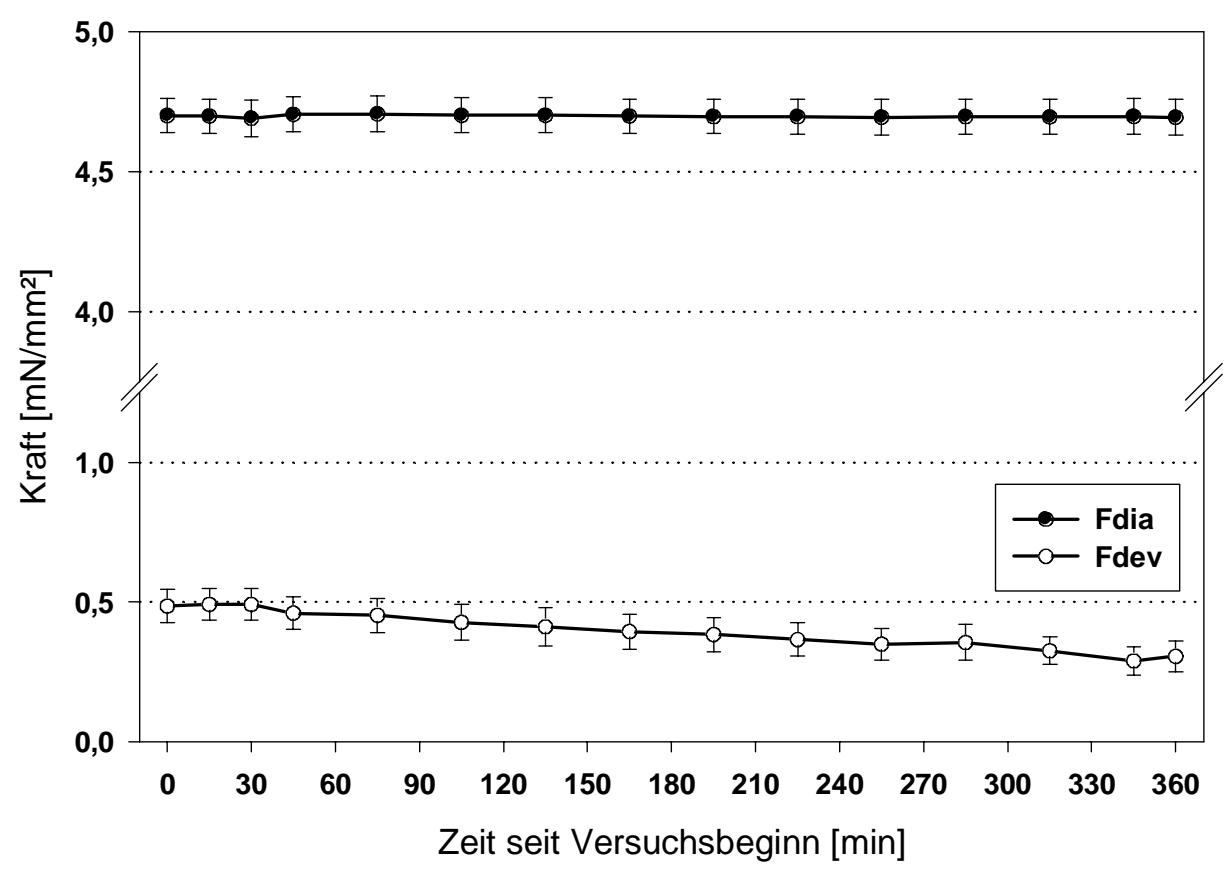

Abbildung 3-2: Entwickelte $\left(\mathrm{F}_{\mathrm{dev}}\right)$ und diastolische $\mathrm{Kraft}\left(\mathrm{F}_{\mathrm{dia}}\right)$ in den isotonischen Versuchen über einen Zeitraum von $6 \mathrm{~h}(\mathrm{n}=17)$.

des Muskelpräparates, d. h. den Quotienten aus absoluter Verkürzung geteilt durch die diastolische Ausgangslänge vor der Kontraktion multipliziert mit 100. Die Normalisierung auf die Ausgangslänge ist notwendig, da ein längerer Muskel eine größere absolute Verkürzung erreicht als ein kürzerer.

In unseren Versuchen beträgt VF zu Beginn 7,9 $\pm 0,7 \%$ und fällt, wie aus Abb. 3-3 ersichtlich,

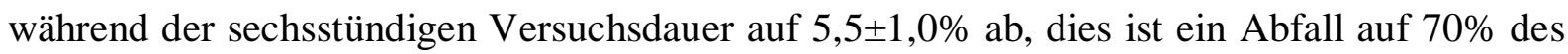
Ausgangswertes. Dieser Abfall ist bereits nach 45 min signifikant $(\mathrm{p}<0,05$; signifikante Unterschiede zu anderen Zeitpunkten s. Abb. 3-3), das Minimum liegt bei 5,5 $\pm 0,9 \%(\mathrm{t}=285$ $\min )$.

Ein Maß für die diastolische Funktion ist die diastolische Länge $\left(\mathrm{L}_{\mathrm{dia}}\right)$. Kommt es während des Versuches - z. B. durch eine Membranschädigung - zu einer Kontraktur des Präparates, so äußert sich dies in einer deutlichen Verkürzung des Muskels, da die diastolische Spannung konstant gehalten wird.

Bei den vorliegenden Versuchen verhielt sich $\mathrm{L}_{\text {dia }}$ ausgesprochen konstant (Abb. 3-4). Ausgehend von der Länge zu Beginn von $2560 \pm 267 \mu \mathrm{m}$ steigt $\mathrm{L}_{\text {dia }}$ nur leicht an, bis auf ein Maximum von $2679 \pm 277 \mu \mathrm{m}$ bei $\mathrm{t}=225 \mathrm{~min}$ (dies entspricht 104,7\% der Ausgangslänge). 


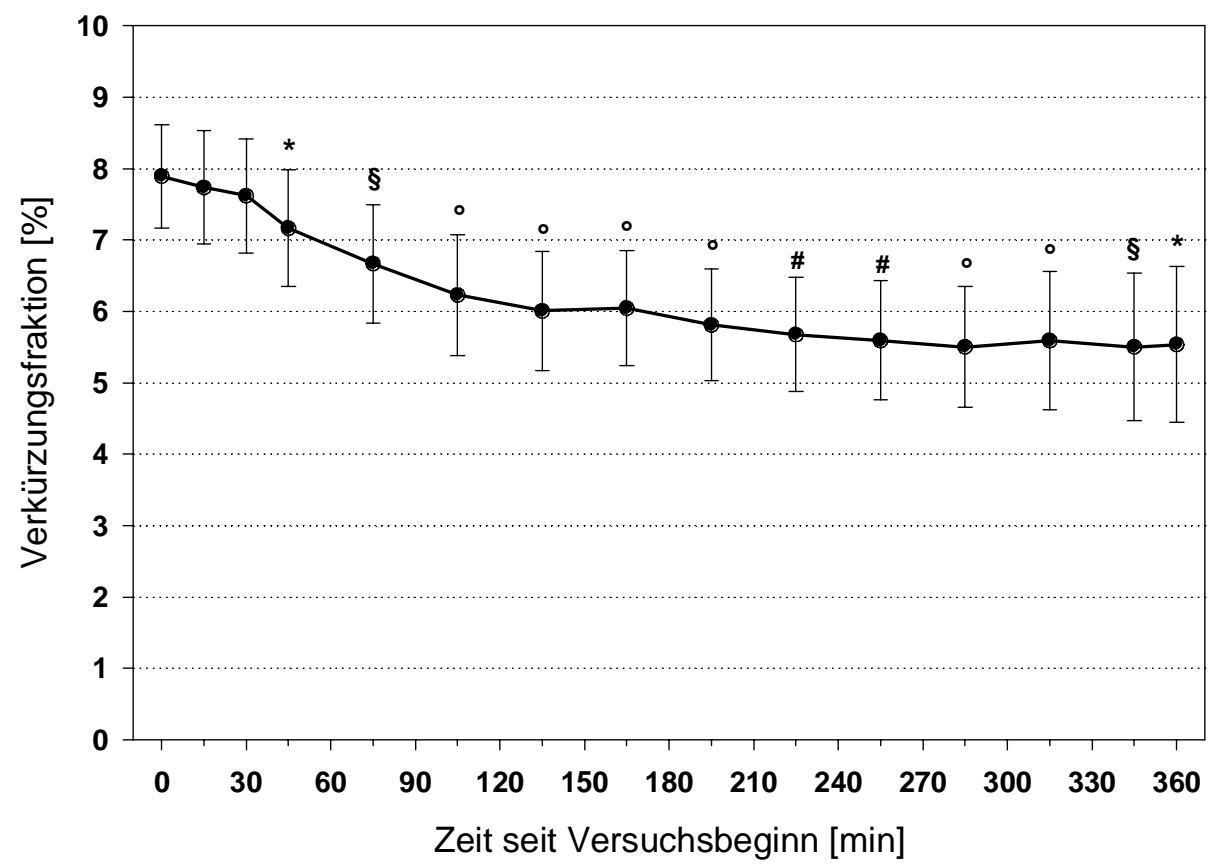

Abbildung 3-3: Verkürzungsfraktion (VF), d. h. prozentuale Verkürzung in Bezug auf die diastolische Länge, in den isotonischen Versuchen über einen Zeitraum von $6 \mathrm{~h}(\mathrm{n}=17){ }^{\star}: \mathrm{p}<0,05$ vs. $\mathrm{t}=0 \mathrm{~min}$, $\boldsymbol{\S}: \mathrm{p}<0,01$ vs. $\mathrm{t}=0 \mathrm{~min},{ }^{\circ}: \mathrm{p}<0,005$ vs. $\mathrm{t}=0 \mathrm{~min}, \#: \mathrm{p}<0,001$ vs. $\mathrm{t}=0 \mathrm{~min}$.

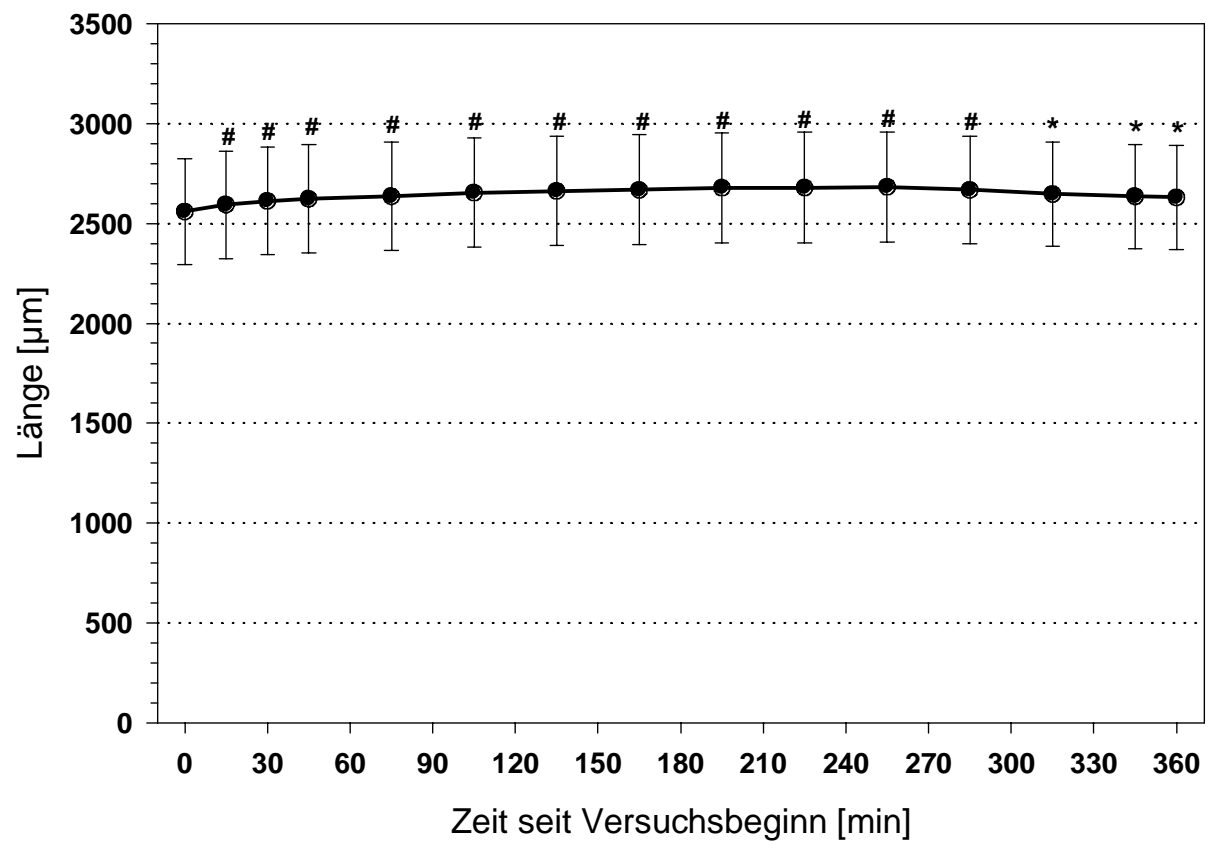

Abbildung 3-4: Diastolische Länge $\left(\mathrm{L}_{\mathrm{dia}}\right)$ der Präparate in den isotonischen Versuchen über einen Zeitraum von $6 \mathrm{~h}(\mathrm{n}=17) .^{*}: \mathrm{p}<0,05$ vs. $\mathrm{t}=0 \mathrm{~min}, \boldsymbol{\S}: \mathrm{p}<0,01$ vs. $\mathrm{t}=0 \mathrm{~min},{ }^{\circ}: \mathrm{p}<0,005$ vs. $\mathrm{t}=0$ min, \#: $\mathrm{p}<0,001$ vs. $\mathrm{t}=0 \mathrm{~min}$. 
Anschließend fällt $\mathrm{L}_{\text {dia }}$ wieder leicht $\mathrm{ab}$, auf $2631 \pm 260 \mu \mathrm{m}$ nach $6 \mathrm{~h}$. Der relativ große Standardmessfehler dieser Messreihe deutet nicht auf eine große Streuung der Messdaten hin, sondern begründet sich vielmehr aus der Streuung der unterschiedlichen Ausgangslängen der Präparate. Zur Verdeutlichung ist in Abb. 3-5 die relative diastolische Länge bezogen auf die Ausgangslänge der Präparate abgebildet, hier zeigt sich die vergleichsweise kleine Streuung der Längenänderungen.

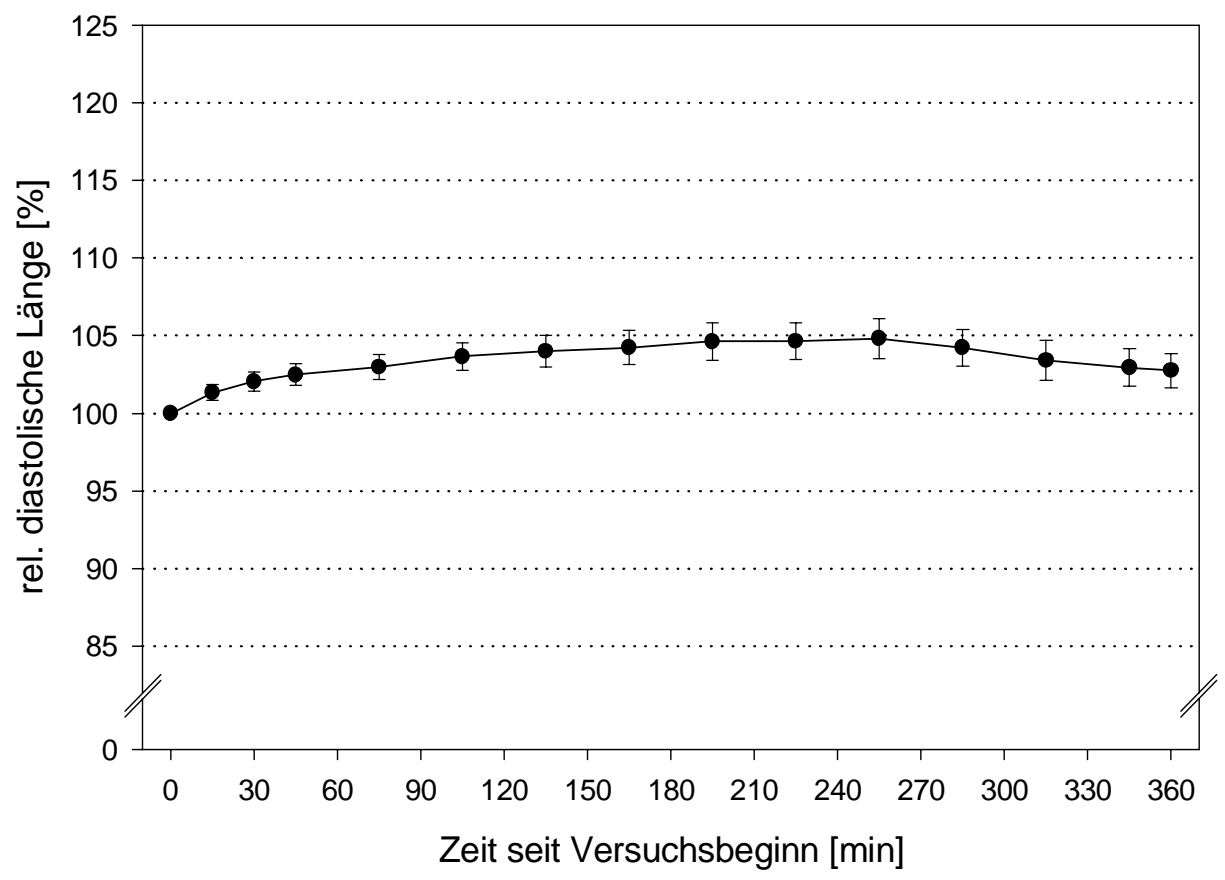

Abbildung 3-5: Prozentuale Veränderung der diastolischen Länge $\left(\mathrm{L}_{\mathrm{dia}}\right)$ der Präparate in den isotonischen Versuchen über einen Zeitraum von $6 \mathrm{~h}$ bezogen auf die jeweilige Ausgangslänge zum Zeitpunkt $\mathrm{t}=0 \mathrm{~min}$ $(\mathrm{n}=17)$.

\subsubsection{Zeitparameter der Verkürzung}

Als weitere physiologische Parameter wurden die Zeit bis zum Maximum der Kontraktion (time to peak - TTP), sowie die Zeit vom Maximum der Kontraktion bis zur 50\%igen Relaxation (relaxation time 50\% - RT50) erfasst. Der Zeitverlauf dieser Parameter ist aus Abb. 3-6 ersichtlich.

Die Zeit bis zum Maximum der Verkürzung (TTP) als Maß für die systolische Funktion steigt über die Versuchdauer kontinuierlich an, von $145 \pm 2 \mathrm{~ms}$ zu Versuchsbeginn bis auf $185 \pm 5 \mathrm{~ms}$ nach 6 h (p < 0,001, s. auch Abb. 3-6). Dies entspricht einem Anstieg auf etwa 128\%. Dieser Anstieg ist $a b t=45$ min signifikant $(\mathrm{p}<0,005)$. 


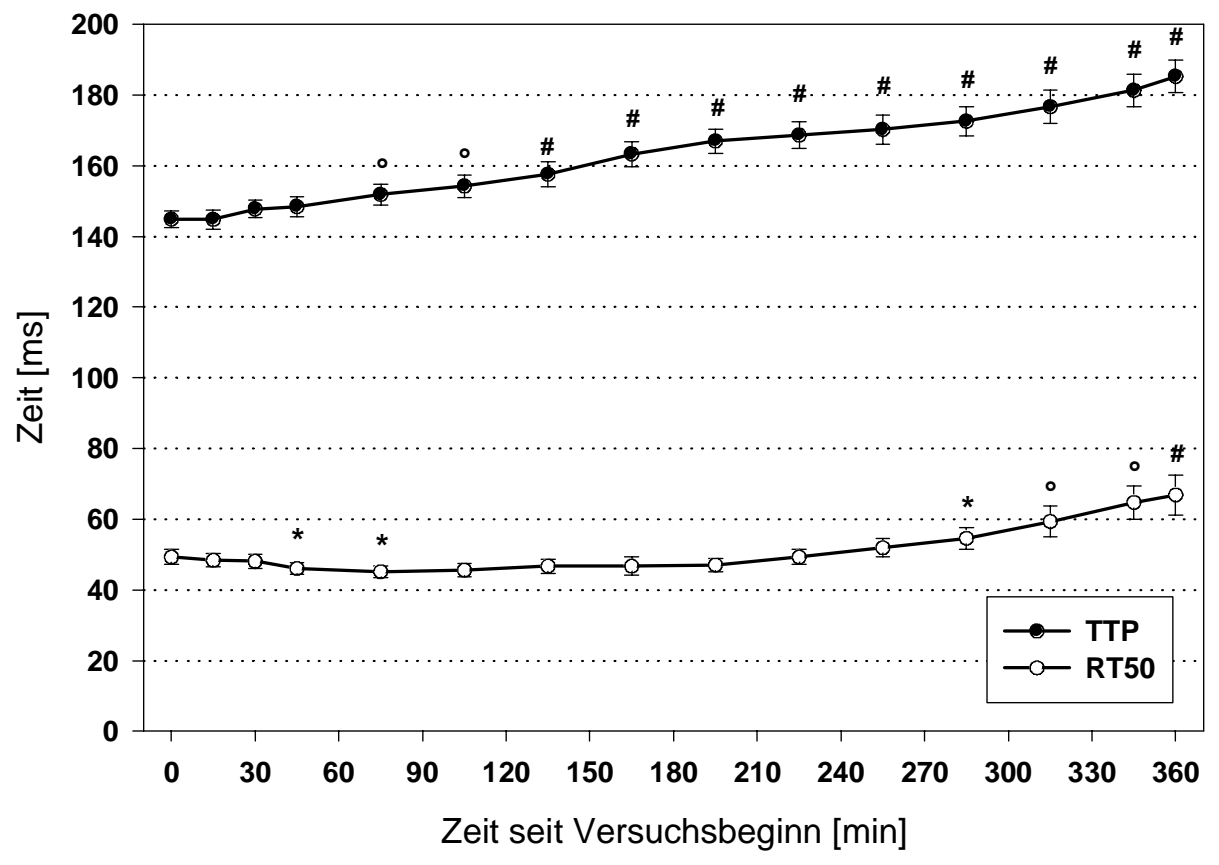

Abbildung 3-6: Zeit bis zum Maximum der Kontraktion (TTP) und Zeit bis zur 50\%igen Relaxation (RT50) in den isotonischen Versuchen (bezogen auf die Verkürzungsfraktion) über einen Zeitraum von $6 \mathrm{~h}(\mathrm{n}=17) .^{\star}: \mathrm{p}<0,05$ vs. $\mathrm{t}=0 \min , \boldsymbol{\S}: \mathrm{p}<0,01$ vs. $\mathrm{t}=0 \mathrm{~min},{ }^{\circ}: \mathrm{p}<0,005$ vs. $\mathrm{t}=0 \mathrm{~min}, \#: \mathrm{p}<0,001$ vs. $\mathrm{t}=0 \mathrm{~min}$.

Die Zeit bis zur 50\%igen Relaxation (RT50) kann als Maß für die Relaxationsgeschwindigkeit genommen werden. Eine Zunahme kann z. B. durch eine gestörte diastolische Calciumelimination verursacht werden. Vom Ausgangswert von $49 \pm 2 \mathrm{~ms}$ nimmt sie nach einem anfänglichen geringen Abfall (bei $t=45$ min bzw. $t=75$ min signifikant, $(p<0,05)$ ) gegen Ende des Versuches leicht zu, auf schließlich $66 \pm 6 \mathrm{~ms}(\mathrm{p}<0,001)$. Dieser Anstieg überschreitet den Ausgangswert erst nach 255 min und ist $a b t=285$ min signifikant $(p<0,05)$. Er entspricht einem maximalen Anstieg gegenüber dem Ausgangswert auf 134\%.

\subsection{Funktionelle Messwerte der isometrisch kultivierten Herzmuskelstreifen}

\subsubsection{Zahl der verwendeten Proben}

Von den insgesamt durchgeführten 25 Experimenten waren nach physiologischer Auswertung und visueller Beurteilung der Präparate auf morphologische Veränderungen und Hinweise für Schädigungen (s. Kap 2.3.2) noch 17 Experimente verwertbar. Bei diesen konnte jeweils mindestens ein gedehntes und ein ungedehntes Präparat gewonnen werden. Davon mussten 
vier weitere Experimente aus der Auswertung genommen werden, da alle gedehnten Proben einen zu hohen Abfall der entwickelten Kraft zeigten (über 50\%, siehe Kap. 2.3.2). Somit mussten auch die dazugehörigen ungedehnten Präparate verworfen werden (s. Kap. 2.5.1). Bei zwei weiteren Versuchen konnten die Proben aufgrund technischer Probleme nicht weiter verarbeitet werden. Von den ursprünglich vorgesehenen Experimenten verblieben somit 11, für die mRNA-Bestimmung wurden die Proben aus 7 Experimenten verwendet.

Ein Muskel, der laut unserer Definition ungedehnt schlägt, hat keine messbare diastolische Spannung und erzeugt keine messbare entwickelte Kraft. Das heißt, dass für die ungedehnten Präparate keine physiologischen Messwerte registriert werden konnten. Somit bezieht sich die gesamte physiologische Auswertung der isometrischen Versuche nur auf die gedehnten Proben. Für diese Auswertung wurden die Messwerte aller verwendeten Proben zusammengefasst. Zusammen mit den zwei oben erwähnten Experimenten, deren Proben aus technischen Gründen biochemisch nicht analysiert werden konnten, ergaben sich somit für alle folgenden Ergebnisse jeweils 13 physiologische Messwerte. 


\subsubsection{Physiologische Parameter}

\subsubsection{Diastolische Spannung und entwickelte Kraft}

Die diastolische Spannung $\left(\mathrm{F}_{\mathrm{dia}}\right)$ der gedehnten Proben wurde unmittelbar nach Beendigung der Vordehnung gemessen. Sie lag bei 3,3 $\pm 0,4 \mathrm{mN} / \mathrm{mm}^{2}$.

Die entwickelte Kraft $\left(\mathrm{F}_{\text {dev }}\right)$ der gedehnten Proben wurde über den gesamten Versuchsablauf aufgezeichnet. Dieser Zeitverlauf ist in Abb. 3-7 dargestellt. $F_{\text {dev }}$ sank von 7,3 $\pm 1,5 \mathrm{mN} / \mathrm{mm}^{2}$ bei Versuchsbeginn auf 5,6 $\pm 1,19 \mathrm{mN} / \mathrm{mm}^{2}$ nach $6 \mathrm{~h}$ ab, dies entspricht einem Abfall auf $76 \%$ der Ausgangskraft. Dieser Abfall ist bereits nach 150 min signifikant $(\mathrm{p}<0,05)$, nach 300 min ist $\mathrm{p}<0,01$. Der Hauptteil dieses Abfalls fand in den ersten 180 min des Versuches statt (auf 79\%), danach sank $\mathrm{F}_{\mathrm{dev}}$ nur noch in einem geringen Maße bzw. stieg zwischenzeitlich kurzzeitig an $(\mathrm{t}=270 \mathrm{~min})$.

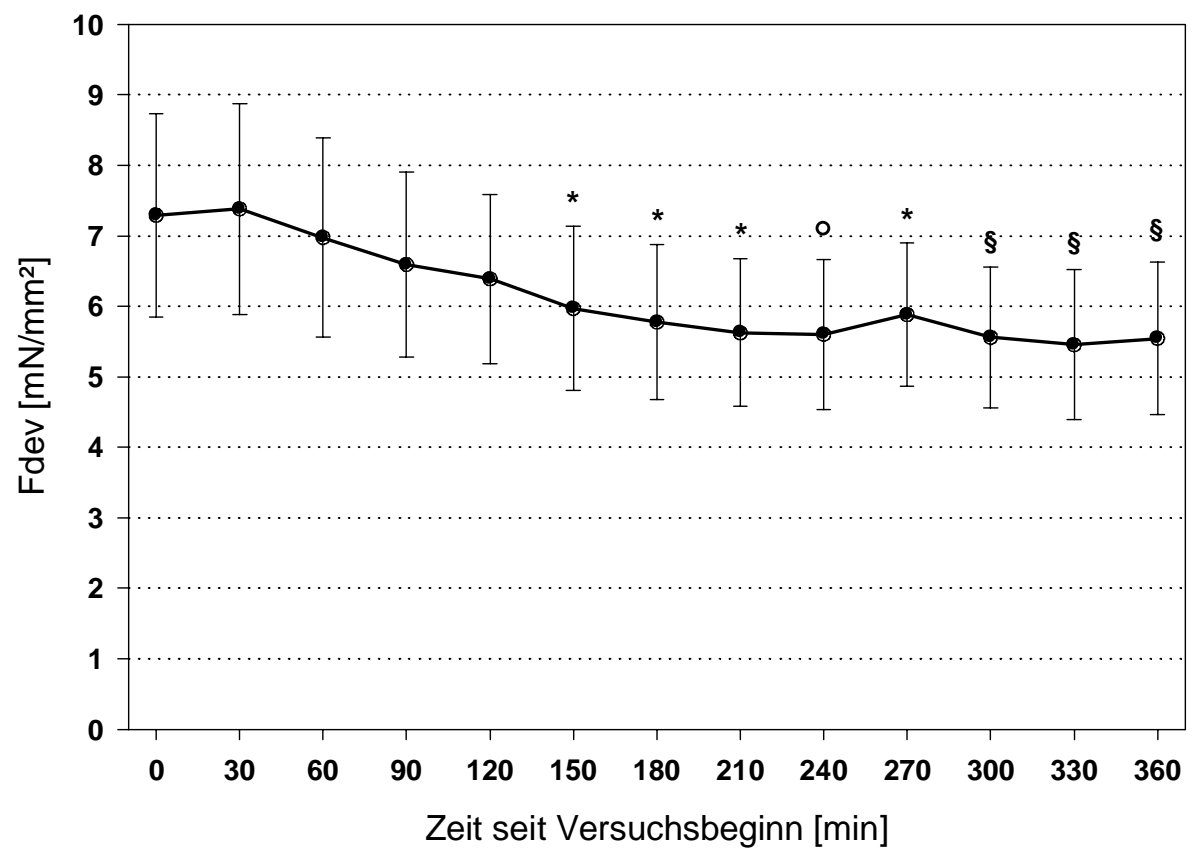

Abbildung 3-7: Entwickelte Kraft $\left(\mathrm{F}_{\mathrm{dev}}\right)$ in den isometrischen Versuchen über einen Zeitraum von $6 \mathrm{~h}$ $(\mathrm{n}=13) .^{*}: \mathrm{p}<0,05$ vs. $\mathrm{t}=0 \min , \boldsymbol{\S}: \mathrm{p}<0,01$ vs. $\mathrm{t}=0 \mathrm{~min},{ }^{\circ}: \mathrm{p}<0,005$ vs. $\mathrm{t}=0$ min, \#: $\mathrm{p}<0,001$ vs. $\mathrm{t}=0 \mathrm{~min}$. 


\subsubsection{Zeitparameter der Kraftentwicklung}

Als weitere physiologische Parameter wurden die Zeit bis zum Maximum der Kontraktion (time to peak - TTP), sowie die Zeit vom Maximum der Kontraktion bis zur 50\%igen Relaxation (relaxation time 50\% - RT50) erfasst.

Bei den isometrischen Experimenten zeigte sich ein kontinuierlicher Anstieg der TTP von $132 \pm 6,8 \mathrm{~ms}$ zu Beginn der Versuche auf 152 $\pm 9,5 \mathrm{~ms}$ nach $6 \mathrm{~h}$ (s. Abb. 3-8), das ist ein Anstieg auf 115\% des Ausgangswertes. Ab 210 min ist dieser Unterschied signifikant (p < 0,05), ab $t=330$ min ist $p<0,005$. Wie aus Abb. 3-8 ersichtlich, nimmt auch die RT50 über

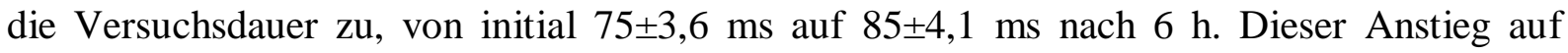
114\% des Ausgangswertes verläuft eher ungleichmäßig und ist erst nach 270 min signifikant gegenüber dem Ausgangswert ( $\mathrm{p}<0,05)$.

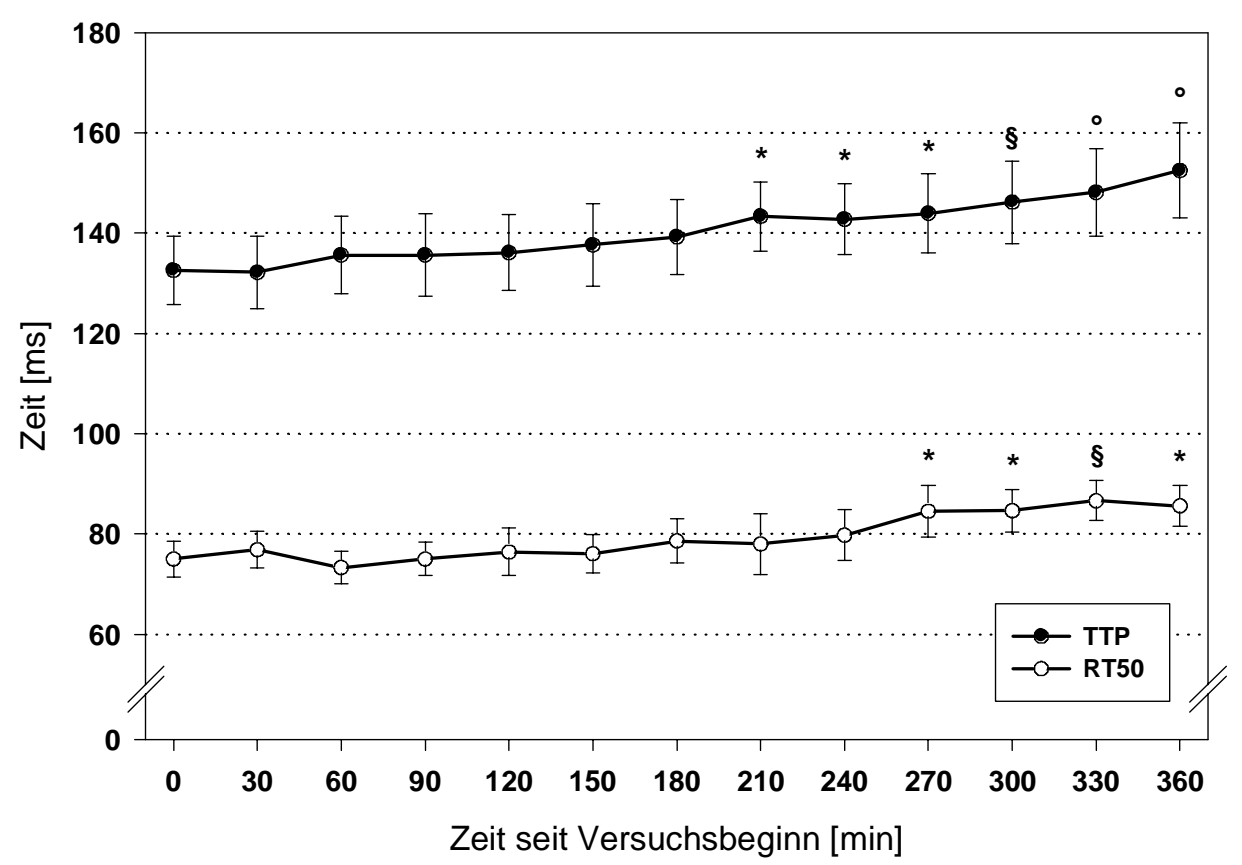

Abbildung 3-8: Zeit bis zum Maximum der Kontraktion (TTP) und Zeit bis zur 50\%igen Relaxation (RT50) in den isometrischen Versuchen über einen Zeitraum von $6 \mathrm{~h}(\mathrm{n}=13) .{ }^{\star}: \mathrm{p}<0,05$ vs. $\mathrm{t}=0 \mathrm{~min}$, $\boldsymbol{\S}: \mathrm{p}<0,01$ vs. $\mathrm{t}=0 \mathrm{~min},{ }^{\circ}: \mathrm{p}<0,005$ vs. $\mathrm{t}=0 \min , \#: \mathrm{p}<0,001$ vs. $\mathrm{t}=0 \mathrm{~min}$. 


\subsection{Vergleich von isotonischen und isometrischen Kulturbedingungen}

\subsubsection{Zusammenfassung und Vergleich der funktionellen Ergebnisse}

Es wurde gezeigt, dass es mit der hier entwickelten Steuerung möglich ist, Muskelstreifen über 6 Stunden unter isotonischen Bedingungen in Kultur zu halten. Während der gesamten Versuchslaufzeit wurde die diastolische Spannung konstant gehalten. Es gelang, die noch verbleibende entwickelte Kraft auf maximal 1,9\% der üblicherweise unter isometrischen Bedingungen entwickelten Kraft zu reduzieren.

Es zeigt sich sowohl bei den isotonisch, als auch bei den isometrisch kultivierten Herzmuskelstreifen ein signifikanter Abfall der Verkürzungsfraktion bzw. der entwickelten Kraft. Dieser Abfall ist unter isotonischen Bedingungen etwas höher (auf 70\% des Ausgangswertes vs. auf $76 \%$ isometrisch, dieser Unterschied ist nicht signifikant), insgesamt ist das Verhalten aber vergleichbar. $\mathrm{Zu}$ beachten ist in diesem Zusammenhang, dass - bedingt durch technische Gründe - bei den isotonischen Versuchen eine höhere diastolische Spannung $F_{\text {dia }}$ benutzt wurde $\left(4,7 \mathrm{mN} / \mathrm{mm}^{2}\right.$ vs. $3,3 \mathrm{mN} / \mathrm{mm}^{2}$ bei den isometrischen Versuchen).

Die Verkürzungsparameter TTP und RT50 nahmen in beiden Versuchsreihen während $6 \mathrm{~h} \mathrm{zu}$, auf 128\% (TTP) bzw. 134\% (RT50) des Ausgangswertes bei den isotonischen Versuchen. Dieser Anstieg ist etwas höher als bei den isometrischen Versuchen (115\% bzw. 114\% für TTP bzw. RT50).

\subsubsection{SERCA2a-mRNA-Level in isotonisch bzw. isometrisch kultivierten Herzmuskelstreifen}

In Abb. 3-9 sind die Messwerte für die mRNA-Menge von SERCA2a im Verhältnis zur Calsequestrin(CS)-Menge im selben Präparat dargestellt. Der Quotient aus den mRNALeveln von SERCA2a und CS beträgt für die gedehnten isotonischen Proben 31,3 $\pm 4,3$ ( $\mathrm{n}=$ 9), für die gedehnten isometrischen Proben 58,8 $\pm 11,6$ und für die ungedehnten isometrischen Proben 28,2 $\pm 6,2$ (jeweils $n=7$ ). Somit ist der SERCA2a-mRNA-Gehalt in den gedehnten isometrischen Proben gegenüber den ungedehnten um etwa das 1,8-fache, gegenüber den isotonischen um etwa das 2,1-fache erhöht. Diese Unterschiede sind signifikant ( $<<0,05)$. Der Wert der isotonischen Proben liegt etwa auf dem Niveau der ungedehnten isometrischen Präparate, signifikante Unterschiede bestehen nicht. 


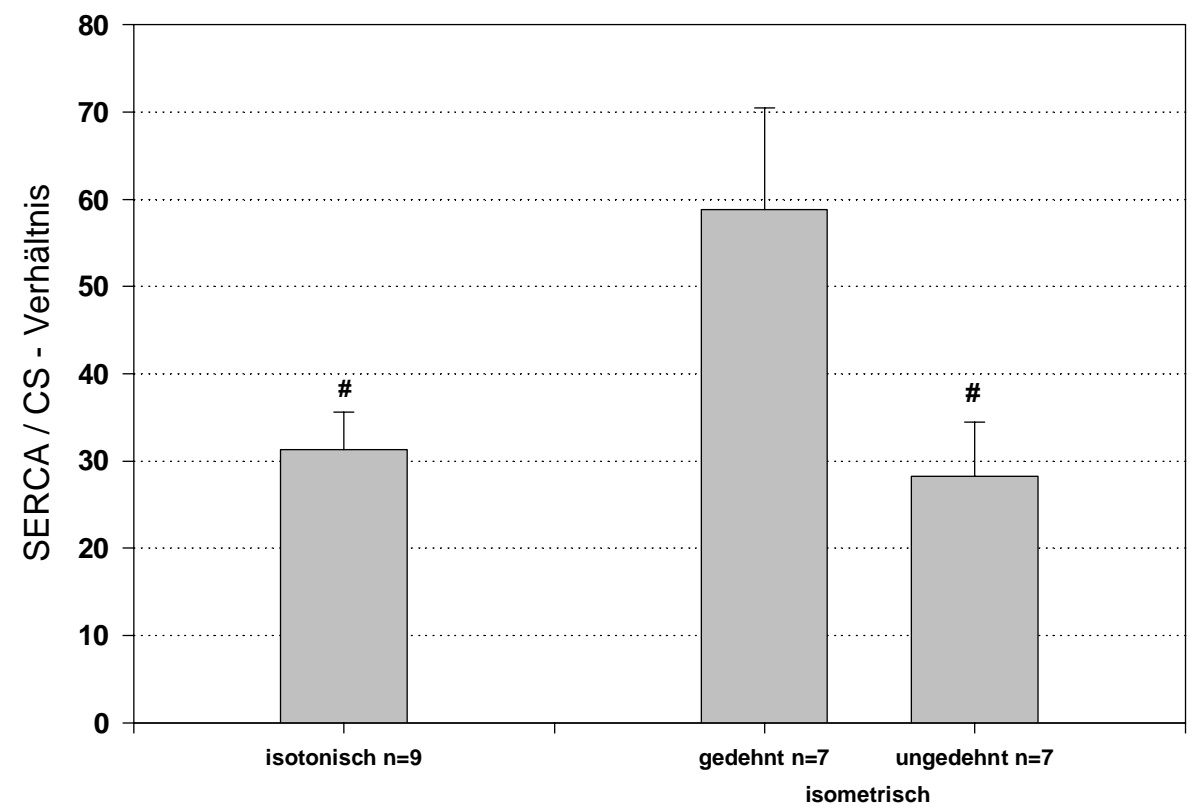

Abbildung 3-9: Vergleich des mRNA-Gehalts von SERCA2a in isotonischen Versuchen, verglichen mit den isometrischen Werten der isometrisch kultivierten gedehnten bzw. ungedehnten Proben, jeweils normalisiert auf den mRNA-Gehalt von Calsequestrin (CS).\#: $\mathrm{p}<0,05$ vs. gedehnt 


\section{Diskussion}

\subsection{Auswahl geeigneter experimenteller Bedingungen zur Untersuchung}

Bei der Planung von Experimenten zur Untersuchung der Genexpression, hier von SERCA2a, gilt es zunächst einmal, bestimmte experimentelle Bedingungen im Voraus zu klären. Zum Beispiel muss die Frage geklärt werden, welcher Versuchsaufbau am geeignetsten für die Untersuchung der konkreten Fragestellung ist. Weiterhin muss ein experimentelles Protokoll gefunden werden, welches die Beantwortung der gestellten Fragen ermöglicht. Für diese Arbeit ist konkret die Frage des ausreichenden Maßes an Vordehnung von Bedeutung, so dass diese im Folgenden diskutiert werden soll.

Schließlich wird noch auf die Kriterien zur Auswahl einer geeigneten biochemischen Methode zur RNA-Analyse und ihre speziellen Probleme eingegangen. Abschließend werden noch generelle technische Schwierigkeiten und Probleme bei der Präparation und Handhabung von Muskelstreifenpräparaten diskutiert.

\subsubsection{Wahl des geeigneten Versuchsaufbaus}

Experimente an menschlichem Myokard sind aufgrund der schlechten Verfügbarkeit von geeignetem Material problematisch und langwierig. Während für Versuche an insuffizientem humanem Myokard Proben aus Herzen gewonnen werden können, die im Rahmen von Herztransplantationen explantiert wurden, ist die Gewinnung von gesundem humanem Myokard nur möglich, wenn Herzen, die zur Organtransplantation entnommen wurden, aus technischen Gründen nicht verwendet werden können (Prestle et al. 1999, Pieske et al. 2002). Es ist somit von großem Vorteil, tierische Modelle zur Verfügung zu haben, welche die Verhältnisse im humanen Myokard annähernd widerspiegeln. Von den vielen bisher etablierten Modellen (u.a. Ratte, Maus, Hund, Kaninchen, siehe Hasenfuß 1998b), erschien das Kaninchen für die Fragestellung dieser Arbeit dae geeignete Tier, weil die Vorgänge im Rahmen der elektromechanischen Kopplung in Kaninchenmyokard denen des Menschen gleichen. Ähnlich wie beim Menschen ist auch beim Kaninchen die Sarkoplasmatisches-Retikulum-Ca ${ }^{2+}$-ATPase (SERCA) für ca. 70\% der diastolischen Calciumelimination verantwortlich (Bers 1993). Somit eignet sich das Kaninchenmodell gut für die Untersuchung von Veränderungen der elektromechanischen Kopplung. 
Solche Untersuchungen könnten im lebenden Organismus oder am isolierten perfundierten Herzen durchgeführt werden. Untersuchungen am lebenden Herzen in situ sind für phänotypische Untersuchungen hilfreich, z. B. für die Entwicklung von tierischen Insuffizienzmodellen (Hasenfuß 1998b). Der Vorteil hierbei ist, dass die physiologische Situation am besten abgebildet ist; einzelne einwirkende Faktoren lassen sich aber nicht untersuchen.

Weiterhin wurden Experimente an isolierten, retrograd perfundierten Herzen durchgeführt (sog. Langendorff-Perfusion, siehe Döring 1990). Hier lassen sich z. B. Vorlast und Druckentwicklung oder Koronarperfusion untersuchen, ohne dass das Herz von übergeordneten Zentren hormonell beeinflusst wird (z. B. durch erhöhte Katecholaminausschüttung). Jedoch spielen hier auch mehrere Faktoren zusammen, z. B. Einfluss von nicht myokardialem Gewebe - wie etwa Bindegewebe - auf das Kontraktions-/Relaxationsverhalten oder die Wirkung von Gewebemediatoren auf die Genexpression.

Somit stellt sich für den Untersucher die Aufgabe, experimentelle Methoden zu finden, welche die isolierte Betrachtung einzelner Einflussfaktoren ermöglichen. Hierzu bieten sich primär zwei Möglichkeiten an: die Untersuchung von isolierten Muskelstreifen oder Trabekeln sowie die Zellkultur von isolierten Myozyten. Letztere haben sich besonders für die Bestimmung der Expression von Genen bzw. deren Produkten oder für die adenovirusinduzierte Überexpression von Genen (Wagner et al. 2003) als geeignet erwiesen. Versuche mit isolierten Muskelstreifen haben den Vorteil, dass hier ein intakter Zellverband vorhanden ist. Außerdem bietet diese Methode die Möglichkeit, Herzgewebe gezielt und reproduzierbar zu dehnen und so eine definierte Vorlast bzw. Nachlast vorzugeben. Dies ist z. B. bei Myozyten nur schwierig und aufwendig möglich (Fink et al. 2000). Daher wurden die Untersuchungen für diese Arbeit an isolierten Herzmuskelstreifen durchgeführt.

Die Untersuchung von isolierten Herzmuskelstreifen unter elektrischer Stimulation ist eine schon seit vielen Jahren etablierte Methode (Bodem und Sonnenblick 1975). Durch die Möglichkeit der direkten Messung von diastolischer Spannung und entwickelter Kraft ist man mit dieser Methode in der Lage, genau definierte Kräfte (d.h. Vordehnung) auf den Muskelstreifen wirken zu lassen und die Kontraktionen (entwickelte Kraft oder Verkürzung) genau zu quantifizieren. Somit lassen sich sehr gut phänotypische und funktionelle Untersuchungen - z.B. über Veränderungen bei Herzinsuffizienz (Mulieri L et al. 1992, Pieske et al. 1995) oder über den Effekt von pharmakologischen Interventionen auf kontrahierende Herzmuskelstreifen (Janssen et al. 2000, Zeitz 2001) - durchführen.

Um Änderungen der Genexpression messen zu können, muss eine Möglichkeit geschaffen werden, kardiale Muskelstreifenpräparate über einen längeren Zeitraum zu kultivieren. Hierzu 
bietet sich die von Janssen et al. 1998 entwickelte Langzeitkulturanlage an. Mit ihr ist es möglich, Trabekel oder Papillarmuskeln über einen Zeitraum von bis zu 48 Stunden vital in Kultur zu halten und währenddessen kontinuierlich die Kontraktionskraft sowie den Verlauf der Kontraktion zu messen.

Es stellt sich die Frage, über welchen Zeitraum Herzmuskelstreifen einer definierten Dehnung ausgesetzt werden müssen, um einen Effekt auf die Genexpression nachweisen zu können. Shanker et al. haben 1987 mittels zweidimensionaler Elektrophorese die mRNA-Synthese in Herzen von hyperthyreoten Ratten nach Gabe des Schilddrüsenhormons T3 quantifiziert und herausgefunden, dass es bereits nach einer Stunde zu einem deutlichen Anstieg der RNAMenge für bestimmte Gene kommt. Weiterhin sind im Rahmen der HerzhypertrophieEntwicklung sog. ,early response“-Gene, wie c-fos, c-jun, egr-1 oder c-myc beteiligt, die als Transkriptionsfaktoren wirken und deren Induktion (auf mRNA-Ebene) innerhalb von Minuten erfolgen kann (Eschenhagen und Weil 1998). Dies zeigt, dass im Herzmuskel Änderungen der Genexpression als akute Reaktion auf bestimmte Reize prinzipiell sehr schnell möglich sind. Die Folge einer Änderung der mRNA-Konzentration ist üblicherweise auch eine Änderung der Menge des kodierten Proteins. Wenn man sich den Mechanismus der Proteinbiosynthese vor Augen hält, so wird deutlich, dass zur Messung von Änderungen der Proteinsynthese längere Beobachtungszeiträume vonnöten sind. Auch ist eine Abnahme der Proteinmenge abhängig von der Lebensdauer der Proteine, d.h. von der Geschwindigkeit des physiologischen Proteinabbaus.

Die für diese Arbeit gewählte Versuchsdauer von sechs Stunden berücksichtigt neben dem eben genannten auch technische Aspekte des Versuchsaufbaus. Vorversuche haben gezeigt, dass Experimente in der Langzeitkulturanlage bis zu einer Dauer von etwa sechs Stunden unter nichtsterilen Bedingungen möglich sind. Danach kommt es mit zunehmender Versuchsdauer vermehrt zu einer Infektion des Kulturmediums mit Bakterien und Pilzen, was die Herzmuskelstreifen schädigt. Für Versuche, die länger als sechs Stunden dauern, ist es somit unerlässlich, unter sterilen Bedingungen zu arbeiten. Dies bedeutet aber einen erheblichen zeitlichen sowie materiellen Mehraufwand, da nach jedem Versuch die Anlage demontiert, gereinigt, sterilisiert, steril aufgebaut, sowie anschließend neu kalibriert werden muss.

Die für diese Untersuchung gewählte Versuchsdauer von sechs Stunden ermöglicht die Durchführung von Experimenten mit vertretbarem Aufwand und scheint - wie aus den Ergebnissen dieser Arbeit ersichtlich ist - für die Untersuchung eines akuten Effektes von Dehnung auf die SERCA2a-Expression auf mRNA-Ebene ausreichend zu sein. Weitere 
Untersuchungen über einen kürzeren Zeitraum könnten interessante Hinweise bringen, ab welchem Zeitpunkt es zu einer SERCA2a-Expressionsänderung kommt.

\subsubsection{Wahl der Vordehnung}

Es ist lange bekannt, dass bei zunehmender Vorlast des Herzens und damit verbundener höherer diastolischer Spannung der Herzmuskelzellen die Kontraktionskraft und somit das Auswurfvolumen zunimmt. Dieser sog. Frank-Starling-Mechanismus (erstmalig von Frank 1895 und Starling 1918 beschrieben) lässt sich auch in vitro nachweisen (Holubarsch et al. 1996). Die Stärke der Kontraktionskraft korreliert dabei eng mit der Länge der Sarkomere. Es wurde gezeigt, dass es im Skelettmuskel des Frosches bei Erhöhung der Sarkomerlänge zu einer Zunahme der isometrischen Kontraktionskraft kommt (sog. positive Längen-SpannungsBeziehung). Bei einer Länge von etwa 2,0 - 2,2 $\mu \mathrm{m}$ liegt das Maximum der Kontraktionskraft. Diese Sarkomerlänge wird allgemein als $\mathrm{L}_{\max }$ bezeichnet. Mit weiterer Dehnung, und damit Erhöhung der Sarkomerlänge, kommt es zu einer stetigen Abnahme der Kontraktionskraft (Gordon et al. 1966). Dieser gesamte Mechanismus gilt, was den Bereich unterhalb von $\mathrm{L}_{\max }$ angeht, analog für Herzmuskelzellen (Wohlfart et al. 1977, ter Keurs et al. 1980). $\mathrm{L}_{\max }$ liegt hier etwa bei 2,3-2,4 $\mu \mathrm{m}$.

Im Gegensatz zum Skelettmuskel kommt es aber ab einer Sarkomerlänge von $\sim 2,3 \mu \mathrm{m}$ bei Zunahme der Dehnung zu keiner weiteren Längenzunahme mit Abfall der Kontraktionskraft, sondern zu einem steilen Anstieg der diastolischen Spannung, während die Kontraktionskraft zunächst weitgehend konstant bleibt (Pollack und Krueger 1976). Dies ist auf eine Reihe von Faktoren zurückzuführen, beispielsweise die relativ steife kollagene Matrix, die ab einem gewissen Grad der Dehnung starken passiv elastischen Widerstand erzeugt. Somit wird verhindert, dass bei vermehrter Volumenbelastung des Herzens die Sarkomerlänge in Bereiche kommt, in denen die Kontraktionskraft wieder abnimmt, ein Zustand, der zu einer fatalen Dekompensation der Pumpfunktion führen würde. Tatsächlich arbeiten die Sarkomere im schlagenden Herzen in vivo, das haben Messungen von Rodriguez et al. 1992 und Guccione et al. 1997 gezeigt, in Bereichen von 1,9 - 2,25 $\mu \mathrm{m}$.

Diese Ergebnisse zeigen, dass es sinnvoll ist, für die Untersuchung des Einflusses maximaler Dehnung auf Herzmuskelstreifen die Präparate bis in den Bereich von $\mathrm{L}_{\max }$ oder sogar darüber hinaus zu dehnen. Da eine genaue Einstellung der Dehnung auf $\mathrm{L}_{\max }$ aufgrund des Plateaus in der Kraft-Sarkomerlängen-Kurve, die sich proportional zur Kraft-Muskellängen-Beziehung verhält (Wohlfart et al. 1977), schwierig ist, wurde für diese Studie eine Dehnung gewählt, 
die etwa $95 \%$ von $\mathrm{L}_{\max }$ entspricht. Diese Dehnung ließ sich bei den isometrischen Versuchen durch langsames Vordehnen und Kontrolle des Kraftsignals erkennen (siehe Kap. 2.3.2). Bei den isotonischen Versuchen war aus technischen Gründen die individuelle Einstellung des geeigneten Dehnungswertes nicht möglich, daher wurde im Vorfeld ein geeigneter Wert festgelegt, auf den dann die Präparate vorgedehnt wurden. Hierdurch ergibt sich als Maß für die Vordehnung bei den isotonischen Versuchen ein höherer Wert der diastolischen Spannung $\mathrm{F}_{\text {dia }}\left(4,7 \mathrm{mN} / \mathrm{mm}^{2}\right.$ vs. $3,3 \mathrm{mN} / \mathrm{mm}^{2}$ bei den isometrischen Versuchen). Das Verhalten der Muskeln nach der Vordehnung auf den höheren Wert bei den isotonischen Versuchen deutet jedoch nicht darauf hin, dass $\mathrm{L}_{\max }$ hier deutlich überschritten wird.

\subsubsection{Wahl der geeigneten Methode zur biochemischen Probenuntersuchung}

Zur Bestimmung der mRNA-Expression musste eine geeignete Methode gefunden werden, die isolierte mRNA-Menge einzelner Trabekel - die bei etwa 550 ng liegt - so zu amplifizieren, dass sie mittels Elektrophorese quantifizierbar ist. Hierzu bietet sich die NASBA (,nucleic acid sequence-based amplification“) an. Mithilfe dieser Methode ist es möglich, RNA spezifisch um den Faktor $10^{10} \mathrm{zu}$ amplifizieren (Compton 1991).

Aufgrund möglicher Unterschiede bei der mRNA-Isolation sowie interindividueller Schwankungen der mRNA-Menge bei einzelnen Tieren kann nicht immer die gleiche Menge an mRNA gewonnen werden. Somit ist ein direkter Vergleich der absoluten Werte der SERCA2a-mRNA-Menge nicht möglich. Es wurde daher der Quotient aus Menge der SERCA2a-mRNA zur Menge der Calsequestrin-mRNA gebildet. Calsequestrin ist ein Protein, welches im sarkoplasmatischen Retikulum lokalisiert ist und einen Großteil des gespeicherten Calciums bindet (Eschenhagen und Weil 1998). Mehrere Arbeiten haben gezeigt, dass Calsequestrin bei hypertrophierten oder insuffizienten Herzen, in denen es zu einer Abnahme der SERCA2a-Expression kommt, unverändert exprimiert wird (Hasenfuß 1998c, Arai et al. 1993, Arai et al. 1996, Schotten et al. 1999). Somit ist anzunehmen, dass die Regulation der Calsequestrinexpression unabhängig von der SERCA2a-Expression ist. Daher wurde die Calsequestrin-mRNA-Menge hier als interner Standard verwendet.

\subsubsection{Technische Probleme}

Der erste kritische Schritt bei der Durchführung von Experimenten mit Muskelstreifen ist die Präparation der Muskeltrabekel. Nach intravenöser Injektion von Thiopental kommt es bei den Kaninchen rasch zu einer tiefen Narkose und zum Stillstand der Atmung. Da das Herz 
weiter schlägt, entwickelt sich rasch eine kardiale Ischämie. Probleme und Verzögerungen bei der Herzpräparation können also Auswirkungen auf das Überleben und die Qualität der Muskelpräparate haben.

Die Präparation der Trabekel bzw. Papillarmuskeln selber muss sehr vorsichtig erfolgen. Es ist darauf zu achten, den freien Teil des Präparates (d.h. den Bereich zwischen den beiden Muskelblöcken) unter keinen Umständen mit den Präparationswerkzeugen zu berühren. Dies führt nämlich in den meisten Fällen dazu, dass das Präparat in Kontraktur geht, sobald die extrazelluläre $\mathrm{Ca}^{2+}$-Konzentration erhöht wird. Dies lässt sich am ehesten dadurch erklären, dass durch die Berührung Schäden an der Zellmembran verursacht werden, durch die $\mathrm{Ca}^{2+}$ Ionen in die Zelle einströmen können und durch Bindung an den kontraktilen Apparat eine Kontraktur auslösen. Da die Myozyten untereinander durch sog. gap junctions verbunden sind, können die Calciumionen in das gesamte Präparat diffundieren.

Weiterhin muss bei der Präparation darauf geachtet werden, die Muskelstreifen nicht zu dehnen. Besonders ruckhafte, heftige Dehnung (z.B. durch die unruhige Hand des Experimentators) führt häufig dazu, dass das Präparat nach Stimulationsbeginn nicht zu schlagen beginnt. Ein genauer Mechanismus hierfür lässt sich nicht ohne weiteres bestimmen. Denkbar wäre, dass es durch die unkontrollierte Dehnung, die weit über dem physiologischen Bereich liegt, zu strukturellen Schädigungen der Zellen kommt.

Für die Auswahl der geeigneten Trabekel oder Papillarmuskeln wurden strenge Kriterien gesetzt (siehe Kapitel 2.1.3.3). Das hatte zur Folge, dass manche Herzen keine oder nur grenzwertig geeignete Präparate enthielten. Hier stellt sich nun dem Experimentator die Frage, ob es gerechtfertigt ist, das gesamte Herz zu verwerfen (was einem getöteten Tier entspricht), oder ein vielleicht nicht ganz optimales Präparat für die Langzeitkultur zu verwenden. Falls solch ein Präparat Verwendung fand, so wurden hier bei der Beurteilung am Ende der Versuchslaufzeit besonders strenge Maßstäbe angesetzt, so dass einige Präparate und u. U. ganze Experimente aus der Auswertung herausgenommen wurden.

\subsection{Entwicklung einer Versuchsanlage zur Messung von Dehnung an isotonisch kontrahierenden Muskelstreifen}

Wie bereits in Kapitel 1 berichtet, ist das langfristige Ziel, zu dem diese Arbeit einen Beitrag liefern möchte, die Untersuchung des Einflusses von Dehnung auf die Expression von SERCA2a. Dies erfordert eine Langzeitkultur von kontrahierenden Herzmuskelstreifen. Hierfür steht wie bereits erwähnt eine etablierte Kulturanlage zur Verfügung, die es ermöglicht, Muskelpräparate unter isometrischen Bedingungen zu kultivieren. So lässt sich der 
Einfluss einer Änderung der Vorlast auf die Genexpression untersuchen. Um jedoch zusätzlich den Einfluss der Nachlast zu studieren, müssen Experimente unter isotonischen Bedingungen durchgeführt werden. Hierdurch lässt sich die physiologische Situation im menschlichen Herzen, hier findet eine Mischform von isometrischer und isotonischer Kontraktion, eine sog. auxotonische Kontraktion statt, noch besser abbilden. Es ist nun Ziel dieser Arbeit, eine Steuerung zu entwickeln, mit der sich auch isotonische Experimente in der Langzeitkulturanlage durchführen lassen.

Im Folgenden soll auf die Anforderungen an die zu entwickelnde Steuerung, die bisher vorhandenen Modelle sowie die Wahl der geeigneten Steuerungsmethode eingegangen werden. Anschließend werden die Ergebnisse bezüglich der Funktion der Steuerung diskutiert.

\subsubsection{Vorhandene Modelle}

Seit mehreren Jahren wurden von verschiedenen Arbeitsgruppen Versuche mit isotonisch kontrahierenden Muskelstreifenpräparaten durchgeführt. Dabei kamen unterschiedlichste Versuchsaufbauten zur Anwendung. Für die Durchführung von Langzeitversuchen mit isotonisch kontrahierenden Muskelpräparaten ergaben sich im Vorfeld dieser Arbeit verschiedenste Anforderungen, welche die zu verwendende Steuerung erfüllen musste. Die hier geplante Integration in die Langzeitkulturanlage erfordert eine horizontale Anordnung der Muskelstreifen. Zudem sollte die Steuerung mit den vorhandenen Mess- und Steuerelementen kompatibel sein bzw. die gleichen Schnittstellen zur Weitergabe der Signale benutzen.

Die bisherigen Messprogramme wurden alle mit LabView ${ }^{\circledR}$ realisiert (s. Kap 2.2.1.2). Dabei handelt es sich um eine grafische Programmieroberfläche, bei der verschiedene sog. virtuelle Instrumente (VI) miteinander verbunden werden und sich so, ähnlich wie auf einem Schaltplan, eine Applikation visuell entwickeln lässt. Die Umsetzung in das lauffähige Programm wird von der LabView ${ }^{\circledR}$-Umgebung übernommen, d. h. es entstehen keine eigenständig lauffähigen Programme. Die Vorteile von LabView ${ }^{\circledR}$ sind einerseits die leichte Erlernbarkeit der Programmierung und andererseits die große Vielseitigkeit und damit verbunden eine erhebliche Kostenersparnis. Durch die Vielfalt der vorhandenen virtuellen Instrumente lassen sich sehr viele verschiedene Applikationen zur Steuerung und Messung mit einem herkömmlichen PC realisieren.

In der Vergangenheit wurden verschiedentlich Versuche mit analogen Steuereinrichtungen durchgeführt (z. B. Brutsaert et al. 1971, Bodem und Sonnenblick 1975, Peterson et al. 1989 oder Holubarsch et al. 1998). Hierfür waren jedoch aufwendige und kostspielige Apparaturen notwendig. Außerdem wurden viele Experimente bei Temperaturen $<37^{\circ} \mathrm{C}$ durchgeführt 
(beispielsweise $24^{\circ} \mathrm{C}$ bei Peterson et al. 1989 oder $29^{\circ} \mathrm{C}$ bei Brutsaert et al. 1971). In der Arbeit von Holubarsch et al. (1998) wurde ein System benutzt, das auf Komponenten aufbaute, die mit dem hier verwendeten Kraftmessungs- und Stimulationssystem kompatibel waren. Allerdings ließ sich dort nur der systolische Teil der Kontraktion isotonisch steuern, die Relaxation des Muskels erfolgte mit einer vorgegebenen Geschwindigkeit.

Die digitale Steuerung bietet gegenüber einem analogen System einige Vorteile. Neben der höheren Flexibilität und Geschwindigkeit bietet sie auch die Möglichkeit, komplexere Kontraktionen (z. B. auxotone Kontraktionen als Kombination von isometrischer und isotonischer Kontraktion) nachzubilden. Sørhus et al. entwickelten 2000 eine Steuerungsanlage, die dies ermöglichte; zugleich waren auch rein isotonische Kontraktionen möglich. Kern der Steuerung bildete ein programmierbarer digitaler Signalprozessor (DSP). Die Programmierung eines solchen ist jedoch nur in komplexen Programmiersprachen möglich (hier ANSI C), diese $\mathrm{zu}$ erlernen erfordert ein nicht $\mathrm{zu}$ unterschätzendes $\mathrm{Maß}$ an informatischer Vorbildung. Hier bietet LabView ${ }^{\circledR}$ eindeutige Vorteile, da die Programmierung ausschließlich mithilfe der grafischen Benutzeroberfläche erfolgt und kein Quelltext manuell eingegeben werden muss.

Die Entscheidung, die Steuerung mittels einer LabView ${ }^{\circledR}$-Applikation zu verwirklichen, beruht letztlich auf den zwei großen Vorteilen dieses Ansatzes. Zum einen ist die Integration in die Langzeitkulturanlage aufgrund der vorhandenen LabView ${ }^{\circledR}$-Architektur deutlich erleichtert. Beispielsweise konnte zur parallelen Messung von Kraft und Verkürzung das vorhandene 2-Kanal-Kraftmessprogramm zur gleichzeitigen Aufzeichnung von Kraft und Verkürzung verwendet werden. Einzige nötige Modifikation war die Veränderung der Umrechnungsfaktoren, damit das Eingangssignal anstatt in Kraftwerte in Längenwerte umgerechnet werden konnte, sowie eine invertierte Darstellung der Eingangswerte, da die Länge ja bis zum Maximum der Kontraktion abnimmt und nicht, wie die Kraft, zunimmt. Der andere große Vorteil sind die geringen Kosten der Steuerung. Außer einem handelsüblichen PC, einer Analog/Digital-Wandlerkarte sowie dem Linearmotor mit Steuergerät waren keine weiteren Anschaffungen nötig.

Zur Entwicklung der Steuerung wurde bewusst eine offene Kulturanlage benutzt. In diesem Aufbau sind alle Teile sowie das Präparat frei zugänglich und einsehbar, so dass kleine Umbauten oder Modifikationen schneller durchführbar waren. Auch ist die offene Anlage weniger anfällig für Störungen des Kraftsignals, z. B. durch Druckschwankungen im System oder durch vom Magnetrührer verursachte Verwirbelungen, die eine Beurteilung der Funktion der Steuerung in der Entwicklungsphase erschweren. 


\subsubsection{Eigenschaften und Funktion der entwickelten isotonischen Steuerung}

Die hier gewonnenen physiologischen Messwerte zeigen, dass es mit der entwickelten Steuerung möglich ist, Muskelstreifen über sechs Stunden stabil und ohne Anzeichen für eine Schädigung schlagen zu lassen. Letzteres erkennt man vor allem an der diastolischen Länge, die über die gesamte Versuchslaufzeit weitestgehend konstant bleibt und zwischenzeitlich nur um maximal 5\% zunimmt. Besonders bedeutend ist aber, dass sich die Präparate nicht wesentlich verkürzen oder eine Kontraktur entwickeln, was - wie oben erwähnt - ein Zeichen für eine Schädigung der Präparate wäre.

Die Steuerung erfüllt alle an sie gestellten Anforderungen. Die zu Beginn gewählte diastolische Spannung $\left(\mathrm{F}_{\mathrm{dia}}\right)$ soll über die gesamte Versuchsdauer konstant gehalten werden. Dies ist, wie aus den Ergebnissen ersichtlich, gut gelungen. Es gibt verschiedene mögliche Ansätze, wie $F_{\text {dia }}$ konstant gehalten werden kann. Bei der hier verwendeten Steuerung wird ein fester Wert für die diastolische Spannung angegeben. Eine Veränderung dieses Sollwertes ist nur durch das Eingreifen des Experimentators möglich. Die eigentliche Steuerung erfolgt über einen Regelkreis mit der vorgegebenen diastolischen Spannung als Sollwert.

Peterson et al. entwickelten 1989 eine Steuerung, bei der das Steuerungssignal aus zuvor gemessenen isometrischen Kontraktionen errechnet wird. Dieses Verfahren liefert eine sehr gute Steuerungsleistung, hat allerdings den Nachteil, dass zu Beginn des Versuches einige isometrische Kontraktionen durchgeführt werden müssen. Während dies für funktionelle Messungen problemlos ist, verbietet sich dieser Ansatz für das Vorhaben dieser Arbeit, in der Veränderungen der Genexpression im Vergleich von Isometrisch zu Isotonisch untersucht werden. Es kann nicht ausgeschlossen werden, dass selbst einzelne isometrische Kontraktionen die Genexpression beeinflussen.

Entscheidender Nachteil für die Durchführung von Langzeitexperimenten ist, dass in dem Ansatz von Peterson et al. 1989 von einer Uniformität der Kontraktionen ausgegangen wird. Wie jedoch bereits in den isometrischen Ergebnissen gezeigt, verändert sich die Gestalt der Kontraktion während des sechsstündigen Versuchsablaufes (Zunahme von TTP und RT50, die Dauer der Kontraktion nimmt also zu). Somit wäre es erforderlich, immer wieder während der Versuchslaufzeit isometrische Kontraktionen durchzuführen, um den Steueralgorithmus neu zu berechnen. Dies würde allerdings sehr wahrscheinlich, wie oben erwähnt, die Genexpression derart beeinflussen, dass sich die gemessenen Daten deutlich von denen rein isotonisch kontrahierender Präparate unterscheiden. 
Ein weiterer möglicher Ansatz bestünde darin, nur den Sollwert für $\mathrm{F}_{\mathrm{dia}}$ dynamisch anzupassen. Dazu misst man nach dem Ende jeder Kontraktion - wenn also der Muskel in Ruhe ist - den aktuellen Wert für $\mathrm{F}_{\text {dia }}$ und nimmt diesen als Sollwert für die nächste Kontraktion. Die Kontraktion selber läuft dann ähnlich wie in der hier benutzten Anlage über einen Regelkreis ab. Der Vorteil dieses Ansatzes gegenüber einem fest eingestellten Sollwert ist, dass diese Steuerung besser auf exogen verursachte Änderungen der Grundeinstellung reagiert. Wenn es beispielsweise zu einer allmählichen Nullwertverstellung des Kraftaufnehmers kommt, so folgt die Steuerung der scheinbaren Veränderung der diastolischen Spannung und hält weiterhin die diastolische Länge konstant, so dass nicht die Gefahr besteht, dass der Muskel fälschlicherweise überdehnt wird. Ein entscheidender Nachteil dieses Ansatzes ist jedoch, dass die Steuerung ebenso auf Veränderungen des Muskels reagiert. Wenn sich z. B. der Muskelstreifen verlängert und damit entdehnt, so folgt die Steuerung dieser Entdehnung und als Folge sinkt die diastolische Spannung $\mathrm{F}_{\text {dia. }}$. Dies lässt sich jedoch mit der hier verwendeten Steuerung vermeiden. Durch die fest vorgegebene Solldehnung ist gewährleistet, dass der Muskelstreifen über die gesamte Versuchsdauer die gleiche definierte Dehnung erfährt.

Wenn man sich die einzelne aufgezeichnete Kontraktion ansieht (Abb. 3-1), so erkennt man, dass es sich nicht exakt um eine ideale isotonische Kontraktion handelt, bei der das Kraftsignal eine gerade Linie auf Höhe der diastolischen Spannung wäre. Dies zu erreichen ist jedoch praktisch unmöglich, da jedwede Regelung Veränderungen des Sollwertes nicht antizipieren, sondern nur auf messbare Abweichungen vom Sollwert reagieren kann. Man erkennt in Abb. 3-1 zuerst einen geringen Kraftanstieg im Sinne einer noch vorhandenen entwickelten Kraft $\left(\mathrm{F}_{\text {dev }}\right)$. Wie bereits erwähnt, liegt dieser Rest an Kraftentwicklung bei weniger als $2 \%$ der unter isometrischen Bedingungen typischerweise entwickelten Kraft (s. Kap. 3.1.2). Dieser geringe „Fehler“ erscheint verglichen mit der deutlich höheren Nachlast in isometrischen Versuchen vernachlässigbar, zumal eine rein isotonische Kontraktion auch nicht vollständig den physiologischen Bedingungen entspricht.

Weiterhin erkennt man im Anschluss an den leichten Gipfel des Kontraktionssignals einen steilen Abfall und Wiederanstieg der gemessenen Kraft. Dies lässt sich dadurch erklären, dass die Steuerung verspätet auf das Erreichen des Gipfels der Kontraktion reagiert. Wenn man sich die Situation im Herzen in vivo ansieht, so kommt es auch im physiologischen Kontraktionszyklus zu Beginn der Relaxation zu einem plötzlichen Abfall des Ventrikeldruckes und damit der myokardialen Vordehnung. Erst zum Ende der Diastole nach vollständiger Ventrikelfüllung wirkt wieder die maximale Vorlast auf das Herzmuskelgewebe. Dies legt 
nahe, dass die oben erwähnte Überrelaxation in den hier durchgeführten Versuchen zu keinen relevanten Veränderungen in der Genexpression führt, verglichen mit der physiologischen Situation im schlagenden Herzen.

Alles in allem zeigt sich, dass die hier entwickelte Steuerung die an sie gestellten Anforderungen erfüllt hat. Es war möglich, Muskelpräparate über einen Zeitraum von sechs Stunden annähernd isotonisch bei definierter Vorlast schlagen zu lassen.

\subsection{Bewertung und Vergleich der Ergebnisse}

Nachdem im vorherigen Abschnitt gezeigt wurde, dass die Steuerung in der Lage ist, sowohl die diastolische Spannung also auch die entwickelte Kraft zu regulieren, gilt es nun zu klären, ob sich das Verhalten eines isometrisch kultivierten Muskelstreifenpräparates von dem eines isotonisch kultivierten unterscheidet. Es geht dabei zunächst um funktionelle Messwerte. Hier könnten sich bereits Hinweise auf eventuelle Schädigungen oder Belastungen der Präparate ergeben, die mit der Art und Weise der Steuerung einhergehen. Auch soll versucht werden, mögliche Erklärungen für Veränderungen der physiologischen Parameter zu finden, die während der Versuchslaufzeit auftraten.

Um Schädigungen der isotonisch kultivierten Präparate während der Versuchslaufzeit beurteilen zu können, reicht es jedoch nicht aus, sich auf Hinweise aus möglichen Änderungen der funktionellen Parameter gegenüber isometrisch kultivierten Präparaten zu verlassen. Für die Untersuchung der Genexpression ist vielmehr eine erhaltene Proteinbiosynthese erforderlich. Um auch hier erste Hinweise zu erhalten wurde die SERCA2amRNA-Expression von isotonisch und isometrisch kultivierten Präparaten verglichen. Aus größeren Unterschieden zwischen den beiden Versuchsansätzen ließen sich möglicherweise Hinweise für Limitationen eines Ansatzes gewinnen.

\subsubsection{Vergleich von funktionellen isotonischen und isometrischen Ergebnissen}

Während bei isometrisch kontrahierenden Muskelpräparaten die entwickelte $\mathrm{Kraft}\left(\mathrm{F}_{\mathrm{dev}}\right)$ als Maß für die Kontraktionsfähigkeit gemessen wurde, tritt bei isotonisch kontrahierenden Muskeln die Verkürzungsfraktion (VF) - also das Verhältnis von maximaler Kontraktion zu diastolischer Länge des Präparates - an ihre Stelle. Wie in Kap. 3 beschrieben, fallen in den isotonischen Versuchen VF und $\mathrm{F}_{\mathrm{dev}}$ über die Versuchslaufzeit ab. 
Abb. 4-1 zeigt die relative Veränderung von VF (isotonische Versuche) und $F_{\text {dev }}$ (isometrische Versuche), bezogen auf den Wert bei Versuchsbeginn. Dies ermöglicht es, den Zeitverlauf der beiden Parameter miteinander zu vergleichen. Hier erkennt man, dass VF und $F_{\text {dev }}$ einen sehr ähnlichen Abfall über die Versuchslaufzeit zeigen, der bei $F_{\text {dev }}$ etwas später (nach $30 \mathrm{~min}$ ) einsetzt und nicht so ausgeprägt ist (76\% vs. 70\%, der Unterschied ist nicht signifikant). Dieses annähernd gleiche Verhalten legt eine direkte Vergleichbarkeit der physiologischen Funktion von isometrisch und isotonisch schlagenden Herzmuskelstreifen nahe. Möglicherweise ist der leichte Unterschied im Ausmaß des Abfalls durch die Unterschiede zwischen offener (isotonisch) und geschlossener Kulturanlage (isometrisch) zu erklären. Hier muss sicherlich auch die unterschiedliche Vordehnung bei den isotonischen

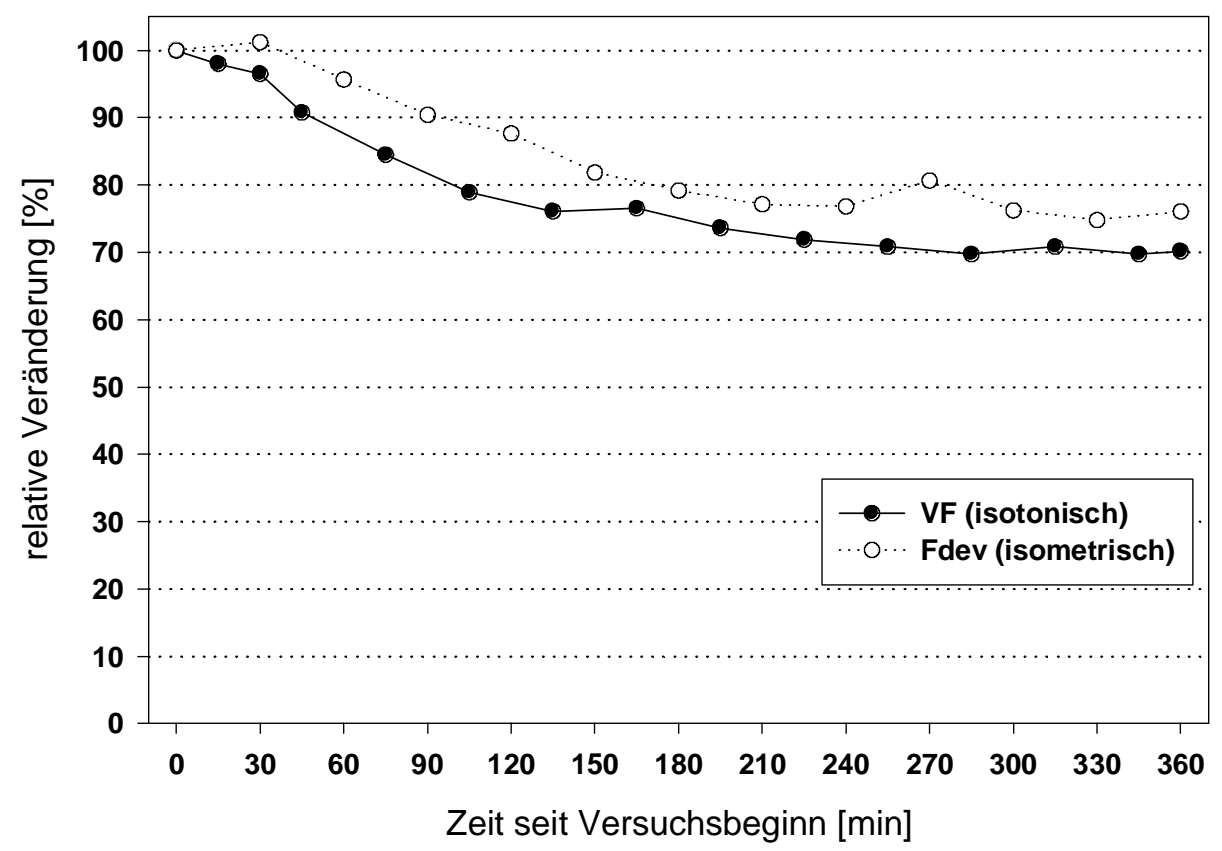

Abbildung 4-1: Vergleich des relativen Verlaufs der Verkürzungsfraktion (isotonisch) und der entwickelten Kraft (isometrisch), bezogen auf den jeweiligen Wert bei Versuchsbeginn. Die Unterschiede zwischen den Kurven sind nicht signifikant. VF: Verkürzungsfraktion, $\mathrm{F}_{\mathrm{dev}}$ : entwickelte Kraft.

bzw. isometrischen Versuchen erwähnt werden. Die höhere diastolische Spannung bei den isotonischen Versuchen allein mag vielleicht den stärkeren Abfall von VF erklären.

Die Kontraktionsparameter TTP (Zeit bis zur maximalen Kontraktion) und RT50 (Zeit bis zur 50\%igen Relaxation) als Maß für die Geschwindigkeit der Kontraktion bzw. der Relaxation 
verhalten sich ähnlich wie VF und $\mathrm{F}_{\mathrm{dev}}$. Sowohl in den isometrischen, als auch in den isotonischen Versuchen kam es zu einer etwa ähnlichen Verlängerung der Zeitintervalle. Auffällig ist, dass bei den isotonischen Versuchen TTP schon zu Beginn der Versuchslaufzeit länger ist als bei den isometrischen Versuchen (144 ms vs. 132,5 ms). Dies lässt sich jedoch methodisch erklären. Bei den isotonischen Versuchen bezieht sich TTP auf die Antwort der Steuerung. Diese hinkt aber der Kontraktion etwas hinterher (siehe Kap. 4.2.2, Abb. 3-1), d.h., das Maximum der Muskelverkürzung ist etwas früher als das Maximum der Steuerung. Dies führt zu der oben beschriebenen Überrelaxation, da die Steuerung den Muskel noch etwas verkürzt, während dieser schon begonnen hat zu relaxieren.

Das Zeitintervall von RT50 in den isotonischen Versuchen hingegen ist schon zu Versuchsbeginn kürzer als bei den isometrischen Versuchen (49 ms vs. $75 \mathrm{~ms}$ ). Dies lässt sich auch mit oben Gesagtem erklären. Wie der Kontraktion, so hinkt die Motorsteuerung auch der Relaxation des Muskelstreifens hinterher. Dies gleicht sie durch eine beschleunigte Längenänderung aus. Die Veränderung von RT50 während der Versuchslaufzeit zeigt, dass die Motorsteuerung zum Zeitpunkt der 50\%igen Relaxation ihren initialen „Rückstand“ weitgehend aufgeholt hat und die Messwerte für VF die Relaxation des Präparates widerspiegeln. Wenn die Steuerung nicht schnell genug reagieren könnte, so dass sie zum Zeitpunkt von RT50 dem Präparat weiter hinterherliefe, so wäre RT50 über die ganze Versuchslaufzeit konstant und hier dann ein Maß für die maximal mögliche Relaxationsgeschwindigkeit der Steuerung.

Wenn nun das Maximum der Verkürzung der Steuerung zeitlich hinter dem Maximum der Verkürzung des Muskels liegt und der Zeitpunkt von RT50 von Steuerung und Muskel identisch sind, so ist ersichtlich, dass das aus dem Steuerungssignal gemessene Zeitintervall von RT50 kürzer ist als das tatsächliche. Somit ist anzunehmen, dass in Wirklichkeit der Wert für RT50 bei den isotonischen und den isometrischen Versuchen annähernd gleich ist. Abgesehen hiervon zeigen beide Versuchsansätze (isotonisch und isometrisch) einen annähernd gleichen Abfall von RT50 über die Versuchslaufzeit.

Zusammenfassend kann man Folgendes feststellen: In der hier entwickelten Anlage lassen sich Muskelstreifenpräparate über sechs Stunden unter isotonischen Bedingungen kultivieren. Das hier gemessene physiologische Kontraktionsverhalten entspricht annähernd dem im isometrischen Versuchsaufbau (VF, TTP, RT50). Die im Vergleich zu den isometrischen Versuchen verkürzten Zeitintervalle von TTP und RT50 in den isotonischen Versuchen lassen sich durch die Arbeitsweise der Steuerung erklären. 


\subsubsection{Interpretation der Messwerte}

\subsubsection{Verkürzungsfraktion bzw. entwickelte Kraft und diastolische Spannung}

Die hier durchgeführten Messungen zeigen einen signifikanten Abfall der Verkürzungsfraktion (VF) sowie der entwickelten Kraft $\left(F_{\text {dev }}\right)$ über sechs Stunden. Dies scheint überraschend, wenn man von der These ausgeht, dass bei einer vermehrten SERCA2a-Expression eher eine Erhöhung der Kontraktionskraft zu erwarten wäre, da nun diastolisch mehr $\mathrm{Ca}^{2+}$ Ionen in das sarkoplasmatische Retikulum gepumpt werden könnten, so dass in der nächsten Systole mehr $\mathrm{Ca}^{2+}$ zur Verfügung stünde.

Der festgestellte Kraftabfall ist allerdings in Einklang mit den Arbeiten von Janssen et al., die sowohl beim Kaninchen, als auch beim Menschen während der Langzeitkultur einen Abfall von $F_{\text {dev }}$ innerhalb der ersten 12 Stunden nachwiesen, der allerdings bei längerer Versuchsdauer reversibel war (Janssen et al. 1998, Janssen et al. 1999b, Janssen et al. 2002).

Beim Vergleich der Ergebnisse der RNA-Analyse zeigt sich eine durch Dehnung induzierte SERCA2a-Überexpression. Somit ist der festgestellte Kraftabfall nicht durch eine Verminderung der SERCA2a-RNA-Expression durch den Einfluss von Dehnung zu erklären.

Eine Hypothese zur Erklärung des Phänomens der verminderten Kontraktiliät liefert die Arbeit von Donald et al. Diese Autoren haben 1980 festgestellt, dass sich das zentrale Segment eines präparierten Papillarmuskels, der ähnlich wie hier unter elektrischer Stimulation kultiviert wird, auch bei isometrischen Kontraktionen (d. h. bei konstanter Muskellänge) minimal kontrahiert. Als Ursache wurden Schäden an den Muskelenden durch die Präparation und die Befestigung in der experimentellen Anlage festgemacht. Daher wurden nun Versuche durchgeführt, bei denen mittels Längenänderung der Präparate nicht die Muskellänge, sondern die Länge des zentralen Muskelsegments konstant gehalten wurde. Es zeigte sich, dass die Präparate bei dieser Art der isometrischen Kontraktion eine signifikant höhere maximale Kraft als bei der herkömmlichen Methode (Konstanthalten der Muskellänge) entwickelten. Dies bedeutet, dass die geschädigten Enden der Präparate weniger zur Kontraktion beitragen als das intakte zentrale Segment. Weiterhin zeigten die Autoren eine verkürzte Zeit bis zur maximalen Kontraktion unter isometrischer Kontrolle der Segmentlänge.

Aus diesen Erkenntnissen lässt sich folgern, dass der Abfall der Verkürzungsfraktion bzw. der entwickelten Kraft, von TTP und auch von RT50 möglicherweise in einer zunehmenden Schädigung der Präparatenden begründet ist. Dies passt auch zu der von Janssen et al. 2002 festgestellten gesteigerten Apoptoserate in gedehnten Muskelstreifenpräparaten. Eine Schädi- 
gung der Präparatenden ist sicherlich nicht unerwartet, denn trotz sorgfältigster Präparation und Wahl der Versuchsbedingungen handelt es sich immer noch um ein artifizielles System, das die Bedingungen im lebenden Organismus immer nur bis zu einem gewissen Grad nachbilden kann. Selbst mit sorgfältiger Präparation lässt sich das Maß der schnittbedingten Zellschädigung nur minimieren, aber nicht eliminieren. Es ist durchaus vorstellbar, dass im intakten zentralen Segment des Muskels tatsächlich eine verbesserte Kontraktilität und eine erhöhte Kontraktionskraft messbar ist, wie bei einer Erhöhung der SERCA2a-Expression zu erwarten wäre, dies aber durch einen in höherem Maße zunehmenden Verlust an Kontraktilität in den Endsegmenten ausgeglichen wird. Eine zunehmende Steifigkeit der Präparatenden, z. B. durch eine partielle Kontraktur, könnte den verlangsamten Anstieg sowie die verlangsamte Relaxation, verursacht durch eine mangelnde Elastizität des Präparates, erklären. Um diese Hypothese zu bestätigen, wäre, falls experimentell überhaupt möglich, eine Messung der zentralen Segmentlänge über den gesamten Versuchszeitraum in der Langzeitkulturanlage interessant. Möglicherweise ließe sich auf diesem Wege die erwartete Kontraktilitätssteigerung nachweisen.

Bei den isotonischen Versuchen wurde die diastolische Länge bestimmt $\left(\mathrm{L}_{\mathrm{dia}}\right)$. Eine deutliche Abnahme von $L_{\text {dia }}$ ist ein Zeichen für eine Kontraktur des Muskels und damit - wie oben beschrieben - für eine Schädigung. Wie aus Abb. 3-4 ersichtlich ist, verhält sich $\mathrm{L}_{\mathrm{dia}}$ jedoch über die gesamte Versuchslaufzeit annähernd konstant, es kommt sogar zu einer dauerhaften Verlängerung des Muskels um maximal 4,7\%. Erklären lässt sich dieses Verhalten z. B. durch eine mögliche beginnende Dehnung des bindegewebigen, nicht kontraktilen Anteils des Muskelpräparates, der für die Stabilität des Muskels verantwortlich ist.

\subsubsection{Zeitparameter der Kontraktion}

Der Anstieg der Zeit bis zur maximalen Kontraktion (TTP) deutet auf eine abnehmende Kontraktilität der Präparate über die Versuchsdauer hin. Dies kann nun einerseits an einer Störung der elektromechanischen Kopplung liegen, oder aber an Zellschäden, die eher an den Enden der Präparate zu erwarten sind (s. oben). Wie oben erwähnt könnte ebenso eine erhöhte Steifigkeit der Präparatenden oder des gesamten Muskels den Anstieg von TTP erklären.

Die Zunahme der Zeit bis zur 50\%igen Relaxation (RT50) deutet auf Störungen der diastolischen $\mathrm{Ca}^{2+}$-Elimination, z. B. verursacht durch eine Abnahme der SERCA2a-Aktivität, hin. Dies steht im Widerspruch zu den Ergebnissen der RNA-Analyse, welche eine erhöhte SERCA2a-RNA-Expression zeigen. Unter der Voraussetzung, dass eine erhöhte SERCA2a- 
RNA-Expression auch eine erhöhte SERCA2a-Protein-Expression nach sich zieht, wäre hier demnach eher eine erhöhte SERCA2a-Aktivität zu erwarten.

Für die Änderung von RT50 - sowie auch von TTP - kann aber auch eine Veränderung der Aktivierung der kontraktilen Proteine verantwortlich sein, z. B. eine Abnahme der AktinMyosinkomplexe, was zu einer verlangsamten Kontraktion bei unveränderter SERCA2aAktivität führen würde.

\subsubsection{SERCA2a-mRNA-Expression unter isotonischen und isometrischen Bedingungen}

Um die Funktion der isotonischen Steuerung zu validieren, wurden im vorherigen Abschnitt die funktionellen Messwerte von isotonischen und isometrischen Kontraktionen verglichen. Da das Ziel der Untersuchungen jedoch letztlich die Änderung der Genexpression ist, scheint es erforderlich, einen Vergleich auch auf biochemischer Ebene anzustellen. Hierzu wurde die mRNA-Expression von SERCA2a mittels NASBA-Analyse bestimmt. Um zu erkennen, ob Unterschiede in Vor- oder Nachlast für eine Veränderung der SERCA2a-Expression verantwortlich sind, wurde die mRNA-Menge sowohl in gedehnten, als auch in ungedehnten isotonisch kultivierten Muskelstreifen bestimmt und mit der von isometrisch kultivierten verglichen.

Es zeigte sich, dass die SERCA2a-mRNA-Menge in den gedehnten isometrischen Muskelstreifen signifikant höher ist als in den ungedehnten, d. h., dass es durch Dehnung zu einer Überexpression von SERCA2a-mRNA kommt. Dies ist interessant, gibt es doch bisher noch keine Berichte über eine Änderung der SERCA2a-Expression als Reaktion auf isolierte akute Dehnung. Es stellt sich hierbei natürlich die Frage, ob die Überexpression auch mit einer Aktivitätserhöhung einhergeht.

Im Vergleich zu den isometrisch kultivierten Proben, befindet sich die SERCA2a-mRNAMenge der isotonisch kultivierten Muskelpräparate in etwa auf dem Niveau der ungedehnten isometrischen Proben. Dies zeigt zum einen, dass die mRNA-Synthese in isotonisch kultivierten Präparaten noch voll funktionstüchtig ist, was z. B. gegen eine ausgeprägte Schädigung der Präparate durch die isotonische Langzeitkultur spricht. Zum anderen deuten die Ergebnisse darauf hin, dass nicht allein Dehnung, sondern vielmehr eine Erhöhung der Nachlast für eine SERCA2a-mRNA-Expressionsänderung verantwortlich ist.

Aufgrund der hier benutzten unterschiedlichen Vordehnung in isotonischen bzw. isometrischen Versuchen lässt sich diese Frage jedoch nicht eindeutig beantworten, da eine unterschiedliche Vordehnung allein schon die mRNA-Expression beeinflussen könnte. Gegen 
einen Einfluss der unterschiedlichen Vordehnung spricht, dass die SERCA2a-mRNA-Menge in den isotonischen Versuchen, bei denen eine höhere Vordehung benutzt wurde, niedriger ist als bei den schwächer vorgedehnten isometrisch kultivierten Proben. Sie entspricht - wie erwähnt - eher der mRNA-Menge der ungedehnten Versuche. Um diesen Fragenkomplex abschließend beantworten zu können, sind jedoch sicherlich noch weitere Untersuchungen nötig, die den Rahmen dieser Arbeit sprengen würden.

Abschließend lässt sich jedoch in Bezug auf die oben gestellte Frage aus den Ergebnissen der funktionellen sowie der mRNA-Untersuchungen folgern, dass die Ergebnisse aus Versuchen mit der entwickelten isotonischen Steuerung mit denen aus der isometrischen Langzeitkulturanlage vergleichbar sind. Insbesondere ergeben sich keine Hinweise für eine vermehrte Muskelschädigung in der isotonischen Versuchsanlage. $\mathrm{Zu}$ beachten ist auch die sehr geringe Ausfallquote an Präparaten in den isotonischen Experimenten.

\subsection{Möglichkeiten und Grenzen der isotonischen Steuerung}

Wie erwähnt zeigt sich an den erhobenen Daten, dass die hier entwickelte Steuerung in der Lage ist, isotonisch kontrahierende Muskelstreifen über sechs Stunden zu kultivieren. Die Regelungsgeschwindigkeit hat sich als ausreichend erwiesen, die vordefinierte diastolische Spannung wurde über die gesamte Versuchsdauer konstant gehalten. Das Maximum und der Zeitverlauf der Verkürzung sind mit den an der isometrischen Anlage gemessenen Werten vergleichbar. Biochemisch hat sich gezeigt, dass die mRNA-Synthese von SERCA2a erhalten blieb, so dass auf eine weitestgehend intakt erhaltene Zellfunktion geschlossen werden kann.

Die offene isotonische Versuchsanlage eignet sich sehr gut für Versuche, bei denen z. B. der Einfluss von pharmakologischen oder physikalischen Interventionen auf Muskelstreifenpräparate unter definierten Lastbedingungen untersucht werden soll. Solche Arbeiten sind an einer vom Aufbau identischen Anlage unter isometrischen Bedingungen u. a. von Janssen et al. 2000, Hermann et al. 2002 oder Zeitz et al. 2002 durchgeführt worden. Es ist möglicherweise interessant, diese Versuche auch unter isotonischen Bedingungen durchzuführen.

Zur Untersuchung der Genexpression ist es jedoch eher notwendig, Versuche über längere Zeiträume als sechs Stunden durchzuführen. Wie oben erläutert sind länger andauernde Experimente in einer offenen Kulturanlage nicht möglich, sondern müssen in einem geschlossenen System unter sterilen Bedingungen durchgeführt werden. Es ist daher als nächster Schritt unerlässlich, die Steuerung für die Durchführung von isotonischen Versuchen in die geschlossene Kulturanlage zu integrieren. 
Ein besonderer Aspekt der hier verwendeten Steuerung ist die direkte Verarbeitung der Eingangssignale durch den Steueralgorithmus ohne vorherige Filterung. Dies ermöglicht zwar eine ungemein schnelle und genaue Steuerung, hat allerdings den Nachteil, dass es leicht zu Oszillationen des Steuerungssignals als Folge von Phasenverschiebungen und Zeitverzögerungen im Regelkreis kommen kann (Peterson et al. 1989). Diese sind bedingt durch eine gewisse Zeitverzögerung von Kraftmessung und resultierendem Steuerimpuls sowie durch den experimentellen Aufbau an sich (z. B. Compliance von Muskel und kraft- bzw. bewegungsübertragendem Apparat). Die Folge ist ein stark verrauschtes Kraftsignal, das erst nach Mittelung von mehreren Messungen eine auswertbare - dann allerdings gut reproduzierbare - Kraft-Zeit-Kurve ergibt (s. Abb. 3-1). Das Verkürzungssignal in den hier durchgeführten Versuchen ist jedoch sehr sauber und es zeigen sich in der diastolischen Phase keine deutlichen Ausschläge oder Schwingungen ähnlich denen im Kraftsignal. Die nachweisbaren minimalen Ausschläge lagen im Bereich der Grenze der Messgenauigkeit und sind nicht vom normal vorkommenden Grundrauschen der Messeinrichtung zu unterscheiden. Dies deutet darauf hin, dass es sich bei den Störungen im Kraftsignal tatsächlich nur um verstärkte Schwingungen handelt, die sich kaum auf die Funktion der Steuerung auswirken. Ein Einfluss auf die Genexpression erscheint somit sehr unwahrscheinlich.

Im Hinblick auf die Integration in die Langzeitkulturanlage ist das Verhalten der Steuerung allerdings kritisch zu bewerten. Durch die Rotation des Magnetrührers in der Kulturkammer sowie durch die pulsatile Gaszirkulation - verursacht durch die Walzenpumpe (s. Kap. 2) existieren in der geschlossenen Anlage eine Reihe von Störfaktoren, die das Kraftsignal beeinflussen können. Diese Beeinflussungen sind sehr gering und stellen bei isometrischen Versuchen kein großes Problem dar. Anders ist dies jedoch bei isotonischen Versuchen, da sich die Störungen über die Rückkopplung durch die Steuerung verstärken und ein Ausmaß erreichen können, das die Ergebnisse signifikant beeinflussen würde. Die Silikonabdichtung der Kammer, durch die sowohl der Arm vom Kraftmesser zum Muskel, als auch der Arm vom Linearmotor bzw. der Mikrometerschraube geführt wird, wirkt diesem Effekt möglicherweise entgegen, da sie hochfrequente Schwingungen dämpft. Allerdings besteht die Gefahr, dass durch die Viskosität des Materials die Bewegung des Linearmotors abgebremst wird und sich somit die Steuerungsgeschwindigkeit verlangsamt. Alle diese Probleme sind durch leichte Modifikationen des Versuchsaufbaus beherrschbar, jedoch nicht sicher vollständig zu eliminieren. Hier bieten sich als mögliche Lösung weitreichende Eingriffe in das Steuerungssystem an. Eine Möglichkeit ist die Implementierung eines Algorithmus zur Filterung der Signale, so dass hochfrequente oder periodisch wiederkehrende Störungen aus dem Signal eliminiert 
werden. Dies ohne einen digitalen Signalprozessor zu verwirklichen, erfordert ein zusätzliches Maß an Rechenleistung, die dann wieder für den eigentlichen Regelungsprozess fehlt.

Problematisch kann sich bei isotonischen Versuchen in der Langzeitkulturanlage ein Driften des Kraftaufnehmers erweisen. Es zeigt sich gelegentlich eine Veränderung des Nullwertes über die Versuchsdauer, möglicherweise verursacht durch Schädigungen des Kraftaufnehmers während des Auf- oder Abbaus der Anlage. Diese lassen sich jedoch durch vorsichtiges Vorgehen minimieren, zudem sind die verwendeten Kraftaufnehmer bezogen auf ihren Messbereich und ihre Empfindlichkeit äußerst robust gegenüber einwirkenden Kräften. Es hat sich aber gezeigt, dass sich trotz der Driftneigung die interne Kalibration kaum verändert, so dass nicht alle Messdaten aus dem betroffenen Versuch verworfen werden müssen.

Bei der Verwendung der isotonischen Steuerung tritt nun das Problem auf, dass das Steuerungsprogramm die artifizielle Herkunft der Kraftveränderung nicht erkennen kann und somit mit einer Längenänderung entgegensteuert, um die diastolische Spannung konstant zu halten. Bei den Größenordnungen, die teilweise als Kraftaufnehmerdrift auftraten, führt dies unweigerlich zu einer Schädigung des Präparates oder zu einer fast völligen Entdehnung, je nachdem in welche Richtung der Drift auftritt. Wie in Kapitel 4.2.1 bereits diskutiert, gibt es zwei prinzipiell verschiedene Ansätze zur isotonischen Steuerung, deren Vorzüge oben bereits aufgeführt wurden. Aber auch die Verwendung des anderen Ansatzes, bei dem der aktuelle diastolische Kraftwert direkt vor der Stimulation als Sollwert für die Steuerung benutzt wird, ist hier nicht ganz problemlos. Es besteht zwar nicht die Gefahr, dass der Muskel artifiziell gedehnt oder entdehnt wird, da die Steuerung sich kontinuierlich an den Drift anpasst, auf der anderen Seite wird allerdings eine Dehnung oder Entdehnung des Präparates durch Längenänderungen (z. B. Kontraktur) ebenfalls nicht ausgeglichen. Dies lässt sich jedoch nachträglich an der Veränderung der Verkürzungsfraktion erkennen, da gemäß dem FrankStarling-Mechanismus eine Entdehnung einen Abfall der Verkürzungsfraktion bedeutet. Da hier jedoch eine Veränderung der vorher definierten Vordehnung auftritt, können solche Präparate nicht für die biochemische Analyse verwendet werden. Es ist jedoch hier, wie eigentlich bei allen Ansätzen, eine kritische Analyse der Messwerte im Hinblick auf Ihre Validität durch den geschulten Experimentator erforderlich, um artifizielle Veränderungen von wirklichen und ergebnisrelevanten zu unterscheiden. Im Zweifelsfall muss bei festgestelltem Nullwertdrift der entsprechende Versuch verworfen werden. 
Abschließend kann man feststellen, dass die entwickelte Steuerung in dem verwendeten Versuchsaufbau bei Versuchen unter sechs Stunden sehr gut für die Untersuchung von isotonisch kontrahierenden Muskelstreifenpräparaten geeignet ist. Die Integration in die Langzeitanlage scheint prinzipiell ohne größere Modifikationen möglich, es muss jedoch dafür gesorgt werden, ein Driften des Kraftaufnehmers durch vorsichtiges Arbeiten und regelmäßiges Kalibrieren zu vermeiden. Auch ist eine kritische Begutachtung der Präparate auf artifizielle Dehnungsänderungen erforderlich. Um Störungen der Steuerung durch Eigenresonanz oder externe Einflussfaktoren zu minimieren, wäre die Implementierung eines digitalen Filters für hochfrequente Schwingungen zu erwägen.

\subsection{Weitere Forschung}

Wie oben erwähnt, muss ein nächstes Ziel die Integration der isotonischen Steuerung in die Langzeitkulturanlage sein. Nur so ist es möglich, vergleichbare Daten über die Änderung der SERCA2a-Expression in isometrisch bzw. isotonisch schlagenden Präparaten zu erhalten. Durch diese Versuche ließen sich weiter gehende Erkenntnisse über einen möglichen Einfluss der Nachlast auf die SERCA2a-Expression gewinnen. Weiterhin erscheinen auch Versuche mit unterschiedlicher Nachlast zur Quantifizierung eines möglichen Einflusses der Nachlast auf die SERCA2a-Expression sinnvoll.

Von Interesse sind auch Versuche mit kürzerer oder längerer Versuchslaufzeit, um Erkenntnisse über den zeitlichen Verlauf einer SERCA2a-Expressionsänderung zu erhalten. Versuche mit länger andauernder Dehnung (z. B. bei chronischer Druckbelastung durch Aortenkonstriktion, siehe Miyamoto et al. 2000) haben gezeigt, dass es im Verlauf zu einem Abfall der SERCA2a-Expression kommt. Ob dieser Abfall jedoch bereits innerhalb der ersten 48h dem maximal in der Langzeitkulturanlage experimentell zu erreichenden Zeitraum - auftritt, wäre zu untersuchen.

Neben der Untersuchung der SERCA2a-mRNA-Expression ist es selbstverständlich auch notwendig, die SERCA2a-Expression auf Proteinebene zu untersuchen. Eine Änderung der mRNA-Expression bedeutet nicht automatisch auch eine entsprechende Änderung der Proteinexpression. Letztere ist jedoch ausschließlich für die funktionellen Änderungen verantwortlich. Eine erhöhte mRNA-Expression, die nicht in eine erhöhte Proteinexpression umgesetzt wird, bleibt funktionell wirkungslos.

Weiterhin zu untersuchen wäre die SERCA2a-Aktivität, da eine vermehrte SERCA2aExpression nicht automatisch zu einer erhöhten Aktivität führt. Es ist z.B. möglich, dass nicht alle vermehrt gebildeten SERCA2a-Proteine (so diese überhaupt vermehrt exprimiert werden) 
an der Membran des SR lokalisiert sind, sondern sich möglicherweise in Zellkompartimenten, die an der elektromechanischen Kopplung unbeteiligt sind, befinden. $\mathrm{Zu}$ beachten ist auch die Regulation der SERCA2a-Aktivität durch Phospholamban. Es ist möglich, dass sich funktionelle Änderungen des Kontraktionsverhaltens aus einer durch Phospholamban veränderten SERCA2a-Aktivität erklären. Solche Untersuchungen würden allerdings den Rahmen dieser Arbeit sprengen. 


\section{Zusammenfassung}

Die Zielsetzung dieser Arbeit war es, eine Steuerung zu entwickeln, mit der es möglich ist, in der vorhandenen isometrischen Langzeitkulturanlage Muskelstreifenpräparate unter isotonischen Bedingungen zu kultivieren. Dieses würde es ermöglichen, neben der Untersuchung des Einflusses von Dehnung auf die Expression von SERCA2a in isolierten KaninchenHerzmuskelpräparaten auch differenziert den Einfluss von Vor- oder Nachlast zu untersuchen. Diese Untersuchungen könnten möglicherweise wichtige Hinweise auf die Regulationsmechanismen der SERCA2a-Expression bei kardialer Hypertrophie oder Herzinsuffizienz liefern.

Ausgehend von einer offenen Muskelkulturanlage wurde eine praktikable und unkomplizierte Steuerung mittels eines PID-Reglers in der grafischen Programmieroberfläche LabView ${ }^{\circledR}$ realisiert. Anhand der Messwerte ( $\mathrm{L}_{\mathrm{dia}}, \mathrm{F}_{\mathrm{dev}}, \mathrm{F}_{\mathrm{dia}}$, Erklärung s. Kap. 3.1.2) zeigte sich, dass die Steuerung die an sie gesetzten Anforderungen erfüllte und die Herzmuskelstreifen in einer offenen Kultur über sechs Stunden isotonisch kontrahierten. Zur Validierung der Anlage wurden die funktionellen Messwerte (VF, TTP, RT50, s. Kap 3.2.3) mit denen aus Versuchen mit in der Langzeitkulturanlage isometrisch kultivierten Muskelpräparaten verglichen. Diese Werte verhielten sich annähernd so, wie die entsprechenden Parameter bei den isometrisch kontrahierenden Muskelstreifen. Dies zeigt, dass die entwickelte Steuerung ein geeignetes Modell für die isotonische Langzeitkultur von Herzmuskelstreifen über sechs Stunden darstellt.

Zur weiteren Validierung und zur Überprüfung eines möglichen Einflusses von isotonischer Dehnung auf die Genexpression wurde die SERCA2a-mRNA-Konzentration in isotonisch kultivierten Muskelstreifen mit der von gedehnt bzw. ungedehnt isometrisch kultivierten Präparaten verglichen. Dabei zeigte sich eine signifikante Überexpression von SERCA2amRNA in Präparaten aus gedehnten isometrischen Versuchen gegenüber den ungedehnt isometrisch bzw. isotonisch kultivierten Präparaten; die letzteren beiden zeigten eine beinahe identische SERCA2a-mRNA-Expression. Dies zeigt, dass isometrische Dehnung über 6 Stunden zu einer SERCA2a-Überexpression auf mRNA-Ebene führt. Im Vergleich von isotonisch und isometrisch kultivierten Präparaten ergeben sich Hinweise auf eine SERCA2aExpressions-regulation durch den Einfluss der Nachlast. Der Stellenwert dieser ersten Ergebnisse muss jedoch noch in Zukunft durch weitere Experimente überprüft werden. 
Somit ist es gelungen, eine Steuerung zu entwickeln, die es ermöglicht, Muskelstreifenpräparate über einen Zeitraum von 6 Stunden unter isotonischen Bedingungen zu kultivieren. Die gewonnenen funktionellen sowie biochemischen Messwerte sind mit denen aus isometrisch kultivierten Muskelpräparaten vergleichbar. 


\section{Literaturverzeichnis}

Arai M, Alpert N, MacLennan D, Barton P, Periasamy M (1993): Alterations in sarcoplasmic reticulum gene expression in human heart failure. A possible mechanism for alterations in systolic and diastolic properties of the failing myocardium. Circ Res $\underline{72}, 463-469$

Arai M, Suzuki T, Nagai R (1996): Sarcoplasmic reticulum genes are upregulated in mild cardiac hypertrophy but downregulated in severe cardiac hypertrophy induced by pressure overload. J Mol Cell Cardiol 28, 1583-1590.

Bers DM: Excitation-contraction coupling and cardiac contractile force; Kluwer Academic Publishers, Dordrecht (Niederlande) 1993

Beuckelmann DJ, Näbauer M, Erdmann E (1992): Intracellular calcium handling in isolated ventricular myocytes from patients with terminal heart failure. Circulation $\underline{85}, 1046-1055$

Bodem R, Sonnenblick EH (1975): Time course of mechanical activity in mammalian cardiac muscle: dependence on species, loading, and displacement. Recent Adv Stud Cardiac Struct Metab 10, 91-118.

Böttle P, Boy G, Grothusmann G: Elektrische Meß- und Regeltechnik; Vogel-Buchverlag, Würzburg 1985

Bowditch H (1871): Über die Eigentümlichkeiten der Reizbarkeit, welche die Muskelfasern des Herzens zeigen. Ber Sächs Ges (Akad) Wiss 23, 652-689

Brutsaert DL, Claes VA, Sonnenblick EH (1971): Velocity of shortening of unloaded heart muscle and the length-tension relation. Circ Res $\underline{29}$, 63-75.

Compton J (1991): Nucleic acid sequence-based amplification. Nature 350, 91-92.

Donald TC, Reeves DN, Reeves RC, Walker AA, Hefner LL (1980): Effect of damaged ends in papillary muscle preparations. Am J Physiol 238, H14-23.

Döring HJ (1990): The isolated perfused heart according to Langendorff technique--function-application. Physiol Bohemoslov $\underline{39}$, 481-504.

Eschenhagen T, Weil J: Molekulare Grundlagen der Herzinsuffizienz; in: Handbuch der molekularen Medizin: Herz-Kreislauf-Erkrankungen, Band 3; hrsg. v. Ganten D, Ruckpaul K; Springer-Verlag, Berlin 1998, 147-221

Fink C, Ergun S, Kralisch D, Remmers U, Weil J, Eschenhagen T (2000): Chronic stretch of engineered heart tissue induces hypertrophy and functional improvement. FASEB J $\underline{14}$, 669-679.

Frank O (1895): Zur Dynamik des Herzmuskels. Z Biol $\underline{32}$, 370-447

Gordon AM, Huxley AF, Julian FJ (1966): The variation in isometric tension with sarcomere length in vertebrate muscle fibres. J Physiol 184, 170-192.

Guccione JM, O'Dell WG, McCulloch AD, Hunter WC (1997): Anterior and posterior left ventricular sarcomere lengths behave similarly during ejection. Am J Physiol 272, H469-477. 
Hasenfuß G (1998a): Calcium pump overexpression and myocardial function. Implications for gene therapy of myocardial failure. Circ Res $\underline{83}, 966-968$

Hasenfuß G (1998b): Animal models of human cardiovascular disease, heart failure and hypertrophy. Cardiovasc Res $\underline{39}$, 60-76.

Hasenfuß G (1998c): Alterations of calcium-regulatory proteins in heart failure. Cardiovasc Res $\underline{37}$, 279-289.

Hasenfuß G, Mulieri L, Leavitt B, Allen P, Haeberle J, Alpert N (1992): Alteration of contractile function and excitation-contraction coupling in dilated cardiomyopathy. Circ Res $\underline{70}, 1225-1232$

Hasenfuß G, Reinecke H, Studer R, Meyer M, Pieske B, Holtz J, Holubarsch C, Posival H, Just H, Drexler H (1994): Relation between myocardial function and expression of sarcoplasmic reticulum $\mathrm{Ca}(2+)$-ATPase in failing and nonfailing human myocardium. Circ Res $\underline{75}$, 434-442.

Heim A, Grumbach IM, Zeuke S, Top B (1998): Highly sensitive detection of gene expression of an intronless gene: amplification of mRNA, but not genomic DNA by nucleic acid sequence based amplification (NASBA). Nucleic Acids Res 26, 2250-2251.

Hermann HP, Zeitz O, Lehnart SE, Keweloh B, Datz N, Hasenfuss G, Janssen PM (2002):

Potentiation of beta-adrenergic inotropic response by pyruvate in failing human myocardium.

Cardiovasc Res 53, 116-123.

Holubarsch C, Ruf T, Goldstein DJ, Ashton RC, Nickl W, Pieske B, Pioch K, Ludemann J, Wiesner S, Hasenfuß G (1996): Existence of the Frank-Starling Mechanism in the Failing Human Heart:

Investigations on the Organ, Tissue, and Sarcomere Levels. Circulation 94, 683-689

Holubarsch C, Ludemann J, Wiessner S, Ruf T, Schulte-Baukloh H, Schmidt-Schweda S, Pieske B, Posival H, Just H (1998): Shortening versus isometric contractions in isolated human failing and nonfailing left ventricular myocardium: dependency of external work and force on muscle length, heart rate and inotropic stimulation. Cardiovasc Res 37, 46-57

Janssen PM, Lehnart SE, Prestle J, Lynker JC, Salfeld P, Just H, Hasenfuss G (1998): The trabecula culture system: a novel technique to study contractile parameters over a multiday time period. Am J Physiol 274, H1481-1488

Janssen PM, Zeitz O, Hasenfuss G (1999a): Transient and sustained impacts of hydroxyl radicals on sarcoplasmic reticulum function: protective effects of nebivolol. Eur J Pharmacol 366, 223-232

Janssen PM, Lehnart SE, Prestle J, Hasenfuss G (1999b): Preservation of contractile characteristics of human myocardium in multi-day cell culture. J Mol Cell Cardiol $\underline{31}$, 1419-1427

Janssen PM, Datz N, Zeitz O, Hasenfuss G (2000): Levosimendan improves diastolic and systolic function in failing human myocardium. Eur J Pharmacol 404, 191-199.

Janssen PM, Hasenfuß G, Zeitz O, Lehnart SE, Prestle J, Darmer D, Holtz J, Schumann H (2002): Load-dependent induction of apoptosis in multicellular myocardial preparations. Am J Physiol Heart Circ Physiol 282, H349-356.

Ladilov Y, Haffner S, Balser-Schafer C, Maxeiner H, Piper HM (1999): Cardioprotective effects of KB-R7943: a novel inhibitor of the reverse mode of $\mathrm{Na}+/ \mathrm{Ca} 2+$ exchanger. Am J Physiol 276, H18681876 
Lehnart SE, Janssen PM, Franz WM, Donahue JK, Lawrence JH, Marban E, Prestle J, Hasenfuß G (2000): Preservation of myocardial function after adenoviral gene transfer in isolated myocardium. Am J Physiol Heart Circ Physiol 279, H986-991

Miyamoto MI, del Monte F, Schmidt U, DiSalvo TS, Kang ZB, Matsui T, Guerrero JL, Gwathmey JK, Rosenzweig A, Hajjar RJ (2000): Adenoviral gene transfer of SERCA2a improves left-ventricular function in aortic-banded rats in transition to heart failure. Proc Natl Acad Sci U S A 97, 793-798

Mulieri L, Hasenfuss G, Ittleman F, Blanchard EM, Alpert NR (1989): Protection of human left ventricular myocardium from cutting injury with 2,3-butanedione monoxime. Circ Res $\underline{65}, 1441-1449$

Mulieri L, Hasenfuss G, Leavitt B, Allen P, Alpert N (1992): Altered myocardial force-frequency relation in human heart failure. Circulation $\underline{85}, 1743-1750$

Nichols CG, Hanck DA, Jewell BR (1988): The Anrep effect: an intrinsic myocardial mechanism. Can J Physiol Pharmacol 66, 924-929.

Peterson JN, Hunter WC, Berman MR (1989): Control of segment length or force in isolated papillary muscle: an adaptive approach. Am J Physiol 256, H1726-1734.

Pieske B, Kretschmann B, Meyer M, Holubarsch C, Weirich J, Posival H, Minami K, Just H, Hasenfuss G (1995): Alterations in intracellular calcium handling associated with the inverse forcefrequency relation in human dilated cardiomyopathy. Circulation 92, 1169-1178

Pieske B, Maier LS, Schmidt-Schweda S (2002): Sarcoplasmic reticulum Ca2+ load in human heart failure. Basic Res Cardiol 97, I63-71.

Pollack GH, Krueger JW (1976): Sarcomere dynamics in intact cardiac muscle. Eur J Cardiol 4 Suppl, 53-65.

Prestle J, Dieterich S, Preuss M, Bieligk U, Hasenfuss G (1999): Heterogeneous transmural gene expression of calcium-handling proteins and natriuretic peptides in the failing human heart.

Cardiovasc Res $\underline{43}, 323-331$.

RNAmplifier Handbook; Fa. Qiagen, Hilden 2001

Rodriguez EK, Hunter WC, Royce MJ, Leppo MK, Douglas AS, Weisman HF (1992): A method to reconstruct myocardial sarcomere lengths and orientations at transmural sites in beating canine hearts. Am J Physiol 263, H293-306.

Schotten U, Koenigs B, Rueppel M, Schoendube F, Boknik P, Schmitz W, Hanrath P (1999): Reduced myocardial sarcoplasmic reticulum $\mathrm{Ca}(2+)$-ATPase protein expression in compensated primary and secondary human cardiac hypertrophy. J Mol Cell Cardiol 31, 1483-1494.

Schwinger RHG, Bohm M, Schmidt U, Karczewski P, Bavendiek U, Flesch M, Krause E-G, Erdmann E (1995): Unchanged protein levels of SERCA II and phospholamban but reduced Ca2+ uptake and $\mathrm{Ca} 2+-\mathrm{ATPase}$ activity of cardiac sarcoplasmic reticulum from dilated cardiomyopathy patients compared with patients with nonfailing hearts. Circulation $\underline{92}$, 3220-3228

Sellin LC, McArdle JJ (1994): Multiple effects of 2,3-butanedione monoxime. Pharmacol Toxicol 74 , 305-313.

Shanker R, Neeley WE, Dillmann WH (1987): Time course of response of individual messenger RNAs in the rat heart to T3. J Mol Cell Cardiol 19, 595-601. 
Sørhus V, Sys SU, Natås A, Demolder MJ, Angelsen BA (2000): Controlled auxotonic twitch in papillary muscle: a new computer-based control approach. Comput Biomed Res $\underline{33}$, 398-415.

Starling E: The lineacre lecture on the law of the heart; Logmans, Green, London 1918

ter Keurs HE, Rijnsburger WH, van Heuningen R, Nagelsmit MJ (1980): Tension development and sarcomere length in rat cardiac trabeculae. Evidence of length-dependent activation. Circ Res $\underline{46}, 703-$ 714.

Wagner S, Seidler T, Picht E, Maier LS, Kazanski V, Teucher N, Schillinger W, Pieske B, Isenberg G, Hasenfuss $\mathrm{G}$ (2003): $\mathrm{Na}(+)-\mathrm{Ca}(2+)$ exchanger overexpression predisposes to reactive oxygen speciesinduced injury. Cardiovasc Res $\underline{60}, 404-412$.

Wohlfart B, Grimm AF, Edman KA (1977): Relationship between sarcomere length and active force in rabbit papillary muscle. Acta Physiol Scand 101, 155-164.

Wong AY, Rautaharju PM (1968): Stress distribution within the left ventricular wall approximated as a thick ellipsoidal shell. Am Heart J 75, 649-662

Yin FC (1981): Ventricular wall stress. Circ Res $\underline{49}, 829-842$.

Zeitz O: Einfluß von Hydroxylradikalen auf die Myocardfunktion: protektiver Effekt von Nebivolol. Med. Diss. Freiburg 2001

Zeitz O, Maass AE, Van Nguyen P, Hensmann G, Kogler H, Moller K, Hasenfuss G, Janssen PM (2002): Hydroxyl radical-induced acute diastolic dysfunction is due to calcium overload via reversemode $\mathrm{Na}(+)-\mathrm{Ca}(2+)$ exchange. Circ Res 90, 988-995. 


\section{Danksagungen}

Mein erster Dank gilt Dr. med. Oliver Zeitz, meinem Betreuer während der Planungsphase und während der experimentellen Arbeit. Von ihm lernte ich die Durchführung muskelphysiologischer Versuche sowie die Kunst der Präparation von Muskelstreifen. Während der Entwicklungsphase der Steuerung war er mir mit viel Engagement und Einsatz ein unentbehrlicher Ratgeber. Für seine kompetenten und hilfsreichen Anmerkungen und Verbesserungsvorschläge am Manuskript bin ich ihm sehr dankbar.

Danken möchte ich Prof. Dr. med. Gerd Hasenfuss für die Überlassung des Themas und die Möglichkeit, den experimentellen Teil meiner Arbeit an seinem Labor durchführen zu können. Dank des freundlichen und hilfsbereiten Klimas habe ich mich dort sehr wohl gefühlt.

Dr. med. Harald Kögler möchte ich danken für die rasche und kompetente Hilfe bei Fragen, die während des Verfassens der Arbeit auftauchten sowie für seine Anmerkungen und Verbesserungsvorschläge für das endgültige Manuskript.

Dr. Phuc Van Nguyen, Frank Schaub und Dr. med. Peter Schott danke ich für die Hilfe bei der biochemischen Analyse der Präparate. Ohne sie wäre diese Arbeit für mich nicht durchführbar gewesen.

Zu guter Letzt danke ich Claus Christians für die Überlassung der Vergleichsdaten über isometrische Kontraktionen in der offenen Anlage (Kap. 3.1.2). 


\section{Lebenslauf}

Ich, Johannes Werner Junge, wurde als Ältester von 3 Geschwistern am 19.04.1977 in Göttingen geboren. Meine Eltern sind Dr. med. Ulrike Junge und Prof. Dr. med. Ulrich Junge. Meine Grundschulzeit verbrachte ich von 1983 bis 1985 an der Grundschule Eichenplatz in Ulm sowie von 1985 bis 1987 an der Grundschule Bielefeld-Ummeln. Anschließend wechselte ich auf das Ratsgymnasium Bielefeld, wo ich 1996 die allgemeine Hochschulreife erwarb.

Von Juli 1996 bis Juli 1997 leistete ich meinen Zivildienst in den Städtischen Kliniken Bielefeld-Rosenhöhe ab.

Mein Medizinstudium begann ich im Wintersemester 1997/98 an der Georg-AugustUniversität in Göttingen. Nach bestandenem 2. Abschnitt der ärztlichen Prüfung verbrachte ich von April 2003 bis März 2004 mein Praktisches Jahr am Klinikum Oldenburg mit Wahlfach Augenheilkunde am Pius-Hospital Oldenburg. Am 28. April 2004 konnte ich mein Studium mit dem erfolgreichen Bestehen der ärztlichen Prüfung abschließen.

Seit dem 1. Juli 2004 bin ich als Assistenzarzt in der Klink für Innere Medizin I am Klinikum Oldenburg tätig. 